\title{
DINÂMICA DA MATÉRIA ORGÂNICA NA FASE INICIAL DE IMPLEMENTAÇÃO DE UM SISTEMA DE INTEGRAÇÃO LAVOURA- PECUÁRIA-FLORESTA
}

BOBAN JOVANOVIC

DISSERTAÇÃO DE MESTRADO EM AGRONOMIA

Brasília, DF

Fevereiro de 2017 


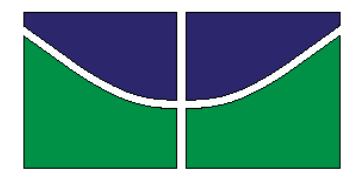

UNIVERSIDADE DE BRASÍLIA

FACULDADE DE AGRONOMIA E MEDICINA VETERINÁRIA PROGRAMA DE PÓS-GRADUAÇÃO EM AGRONOMIA

\section{DINÂMICA DA MATÉRIA ORGÂNICA NA FASE INICIAL DE IMPLEMENTAÇÃO DE UM SISTEMA DE INTEGRAÇÃO LAVOURA- PECUÁRIA-FLORESTA}

Orientador: Professor Doutor Cícero Célio de Figueiredo

DISSERTAÇÃO DE MESTRADO EM AGRONOMIA

Brasília, DF

Fevereiro de 2017 
UNIVERSIDADE DE BRASÍLIA

FACULDADE DE AGRONOMIA E MEDICINA VETERINÁRIA

PROGRAMA DE PÓS-GRADUAÇÃO EM AGRONOMIA

\section{DINÂMICA DA MATÉRIA ORGÂNICA NA FASE INICIAL DE IMPLEMENTAÇÃO DE UM SISTEMA DE INTEGRAÇÃO LAVOURA- PECUÁRIA-FLORESTA}

BOBAN JOVANOVIC

Dissertação de Mestrado submetido à Faculdade de Agronomia e Medicina Veterinária da Universidade de Brasília UnB, como parte dos requisitos necessários à obtenção do grau de Mestre em Agronomia.

APROVADO POR:

Cícero Célio de Figueiredo

Doutor, Universidade de Brasília - UnB

Robélio Leandro Marchão

Doutor, Embrapa Cerrados - CPAC

Thaís Rodrigues Coser

Doutora, Universidade de Brasília -UnB

Brasília, 22 de Fevereiro de 2017 


\section{FICHA CATALOGRÁFICA}

JOVANOVIC, Boban

"DINÂMICA DA MATÉRIA ORGÂNICA NA FASE INICIAL DE IMPLEMENTAÇÃO DE UM SISTEMA DE INTEGRAÇÃO LAVOURAPECUÁRIA-FLORESTA". Orientação: Cícero Célio de Figueiredo, Brasília, 2017. 68 páginas.

Dissertação de Mestrado (M) - Universidade de Brasília/ Faculdade de Agronomia e Medicina Veterinária, 2017.

1. Frações do carbono 2. Sistemas integrados lavoura-pecuária-floresta 3. Sistemas de manejo do solo.

\section{REFERÊNCIA BIBLIOGRÁFICA}

JOVANOVIC, B. Dinâmica da matéria orgânica na fase inicial de implementação de um sistema de integração lavoura-pecuária-floresta. Brasília: Faculdade de Agronomia e Medicina Veterinária. Universidade de Brasília, 2017, 68 páginas. Dissertação.

\section{CESSÃO DE DIREITOS}

\section{Nome do Autor: BOBAN JOVANOVIC}

Título de dissertação de mestrado: Dinâmica da matéria orgânica na fase inicial de implementação de um sistema de integração lavoura-pecuária-floresta.

Grau: Mestre Ano: 2017.

É concedida à Universidade de Brasília a reproduzir cópias desta dissertação de mestrado para única e exclusivamente propósitos acadêmicos e científicos. $\mathrm{O}$ autor reserva para si os outros direitos autorais para publicação. Nenhuma parte desta dissertação de mestrado pode ser reproduzida sem autorização por escrito do autor. Citações são estimuladas desde que citada à fonte.

\section{BOBAN JOVANOVIC}

CPF: 746.802.771-49

Vila Vicenina, Rua Piauí, Qd 03, Lote 15, Apt 01/ CEP: 73320-140, Planaltina - DF. Brasil.

Tel: (61) 3028-2647/(61) 98447-3111/ email: bjovanovic1986@gmail.com. 
Ofereço a toda à equipe do laboratório de matéria orgânica do solo da UnB, todos os professores e colegas que ajudaram nesta agradável jornada, muito obrigado.

Dedico: "Porquanto a criação foi submetida à vaidade, não por sua livre escolha, mas pela vontade daquele, que sujeitou a mesma criatura à esperança". 


\section{AGRADECIMENTOS}

Agradeço muito ao professor Cicero Célio de Figueiredo um grande professor das ciências agrárias, que teve muita paciência e carinho, ao me orientar nesta jornada. Sou muito grato à equipe do laboratório da Matéria Orgânica do Solo da UnB, em especial a professora Thaís Coser com seu entusiasmo e energia, e ao professor Gilberto Leite pela sua orientação sábia, além dos meus colegas: Túlio, Sara, Bia, Alisson, Thamires, Marcela, assim como a nossa química do laboratório Priscila.

Agradeço a Deus por tudo, especialmente pela benção sobre nós, nossas famílias e as muitas vitórias que ainda estão por vir.

Agradecimento aos meus pais, tios e a minha esposa.

Agradecimentos a CAPES por ter possibilitado a realização da pesquisa.

Agradeço especialmente a nossa UnB, que venha fazer parte de mais muitas vidas. 


\section{SUMÁRIO}

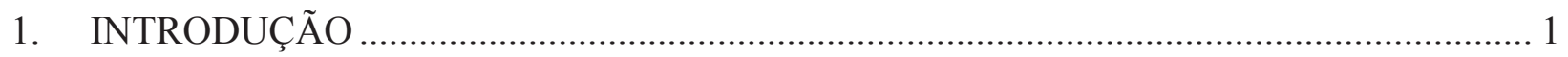

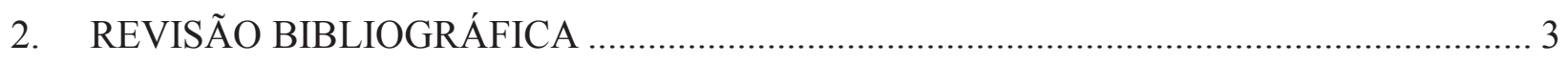

2.1 Uso e manejo do solo do Cerrado ............................................................................. 3

2.2 Sistemas integrados de produção e descrição dos sistemas agrossilvopastoris: integração lavoura pecuária (ILP) e integração lavoura pecuária floresta (ILPF).................... 6

2.3 Uso e características da gliricídia (Gliricidia sepium) e capim colonião (Panicum

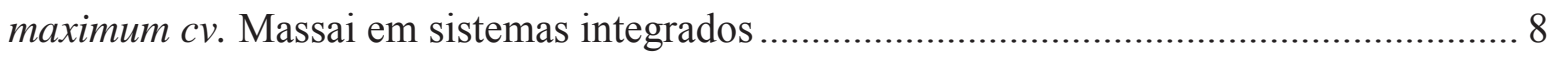

2.4 Matéria orgânica do solo e a influência dos sistemas de manejo do solo......................... 11

2.5 Frações da matéria orgânica do solo obtidas pelo método físico-granulométrico........... 13

2.6 Fracionamento químico baseado na solubilidade da matéria orgânica do solo em meio

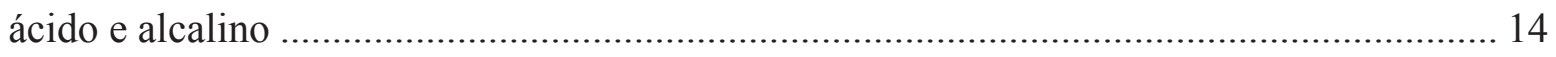

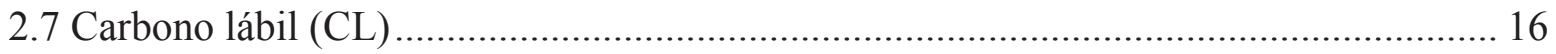

2.8 Carbono da Biomassa Microbiana (CBM) ………..................................................... 17

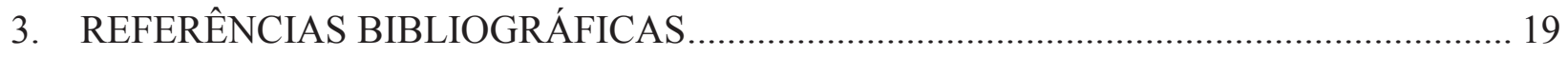

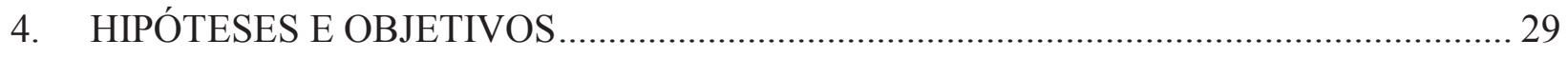

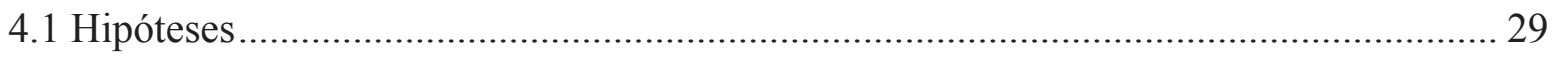

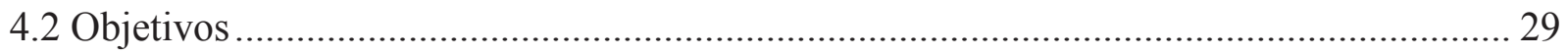

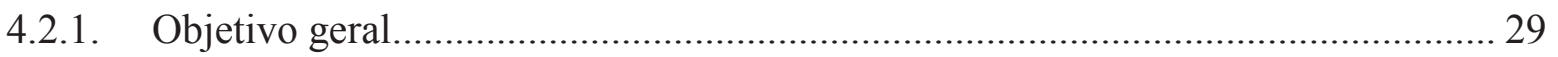

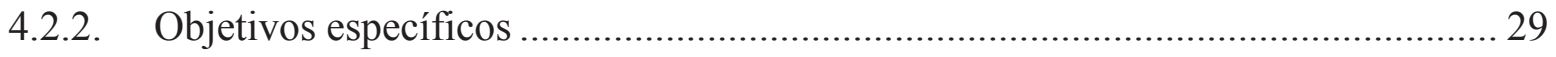

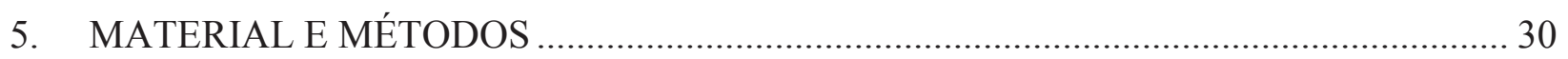

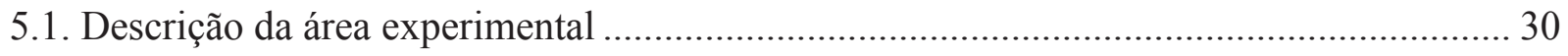

5.2 Delineamento e condução do experimento ……………………………………………….... 33

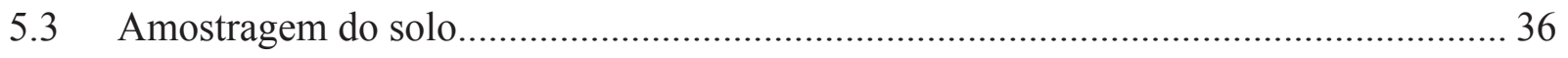

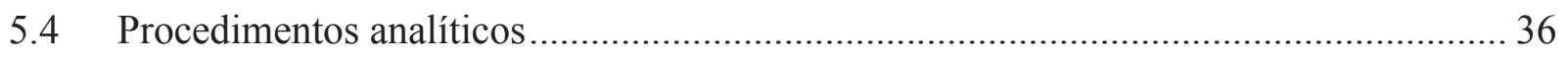

5.4.1 Determinação do carbono orgânico total ................................................................ 36 
5.4.2 Fracionamento físico-granulométrico da matéria orgânica do solo.

5.4.3 Carbono da biomassa microbiana ........................................................... 37

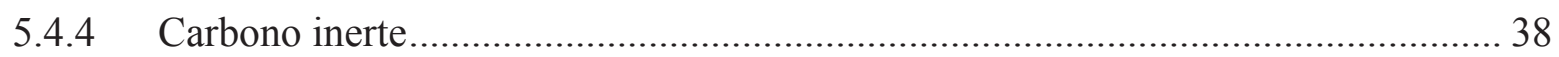

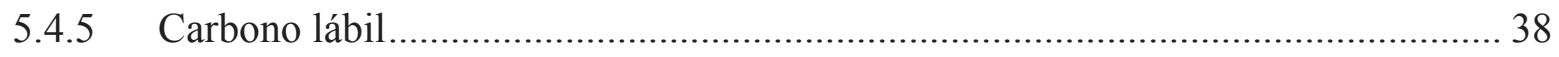

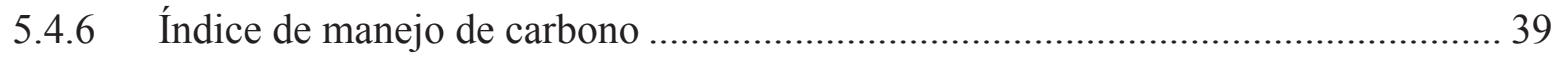

5.4.7 Determinação da produtividade do milho (Zea mays) ....................................... 40

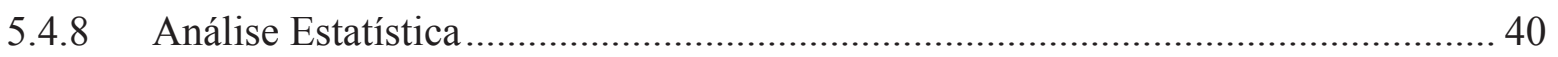

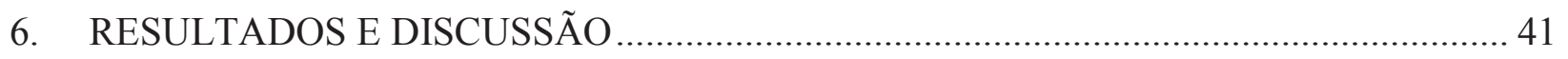

6.1 Frações lábeis da matéria orgânica do solo ............................................................ 44

6.2 Frações estáveis da matéria orgânica do solo.......................................................... 49

6.3 Relações entre as substâncias húmicas............................................................... 55

6.4 Índice de manejo de carbono e a produtividade do milho (Zea mays)......................... 58

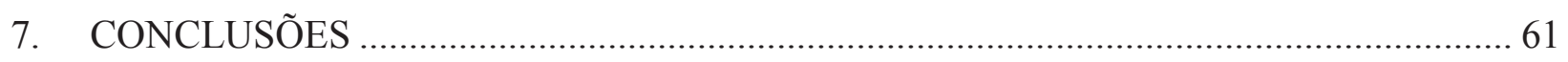

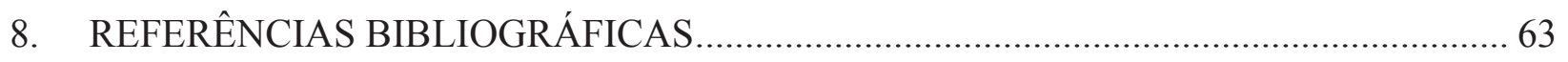

\section{LISTA DE FIGURAS}

Figura 1. Mapa da localidade do experimento, Fazenda Água Limpa, Universidade de Brasília, Distrito Federal, Brasil, localidade exata representada pelo quadrado vermelho. Fonte: (Google Earth, maps). .30

Figura 2. Precipitação pluviométrica mensal, Estação Climatológica da Fazenda Água Limpa, Universidade de Brasília, Distrito Federal. .32

Figura 3. Ilustração do histórico de uso das áreas experimentais e os períodos de coleta de solo (T0, T1, T2, T3 e T4), Fazenda Água Limpa, Universidade de Brasília, Distrito Federal, Brasil....... .33 
Figura 4. Ilustração da mudança no uso do solo, A e B área no tempo T2, sem o componente arbóreo, C e D mostram o período de plantio e desenvolvimento das mudas, E e F mostram o ILPF no tempo T3 com a presença do componente arbóreo.

Figura 5. Teores de carbono orgânico total (COT) nas profundidades 0-10 cm (A); 10-20 cm (B); e 20-40 cm (C), em área sob integração lavoura-pecuária-floresta. Coletas realizadas em 2012 com a área ainda degradada (T0); na safra 2013/2014 (T1); na safra 2014/2015 (T2) e na safra 2015/2016(T3) .43

Figura 6. Teores de carbono das frações lábeis da matéria orgânica do solo na profundidade de 0$10 \mathrm{~cm}, 10-20 \mathrm{~cm}$ e 20-40 cm, em área sob integração lavoura-pecuária-floresta, ao longo de 4 anos de implementação do sistema. CBM - carbono da biomassa microbiana (A); CL - carbono lábil (B) e COP - carbono orgânico particulado (C). Coletas realizadas em 2012 com a área ainda degradada (T0); na safra 2013/2014 (T1); na safra 2014/2015 (T2) e na safra 2015/2016 (T3).....

Figura 7. Teores de carbono inerte e carbono associado aos minerais da matéria orgânica do solo na profundidade de 0-10 cm, 10-20 cm e 20-40 cm, em área sob integração lavoura-pecuáriafloresta, ao longo de 4 anos de implementação do sistema. CI - carbono inerte (A, C, E); CAM carbono associado aos minerais (B, D, F). Coletas realizadas em 2012 com a área ainda degradada (T0); na safra 2013/2014 (T1); na safra 2014/2015 (T2) e na safra 2015/2016 (T3).

Figura 8. Teores das substâncias húmicas na profundidade de $0-10 \mathrm{~cm}, 10-20 \mathrm{~cm}$ e 20-40 cm, em área sob integração lavoura-pecuária-floresta, ao longo de 4 anos de implementação do sistema. AF - ácido fúlvico; AH - ácido húmico; HU- humina. Coletas realizadas em 2012 com a área ainda degradada (T0); na safra 2013/2014 (T1); na safra 2014/2015 (T2) e na safra 2015/2016 (T3).

Figura 9. Produtividade de grãos de milho em área sob integração lavoura-pecuária-floresta.....60 


\section{LISTA DE TABELAS}

Tabela 1. Variação da precipitação e temperatura registrada no local com base em dados dos anos de 2011 a 2016

Tabela 2. Resultados da análise química onde foram instalados os experimentos, após a adubação e a correção da área. .32

Tabela 3. Histórico de manejo da área experimental por safra agrícola

Tabela 4. Valores médios das relações $\mathrm{AH} / \mathrm{AF}$ e $(\mathrm{AH}+\mathrm{AF}) / \mathrm{HU}$ em função da

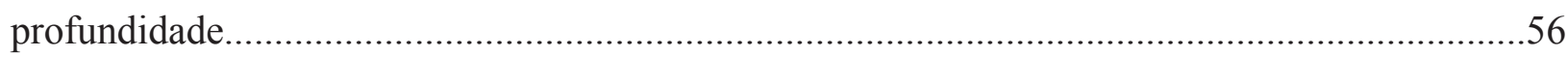

Tabela 5. Valores médios das relações $\mathrm{AH} / \mathrm{AF}$ e $(\mathrm{AH}+\mathrm{AF}) / \mathrm{HU}$ em função da

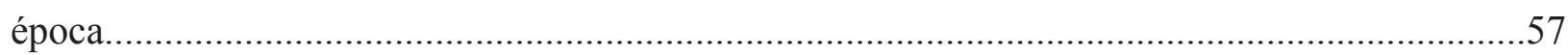

Tabela 6. Índices labilidade e manejo da área, em função da época e da profundidade. .58 
JOVANOVIC, BOBAN. DINÂMICA DA MATÉRIA ORGÂNICA NA FASE INICIAL DE IMPLEMENTAÇÃO DE UM SISTEMA DE INTEGRAÇÃO LAVOURA-PECUÁRIAFLORESTA. 2017. Tese (Mestrado em Agronomia). Universidade de Brasília-UnB.

\section{RESUMO}

A pastagem degradada é um fenômeno constantemente presente na pecuária do Cerrado. Este tem sua origem devido o inadequado manejo da pastagem auxiliado pela insuficiente reposição dos resíduos da serapilheira, assim como a inexistência de manejo dos nutrientes do solo. Desta forma a compressão da vegetação pelo pastoreio se configura superior à capacidade de regeneração natural da forrageira. O manejo da pastagem se apresenta como uma alternativa não só para manutenção a produtividade dos sistemas, bem como incremento da sua capacidade de captação hídrica e incremento da biodiversidade dentro do mesmo sistema, esses ganhos de natureza ambiental são auxiliados pela manutenção e captação de carbono no solo permitindo a fluência dos processos deste ecossistema. Os sistemas de manejo conservacionistas do solo se apresentam como uma alternativa viável para reduzir as pressões exercidas pela pecuária e os processos de erosão e lixiviação dos nutrientes em áreas com algum grau de degradação do solo. Assim o presente trabalho avaliou as mudanças nas frações lábeis e estáveis do carbono de uma área em quatro épocas, denominadas por T0, T1, T2 e T3, em que T0 corresponde à área no seu estado de pasto degradado no ano de 2012, as épocas T1 e T2 correspondem ao sistema de integração lavoura-pecuária (ILP) com consórcio de milho (Zea mays) e capim (Panicum maximum cv. Massai) e T3 ao estabelecimento de um sistema de integração lavoura-pecuáriafloresta (ILPF), cujo componente arbóreo é a gliricídia (Gliricidia sepium). Incrementos foram encontrados para as frações lábeis e estáveis da matéria orgânica do solo com o passar do tempo de implantação do ILPF, cujos valores, entre as épocas T0 e T3, considerando as profundidades de $0-10 \mathrm{~cm} ; 10-20 \mathrm{~cm}$ e $20-40 \mathrm{~cm}$, variaram de $120 \mathrm{mg} \mathrm{kg}^{-1}$ a $330 \mathrm{mg} \mathrm{kg}^{-1}$ para o carbono da biomassa microbiana (CBM), de $0,9 \mathrm{~g} \mathrm{~kg}^{-1}$ a 2,6 $\mathrm{g} \mathrm{kg}^{-1}$ para o carbono lábil (CL) e de $1,9 \mathrm{~g} \mathrm{~kg}^{-1} \mathrm{a}$ $11 \mathrm{~g} \mathrm{~kg}^{-1}$ para o carbono orgânico particulado (COP). Também, do T0 para o T3, as frações estáveis do carbono do solo variaram entre $4 \mathrm{~g} \mathrm{~kg}^{-1}$ a $14 \mathrm{~g} \mathrm{~kg}^{-1}$ no carbono inerte (CI), de $13 \mathrm{~g} \mathrm{~kg}^{-}$ ${ }^{1}$ a $26 \mathrm{~g} \mathrm{~kg}^{-1}$ no carbono associado aos minerais (CAM), de $4 \mathrm{~g} \mathrm{~kg}^{-1}$ a $6,2 \mathrm{~g} \mathrm{~kg}^{-1}$ no carbono da fração ácido fúlvico (AF), de $0,8 \mathrm{~g} \mathrm{~kg}^{-1}$ a 3,6 $\mathrm{g} \mathrm{kg}^{-1}$ na fração ácido húmico (AH) e de $6,4 \mathrm{~g} \mathrm{~kg}^{-1} \mathrm{a}$ $12,7 \mathrm{~g} \mathrm{~kg}^{-1}$ na humina (HU). Os teores de COT também foram incrementados na passagem do T0 
para o T3, com valores que passaram de $19 \mathrm{~g} \mathrm{~kg}^{-1}$ para $24 \mathrm{~g} \mathrm{~kg}^{-1}$ para camada de $0-10 \mathrm{~cm}$, de 18 $\mathrm{g} \mathrm{kg}^{-1}$ para 24,5 $\mathrm{g} \mathrm{kg}^{-1}$ na camada de $10-20 \mathrm{~cm}$ e de $15 \mathrm{~g} \mathrm{~kg}^{-1}$ para $19 \mathrm{~g} \mathrm{~kg}^{-1}$ para a camada de 20$40 \mathrm{~cm}$. Separando-se as profundidades avaliadas, observam-se reduções nas frações CAM e HU conforme o incremento da complexidade do sistema. Da mesma forma, as relações AH/AF e $(\mathrm{AH}+\mathrm{AF}) / \mathrm{HU}$ não tiveram diferenças significativas entre as épocas. Entretanto diferenças nas médias do índice de manejo de carbono (IMC) e no índice de labilidade (IL) foram encontradas entre a época T0 e as demais, sendo que as épocas T1 e T2 não foram distintas entre si, porem foram menores que o T3. A produtividade do milho foi incrementada passando de $2,800 \mathrm{~kg} \mathrm{ha}^{-1}$ no T1 para 8,000 $\mathrm{kg} \mathrm{ha}^{-1}$ no T3, com a adoção do sistema de ILPF. Conclui-se que no período de quatro anos durante a implementação de um sistema de integração lavoura-pecuária-floresta com a espécie gliricídia (Gliricidia sepium) em consórcio com o capim massai (Panicum maximum cv. Massai) é possível acumular carbono orgânico em diferentes frações da matéria orgânica do solo com reflexos no aumento da produtividade do milho.

Palavras-chave: Frações lábeis e estáveis do C do solo; Sistemas integrados de produção; Gliricidia sepium; Panicum maximum cv. Massai.

\begin{abstract}
The phenomenon of degraded pasture is an always present one in pasture activity of the Cerrado region, the phenomenon is originated by the inadequate management of pasture lands, with an excess of nutrient demand by the grass and crop, allied with insufficient nutrient replenishing, poor soil management and excess vegetation intake by the animal component. The pasture management measures ensure not only an increase in productive capacity, as it can also act as a hydric reservoir and consequently increase the biodiversity of the system. The integrated croplivestock systems can be seen as an alternative to mitigate the pressures on land productivity and the processes of erosion and nutrient displacing. The present paper has analyzed the labile and stable fractions of soil carbon contents in three distinct periods named as T0, T1, T2 and T3, in which T0 corresponds to degraded pasture land use, in 2012, at T1 and T2 the land use was an integrated maze (Zea mays) and the switchgrass (Panicum maximum cv. Massai), the T3 period corresponds to an fully integrated crop-livestock system with the (Gliricidia sepium) as the tree component. There were found increased concentrations on booth labile and stable fractions of the organic matter, in regard with the progression stages of the integrated crop-livestock system, the
\end{abstract}


soil microbiological carbon (SMC) had varied from $120 \mathrm{mg} \mathrm{kg}^{-1}$ to $330 \mathrm{mg} \mathrm{kg}^{-1}$ comparing the T0 and T3 stages respectively, the variation observed for the labile carbon (LC) was from $0,9 \mathrm{~g}$ $\mathrm{kg}^{-1}$ to $2,6 \mathrm{~g} \mathrm{~kg}^{-1}$ in the same stages and particulate organic carbon (POC) had an spread of $1,9 \mathrm{~g}$ $\mathrm{kg}^{-1}$ to $11 \mathrm{~g} \mathrm{~kg}^{-1}$. The stable fractions of carbon had also showed increases when comparing the T0 and T3 stages of the area, there being, the inert carbon (IC) had an 1,9 $\mathrm{g} \mathrm{kg}^{-1}$ to $11 \mathrm{~g} \mathrm{~kg}^{-1}$ variation in the T0 and T3 stages respectably, while minerals-associated organic carbon (MOC) had varied from $4 \mathrm{~g} \mathrm{~kg}^{-1}$ to $6,2 \mathrm{~g} \mathrm{~kg}^{-1}$, the fulvic acid (FA) ranged from $0,8 \mathrm{~g} \mathrm{~kg}^{-1}$ to $3,6 \mathrm{~g} \mathrm{~kg}^{-1}$, the humic acid (HA) from $0,8 \mathrm{~g} \mathrm{~kg}^{-1}$ to $3,6 \mathrm{~g} \mathrm{~kg}^{-1}$ and for humin (HU) the spread was from $6,4 \mathrm{~g}$ $\mathrm{kg}^{-1}$ to $12,7 \mathrm{~g} \mathrm{~kg}^{-1}$ for the same stages of the system. The total organic carbon (TOC) had showed an increase in the concentration values between the T0 and T3 timeframes, having those increased from $19 \mathrm{~g} \mathrm{~kg}^{-1}$ to $24 \mathrm{~g} \mathrm{~kg}^{-1}$ in the $0-10 \mathrm{~cm}$ soil layer, from $18 \mathrm{~g} \mathrm{~kg}^{-1}$ to $24,5 \mathrm{~g} \mathrm{~kg}^{-1} \mathrm{in}$ the $10-20 \mathrm{~cm}$ soil layer and from $15 \mathrm{~g} \mathrm{~kg}^{-1}$ to $19 \mathrm{~g} \mathrm{~kg}^{-1}$ in the $20-40 \mathrm{~cm}$ soil layer. In the humic acid/fuvic acid indicator, no significant differences between the stages were found, however in the liability indices and indices of carbon management data has shown differences between the means of T0 and the rest of the stages, T1 and T2 had no differences between each other, but were significantly less than the concentration found in the T3 stage. The maze (Zea mays) had a four times increase in its content when comparing the T0 stage (degraded pasture) with the T3 (integrated crop-livestock system), the variation of productivity had ranged from $2,000 \mathrm{~kg} \mathrm{ha}^{-1}$ in 2012 (T0) to $8,000 \mathrm{~kg} \mathrm{ha}^{-1}$.

Key-words: Integrated crop-livestock; Labile and stable fractions of soil C; Integrated production systems; Gliricidia sepium; Panicum maximum cv. Massai. 


\section{INTRODUÇÃO}

A degradação da pastagem é um fenômeno complexo de múltiplas causas e efeitos tendo como consequência, a gradativa diminuição da capacidade de suporte da pastagem (Dias-Filho, 2011). A tecnologia para o melhoramento de pastagem tem demonstrado eficiência na recuperação do potencial produtivo da forragem e com as atuais pressões ambientais e de mercado, os sistemas integrados de manejo podem se apresentar como uma alternativa para uso e recuperação destas mesmas áreas (Dias-Filho, 2014).

O cultivo agrícola com frequente preparo mecânico do solo e realizado por longos períodos caracteriza-se pela ausência de técnicas de conservação do solo, promove a perda da matéria orgânica do solo e reduz a fertilidade do solo ao longo do tempo (Li et al., 2016).

A partir de meados da década de 1970, com o advento da agricultura no Cerrado, houve expressivo aumento na área cultivada, com obtenção de elevados incrementos na produtividade das culturas (CONAB, 2014). Nesse período, extensas faixas de áreas nativas foram incorporadas para produção agropecuária, normalmente, deixando vastas áreas com solos expostos e degradados. Como consequência, houve redução das taxas de infiltração de água e elevado risco de erosão do solo nessa região (Hunke et al., 2014). Na safra 2014/2015 esta região apresentou 22,865 mil hectares de área cultivada com grãos e uma produtividade média de 3,850 $\mathrm{kg} \mathrm{ha}^{-1}$ (CONAB, 2015).

A introdução de pastagens cultivadas, adaptadas ao Cerrado, principalmente por meio da cultura de Brachiaria decumbens em solos ácidos de baixa fertilidade natural, impulsionou a expansão da pecuária nesse bioma (Alvim et al., 2002). No entanto, extensas áreas nativas foram substituídas por pastagens que com o passar do tempo se transformaram em áreas degradadas, improdutivas, que acumularam e acentuaram danos ambientais, sendo esta relação explícita na perda da qualidade do solo (Chaddad, 2016).

Os sistemas de integração lavoura pecuária (ILP) e integração lavoura pecuária floresta (ILPF) proporcionam melhoria das propriedades do solo e promovem acúmulo de carbono superior à encontrada em pastagens degradadas (Muniz et al., 2011). Em experimentos de longa duração foi observado que a integração das atividades lavoura, pecuária e floresta, possibilitam uma maior eficiência no uso dos nutrientes (Balbino et al., 2011). Os resíduos de matéria seca das plantas proporcionam incremento no estoque de carbono na área, recuperando os teores da matéria orgânica do solo (MOS) (Costa et al., 2015). 
A susceptibilidade das áreas de pasto, sob cobertura de gramíneas, é influenciada por diversos fatores incluindo entre eles, o manejo impróprio do solo, propriedades intrínsecas do solo, como textura e estrutura, condições climáticas, as características das espécies gramíneas cultivadas, bem como a técnica de irrigação empregada (Oliveira et al., 2016).

A matéria orgânica do solo (MOS) serve de base para a sustentabilidade dos sistemas de produção agrícolas, ela é a principal indicadora da qualidade dos solos (Lal, 2004). Em solos tropicais e subtropicais o manejo do carbono orgânico total do solo (COT) interage de maneiras complexas com as características e propriedades do solo, onde se encontra esta matéria orgânica, influenciando os serviços ecossistêmicos deste sistema (Robinson et al., 2013).

As taxas de entrada de matéria orgânica em um sistema podem ser influenciadas pelo homem, contudo a decomposição deste resíduo vegetal tem uma determinada taxa que é influenciada principalmente pelos microrganismos, fatores de ordem climática, umidade, assim como a composição química dos resíduos vegetais integrados ao solo (Costa \& Sangakkara, 2006).

A manutenção e preservação dos serviços ecossistêmicos do solo, como sua capacidade de provisionar, regular e auxiliar serviços de apoio do solo, são uma prioridade no desenvolvimento de sistemas agrícolas sustentáveis. O uso de práticas agrícolas orgânicas provém uma gama maior de serviços ecossistêmicos quando comparadas as práticas tradicionais de cultivo (Reganold \& Wachter, 2016).

Em sua análise de dados e revisão bibliográfica com mais de 70 estudos Gattinger et al. (2012) concluíram que os solos com sistemas integrados de produção agropecuária, com uso de mais insumos orgânicos, tem o potencial de sequestro superior em $0,45 \pm 0,21 \mathrm{Mg} \mathrm{C}^{-1} \mathrm{ano}^{-1}$ ao convencional, autores sugerem que as diferenças foram motivadas primordialmente pelos elementos integrados das culturas, da pecuária e da integração do sistema com leguminosas. 


\section{REVISÃO BIBLIOGRÁFICA}

\subsection{Uso e manejo do solo no Cerrado}

O bioma Cerrado possui uma extensão de $2.039 .386 \mathrm{~km}$, sendo assim o segundo maior bioma da América da Sul, a formação tipo savana tropical possui uma flora com aproximadamente 11.000 espécies das quais 4.400 são consideradas endêmicas. O bioma pode ser encontrado nos estados de Goiás, Tocantins, Mato Grosso, Mato Grosso do Sul, Minas Gerais, Bahia, Maranhão, Piauí, Rondônia, Paraná, São Paulo e Distrito Federal. Em magnitude o bioma Cerrado é o que mais sofre alterações por ações humanas (MMA, 2015).

Ao longo dos anos foi estabelecida uma média anual de $0,44 \%$ de perda das áreas com cobertura natural, fornecendo terreno propício para a produção agrícola e formação de pastagens, sendo que estes últimos são geralmente acompanhados de processos de degradação do solo (Beuchle, 2015).

Mapeamentos recentes indicam que $54,49 \%$ do bioma mantêm a sua vegetação natural, áreas de pastagem ocupam 24,46\% do bioma, enquanto a agricultura anual representa 8,54\% e as culturas perenes ocupam $3,15 \%$, totalizando $41,15 \%$ de ocupação para atividades agropecuárias (MMA, 2015).

A principal forma de uso das terras no Cerrado é a pastagem cultivada correspondendo a $29 \%$ da área total, seguida por agricultura anual e perene que ocupa $12 \%$ do bioma, sendo mais comum seu uso nos estados de Goiás, Mato Grosso, Mato Grosso do Sul e São Paulo (MMA, 2015).

A expansão da atividade agropecuária no Brasil se deu sem muito preparo da terra, usando insumos intensivamente, com limitações tecnológicas e de mão de obra, de forma que predominou pecuária extensiva e agricultura convencional, resultando em perda de fertilidade e erosão do solo (Dias-Filho, 2011).

A caracterização de pastagem degradada pode ser encontrada no trabalho de Hobbs et al. (2009), onde relata que as mudanças ocorridas nos ecossistemas podem ser determinadas como sendo de natureza biótica e abiótica, sendo que a parcela biótica é representada por mudanças na composição da flora local e mudanças na dispersão de sementes e pólen ocasionadas por troca do manejo do solo, inclusão de espécies invasoras ou ainda alteração no uso da área. As alterações 
de ordem abiótica englobam as alterações físicas e químicas do solo ocasionadas pela entrada de insumos agrícolas e práticas de cultivo mecanizado.

A degradação da pastagem tem se tornado um dos maiores limitadores para as práticas de exploração pecuária em distintas regiões brasileiras, a perda do vigor das pastagens e a sua capacidade de recuperação natural, estimativas apontam que $80 \%$ das pastagens se encontram em algum estágio de degradação, indicando que as áreas se encontram com fertilidade inferior a ótima para sustentar a vegetação Zimmer, (2012). O fenômeno de degradação das pastagens é complexo e envolve uma conjuntura de causas e efeitos que levam a gradativa diminuição da capacidade de suporte da pastagem, dos 204 milhões de hectares do Cerrado, 53 milhões se apresentam no regime de pastagens cultivadas e 12,5\% desta área, está com algum indicativo de degradação (Dias-Filho, 2011).

Os desafios do futuro consistem em garantir a segurança alimentar para o Brasil e o mundo. Nessa perspectiva, buscam-se práticas agrícolas com baixo impactos ambientais, que mitiguem a emissão de gases de efeito estufa, e reduzam os processos de erosão do solo, bem como a perda de nutrientes (Nodari \& Guerra, 2015).

Devido à grande extensão do Cerrado, perturbações antrópicas nesse bioma podem refletir na dinâmica global do carbono e outros gases de efeito estufa. Os ambientes savânicos tropicais representam potencial para o incremento da produção de gado de corte, bem como são vistas como potencial agente dreno para os gases de efeito estufa (Ferreira, 2013). Além disso, este bioma é importante para a segurança energética do país, como possível fonte de energia renovável, com foco especial em energia advinda da biomassa (Anater et al., 2016).

A pastagem constitui a base dos sistemas de produção de bovinos, sua importância é demostrada na necessidade de encontrar espécies forrageiras que possibilitem uma eficiência superior do sistema, a prática de fornecimento de nutrientes por adubação, com destaque para o Nitrogênio, favorece o aporte da biomassa necessário para a continuidade do sistema, além disso, a prática da correção do solo é recomendada uma vez que fornece as bases trocáveis essenciais para o desenvolvimento da planta (Santana et al., 2010).

Estudos que visam maximizar o potencial de sequestro de carbono são de grande importância, particularmente aqueles realizados na área do Cerrado devido à crescente velocidade de perda da vegetação nativa (Carvalho et al., 2014). Recuperação e ciclagem de nutrientes nestas áreas por meio de adoção de sistemas conservacionistas, como sistema de 
plantio direto (SPD) e sistemas de integração lavoura pecuária (ILP) ou integração lavoura pecuária floresta (ILPF), representam alternativas práticas de agricultura de baixa emissão de carbono e auxiliam na revitalização de áreas previamente inférteis para prática agrícola (Carvalho et al., 2014).

Observou-se uma reversão do quadro de baixa sustentabilidade por meio de uso e aplicação de tecnologias como SPD e os sistemas agrossilvopastoris. Porém o sucesso desses sistemas depende da rotação de culturas, que é uma das práticas preconizadas para a manutenção da palhada sobre o solo (Macedo, 2009).

Em estudo com 10 anos de experimento, em Eldorado do Sul (RS), com três profundidades (0-5, 5-10 e 10-20 cm) avaliadas, Dorneles et al. (2015), encontraram em três sistemas de manejo distintos (sistema convencional, sistema com revolvimento reduzido e sistema de plantio direto), diferenças para no teor da matéria orgânica na profundidade $0-5 \mathrm{~cm}$. Neste trabalho os autores ressaltam que essas diferenças começam a ser mensuráveis a partir do $40^{\circ}$ mês, tendo seu ponto máximo no $80^{\circ}$ mês da implantação do sistema, evidenciando os efeitos dos distintos manejos.

Em seu trabalho realizado no Cerrado, Perreira et al. (2010) observaram que a variabilidades entre os teores de COT e MOS, nos distintos sistemas de manejo observados: plantio direto, plantio convencional e pousio, e concluíram que estes fatores são de suma importância em um sistema agrícola, a sua contribuição ao sistema é superior aos resultados de acúmulo do $\mathrm{C}$ pelas distinções existentes nas culturas. 


\subsection{Sistemas integrados de produção e descrição dos sistemas agrossilvopastoris:}

integração lavoura pecuária (ILP) e integração lavoura pecuária floresta (ILPF)

O sistema ILP é definido como a diversificação, rotação, consorciação ou sucessão das atividades da agricultura e da pecuária, dentro da propriedade rural, de forma harmônica, em um mesmo sistema onde há benefícios para ambas. Esta integração das atividades por meio do sistema ILP possibilita a exploração econômica da área durante o período do ano inteiro, que aumenta e regula a continuidade da oferta de grãos, carne e leite (Alvarenga \& Noce, 2005).

A adesão dos produtores rurais ao sistema ILP se deu em virtude do incremento na produtividade rural, elevação da produtividade por área plantada e redução na entrada de insumos no sistema, fatores que levam à redução dos custos de produção por área definida (Sulc \& Franzluebbers, 2014).

A adoção dos sistemas ILP pode ser uma alternativa para recuperação de pastagens degradadas e para a sustentabilidade da agricultura que utiliza culturas anuais, uma vez que esses sistemas incrementam a produção de palha por meio do SPD e melhoram as propriedades químicas, físicas e biológicas do solo (Balbino et al., 2011). Além disso, esses sistemas possibilitam o uso eficiente dos equipamentos aumentando o emprego e a renda do produtor (Macedo, 2009).

Em trabalhos como de (Bowman \& Zilberman, 2013) os autores apontam que a adoção de certas práticas, como as que comprovadamente incrementam a produtividade do solo e reduzem os custos, tem enfrentado resistência dos produtores para sua adoção devido à falta de acesso a crédito rural ou falta de conhecimento técnico para implantar o sistema. Em seu estudo (Fernandes \& Finco, 2014) concluem que os sistemas integrados concorrem com os convencionais no Estado do Mato Grosso (MT) e se apresentam como uma alternativa mais atraente conforme o aumento do mercado de créditos de carbono.

A implementação do ILP contribui para viabilizar o SPD com palha bem manejada produzida por espécies forrageiras tropicais que proporcionam um solo com melhor estrutura e fertilidade em função do resíduo de material orgânico deixado na superfície e na sub superfície do solo assim como um sistema radicular abundante (Loss et al., 2011). No sistema ILP também é observada uma redução do uso de agroquímicos em virtude da quebra no ciclo de pragas, doenças e plantas daninhas (Vilela et al., 2011). 
A elevação dos níveis da MOS assim como da qualidade física do solo, com a introdução das pastagens em áreas agrícolas, em solos com níveis adequados de fertilidade, indicam que a ILP tem o potencial de reduzir o impacto ambiental das atividades produtivas ao reduzir as emissões dos gases de efeito estufa, com um consequente aumento da estabilidade na produção de culturas anuais, assim como a melhora do aproveitamento de água e nutrientes. Devido ao conhecido papel das árvores para o sequestro de carbono e consequente mitigação da emissão dos gases de efeito estufa, os sistemas ILPF são considerados relevantes para região do Cerrado (Franchini et al., 2010). Os sistemas ILP tem demonstrado um potencial considerável para o acúmulo de carbono no solo. Na região do Cerrado foram observados incrementos nos estoques de carbono (EstC) no solo em sistemas ILP sob SPD, quando comparados com áreas de SPD com ausência da espécie forrageira na rotação ou sucessão de cultivos (Carvalho et al., 2010).

Ao avaliarem taxas de acúmulo de carbono em diferentes sistemas de uso e manejo do solo no Cerrado, Salton et al. (2011) observaram que maiores estoques de carbono estão relacionados à presença de forrageiras, o que resulta em uma ordem decrescente de estoque de carbono no solo, conforme segue: pastagem permanente sob SPD> ILP sob SPD > lavoura com SPD > lavoura sob cultivo convencional. Estes resultados são indicativos de que a taxa de acúmulo de carbono na conversão de SPD para ILP sob SPD, pode demonstrar significativos acréscimos.

O potencial para a adoção do sistema ILPF em diversos ecossistemas brasileiros está condicionado a uma gama de fatores que incluem: disponibilidade de solos favoráveis, infraestrutura de armazenamento e de produção, recursos financeiros próprios ou acesso a crédito, domínio da tecnologia de produção de grãos e produção animal, acesso aos mercados de insumos e comercialização da produção, acesso a assistência técnica, possibilidade de arrendamento da terra ou parceria com produtores tradicionais de grãos (Balbino et al., 2011).

A intensificação da produção sob os sistemas ILPF acarretou numerosos benefícios ao produtor e ao meio ambiente, de forma que se observa: a) melhora das condições físicas, químicas e biológicas do solo; b) aumenta a ciclagem e a eficiência na utilização dos nutrientes; c) reduz os custos nas atividades agrícolas e pecuárias; d) diversifica e estabiliza a renda das propriedades rurais; e) viabiliza a recuperação de pastagens degradadas (Alvarenga et al., 2010).

O sistema ILPF utiliza na sua base a integração dos componentes com intuito de obter níveis cada vez mais elevados de qualidade dos produtos, qualidade ambiental e competitividade, 
o efeito desejado é a junção entre a recuperação de áreas com sinais de degradação, transformando as mesmas em fonte dreno de carbono atmosférico, enquanto se encontra valor econômico do aproveitamento das culturas (Balbino et al., 2011).

No trabalho de Diel et al. (2014), foi verificado que um sistema ILPF com dois anos não foi capaz de interferir de forma significativa nas características químicas do solo, nem na produtividade das culturas. No entanto em trabalhos com tempo superior a quatro anos onde houve transição dos sistemas ILP a ILPF, observou-se gradual melhora dos atributos químicos, em especial relacionados ao aumento dos teores de fósforo, potássio e matéria orgânica, incremento no peso dos animais por hectare, assim como aumento da fixação biológica do nitrogênio (Oliveira et al., 2013).

Em estudo realizado por Lacerda et al. (2009), observaram que o incremento médio da biomassa por árvore dentro de sistemas florestais pode atingir valores de até $6,55 \mathrm{~kg}$ árvore ${ }^{-1}$. Ainda nesse estudo, em $\mathrm{CO}_{2}$ equivalente este incremento foi de $12,48 \mathrm{~kg}$ árvore ${ }^{-1}$, apresentando um potencial de sequestro, em condições ideais, de até $250 \mathrm{~kg}$ de $\mathrm{CO}_{2}$ equivalente da atmosfera, em um período de 20 anos.

No trabalho realizado por Nunes et al. (2011), foi identificado um teor de biomassa superior para sistemas de plantio direto em relação ao sistema convencional.

A importância do manejo adequado com base no incremento de carbono orgânico do solo se acentua em regiões áridas, nessas regiões a capacidade de absorção de umidade do solo é incrementada por meio do $\mathrm{C}$, desta forma, o seu manejo constitui uma estratégia para se ultrapassar as restrições hídricas da localidade (Glenk et al., 2016).

Para Kahiluoto et al. (2014), a disponibilidade de nutrientes e os ganhos de produtividade das culturas são igualmente de grande importância para assegurar sustentabilidade dos sistemas agrícolas a médio e longo prazo, e devem ser avaliados na implementação dos sistemas.

\subsection{Uso e características da gliricídia (Gliricidia sepium) e capim colonião (Panicum} maximum cv. Massi) em sistemas integrados

A gliricídia (Gliricidia sepium) é originária da América Central e da região Norte da América do Sul, de onde foi expandida, sendo atualmente distribuida entre a América do Sul, Caribe, África, Ásia e entre ilhas do oceano pacífico. Esta espécie tem boa adaptação às regiões de 1300 m acima do nível do mar, a precipitação adequada para esta cultura está entre 600 e 
$6000 \mathrm{~mm} \mathrm{ano}^{-1}$, temperatura ideal de $15{ }^{\circ} \mathrm{C}$ a $30{ }^{\circ} \mathrm{C}$ e tem capacidade de resitir a longos períodos de seca (Cuervo-Jilménes et al., 2013).

O cultivo da gliricídia como um componente arbóreo tem se mostrado muito eficiente para superar a insuficiência da pastagem durante a estação seca, as folhas desta espécie tem alta concentração de proteína, são energéticas e de boa digestibilidade pelas espécies animais, bovinas e ovinas (Diouf et al., 2008).

No trabalho de Beedy et al. (2010), foi encontrado que a presença da gliricídia, em consórcio com outras culturas, promoveu incrementos significativos nos teores de carbono orgânico total (COT), carbono orgânico particulado (COP), nitrogênico $(\mathrm{N})$ da matéria orgânica particulada, $\mathrm{N}$ inorgânico, na capacidade de troca de cátions (CTC) e uma redução na relação $\mathrm{C} / \mathrm{N}$.

A utilização da Brachiaria ocorreu no Brasil na década de 1950, porém a maior expansão ocorreu nas décadas de 1970 e 1980, quando a produção animal passou de $20 \mathrm{~kg}^{-1} \mathrm{ha}^{-1}$ ano $^{-1}$ para $180 \mathrm{~kg}^{-1} \mathrm{ha}^{-1} \mathrm{ano}^{-1}$. Metade das pastagens do Brasil estão cobertas por Brachiaria, totalizando aproximadamente 100 milhões de hectares (Araújo \& Pedroso, 2013).

O Panicum maximum cv. Massai é um híbrido espontâneo que foi coletado em 1969 na Tanzânia e introduzido no Brasil em 1982, como resultado de um convênio entre instituições de pesquisa. Este híbrido tem sido utilizado pelos agricultores por ser muito produtivo, ter uma boa rebrota após cortes, e sua grande produção de sementes Jank et al. (1997).

Embora espécies forrageiras como o Panicum maximum apresentem elevado valor nutritivo, assim como uma produtividade alta, as pressões exercidas pelo manejo inadequado tanto da exploração da área pelo componente bovino, assim como inadequado manejo do resíduo das forrageiras, pode comprometer ainda mais a fertilidade do solo e a produtividade do mesmo, de tal forma que devem ser observadas as recomendações de capacidade de carga, assim como intensidade do pastoreio (Dias-Filho, 2007).

A capacidade da gliricídia de fixar o $\mathrm{N}$ atmosférico é devida a sua relação simbiótica com as bactérias do gênero Rhizobium sp. (Cubillos-Hinojosa, 2011).

A gliricídia favorece a ciclagem de nutrientes como o $\mathrm{P}, \mathrm{K}^{+}, \mathrm{Ca}^{+2}$ e $\mathrm{Mg}^{+2}$ de forma que é reconhecida sua função como componente arbóreo de ciclagem de nutrientes. Em sistemas integrados de pasto-gliricídia, foram observadas forragens que se mantiveram por períodos de até sete anos, sem a necessidade de adubação mineral (Cuervo-Jilménes et al., 2013). 
Em experimentos com sistemas agroflorestais, Martins et al. (2015) encontraram que a gliricídia em regime de consórcio com capim-buffel (Cenchrus ciliaris) e palma forrageira (Nopalea cochenillifera), fixou simbioticamente proporções de $\mathrm{N}$ superiores a $50 \%$ e contribuiu com $40 \mathrm{~kg} \mathrm{ha}^{-1}$ de $\mathrm{N}$ nas folhas, comparado com $11 \mathrm{~kg} \mathrm{ha}^{-1}$ em grãos e $18 \mathrm{~kg} \mathrm{ha}^{-1}$ na palhada dos sistemas convencionais.

Em seu trabalho Bah \& Rahman (2001) demonstraram o grande potencial da gliricídia no manejo do $\mathrm{N}$ em solos ácidos dos trópicos, devido à rápida decomposição de sua palhada. Os autores não observaram relação de competição entre a cultura do milho e a gliricídia pelos nutrientes. Em trabalhos realizados por Queiroz et al. (2007), observou-se um acúmulo médio de $89 \mathrm{~kg} \mathrm{ha}^{-1}$ de $\mathrm{N}$ em experimentos com adição de $\mathrm{P}$ e uma média de $74 \mathrm{~kg} \mathrm{ha}^{-1}$ em áreas que não receberam adição de $\mathrm{P}$, na cultura da gliricídia.

Em suas observações, Breedy et al. (2014) reforçam a dupla habilidade da Gliricidia sepium de fixar biológicamente o $\mathrm{N}$ atmosférico e ser uma espécie própria para sistemas integrados com pecuária devido a capacidade de rápida regeneração do volume foliar da espécie, bem como a qualidade e quantidade protéica das folhas da espécie.

Em estudos de Paula et al. (2015) é sugerido que as altas taxas de incremento da biomassa por intermédio da gliricídia podem ser observadas quando analisados longos períodos de tempo, esta espécie ainda favorece o aumento da fertilidade do solo e disponibilidade de nutrientes, devido ao curto período de meia-vida da liberação dos nutrientes no solo, provenientes da liteira das folhas desta espécie.

Em estudo realizado por Reckling et al. (2015), encontrou-se que em dois sistemas analisados, com rotação de culturas, compostas por leguminosas, foram econômica e ecologicamente mais rentáveis em comparação com às áreas sem a presença de leguminosas. Em seu estudo os autores propõem que a configuração e o arranjo dos fatores de um sistema integrado exercem influência sobre a rentabilidade e sustentabilidade do mesmo, na opinião dos autores os dados apontam que a integração dos fatores poderia ser optimizada utilizando ao máximo as relações de interação entre os fatores. 


\subsection{Matéria orgânica do solo e a influência dos sistemas de manejo do solo}

A matéria orgânica do solo (MOS) é componente essencial nos diversos processos químicos, físicos e biológicos dos ecossistemas terrestres, como ciclagem e retenção de nutrientes, agregação do solo e dinâmica da água, desempenhando importantes funções na manutenção de qualidade do solo, sustentabilidade dos sistemas naturais e agrícolas, assim como no balanço dos gases de efeito estufa (Balbino et al., 2011). A perda da matéria orgânica pode interferir drasticamente nestes processos, dificultando o emprego das funções do solo, provocando desequilíbrio nos sistemas e consequente desencadeamento do processo de degradação (Roscoe et al., 2006).

A conversão de áreas naturais em áreas de cultivo, com a derrubada e a queima da vegetação natural, pode reduzir os teores de MOS e acarretar perda da fertilidade e aumento da erosão do solo (Bernoux et al., 2004).

Os sistemas de manejo do solo, associados a certas práticas agrícolas, como a rotação de culturas e uso de plantas de cobertura promovem alterações significativas na dinâmica da MOS (Loss et al., 2009). Em estudos conduzidos por Torres et al. (2008), destacou-se o efeito benéfico das plantas de cobertura nas propriedades edáficas e no rendimento de culturas, decorrentes da ciclagem de nutrientes e decomposição da palhada.

O tipo de cultura, bem como as práticas agronômicas como rotação de culturas, fertilização e aplicação de adubos orgânicos influenciam na produção de biomassa (Balbino et al., 2011), desta forma é essencial entender como a produção de biomassa é influenciada por distintos sistemas de manejo que variam de acordo com o tipo do solo, clima e rotação de culturas (Koga \& Tsuji, 2009).

O solo é importante compartimento terrestre na ciclagem e armazenamento de carbono e as mudanças na vegetação local ou uso inadequado são elementos conhecidos em prejudicar a ciclagem de $\mathrm{C}$, diminuir o teor da MOS e aumentar as emissões de $\mathrm{CO}_{2}$ (Park et al., 2012).

O fracionamento granulométrico da MOS permite a obtenção de duas frações orgânicas: carbono orgânico particulado (COP) e carbono orgânico associado aos minerais (CAM). A fração COP é associada à porção da areia e é composta por resíduos de hifas, esporos de fungos e resíduos de plantas, em processo de decomposição, livres ou fisicamente protegidas dentro dos agregados do solo. O CAM é associado às frações silte e argila, protegida por mecanismos de proteção coloidal (Carmo et al., 2012). 
No trabalho realizado por Gauder et al. (2016) a entrada e saída de C no solo são dependentes das especificidades da cultura, sistema de manejo, rotação de culturas e interação entre vários fatores.

A literatura tem sugerido que há limites para a perda de $\mathrm{C}$, assim como para o armazenamento de $\mathrm{C}$, estes limites de saturação descreveriam o comportamento do solo como fonte ou dreno até a estabilização dos estoques de $\mathrm{C}$ em um determinado horizonte do solo, onde os processos de emissão e de absorção de C, estão em equilíbrio dinâmico (Resck, 2000). Ocorrendo mudanças no uso do solo, na entrada de resíduos vegetais, espera-se que haja uma mudança no estoque de C do solo, porém de efeito finito (Hillel \& Rosenzweig, 2010).

Em diversos estudos foi comprovado que a taxa de armazenamento do carbono é influenciada pelo regime climático (Guo \& Gilfford, 2002; Carvalho et al., 2009), pelo regime de manejo de solo (Bayer et al., 2006; Green et al., 2007), pela quantidade e qualidade dos resíduos (Six et al., 2002; Carvalho et al., 2009), e pela mineralogia e tipo de solo (Tristam \& Six, 2007).

A matéria orgânica além da sua influência no ciclo global do carbono, também contribui para a melhoria da fertilidade do solo (especialmente por meio de aumento da capacidade de troca cátions - CTC) (Bayer \& Mielniczuk, 1999), no incremento da estabilidade dos agregados e no armazenamento de água em solos tropicais (Ferreira, 2013). Em determinadas situações o COT pode não ser indicador eficiente para descrever os impactos da mudança do uso da terra em curto espaço de tempo. Na literatura alterações no COT ocorrem de três a cinco anos após a mudança no sistema de manejo (Prasad et al., 2015).

Quando se objetiva realizar uma análise precisa das alterações sofridas pela MOS é importante ter um conjunto de metodologias apropriadas para avaliar os efeitos de uso e manejo sobre os compartimentos desta, para tal são utilizadas técnicas de fracionamento da MOS baseadas em métodos físicos e químicos (Klug, 2014).

O histórico do manejo de solo, assim como as práticas de manejo utilizadas no momento do estudo, tem influência na concentração de COT, assim como podem influenciar decisivamente no estoque de carbono orgânico observado no futuro (Tomita, 2009). O carbono orgânico particulado (COP) constitui fração lábil da MOS e é controlado principalmente pela adição de resíduos sólidos, clima e por outras propriedades químicas e físicas do solo, que afetam a atividade dos organismos decompositores (Nunes et al., 2011). Desta forma constitui uma das frações mais afetadas pelas mudanças no uso do solo, mais indicativo de alterações que 
CAM associando as frações finas (Sturmer et al., 2011). Em seus estudos, Loss et al. (2011), concluíram que COP pode funcionar como um indicador eficiente frente a alterações decorrentes do manejo em um dado solo, em um período de tempo curto.

Os teores de COP e CAM apresentaram uma relação contrária, conforme uma das frações sofre incremento a outra reduz a sua participação, esta relação foi verificada no trabalho de Figueiredo et al. (2010), e confirmada no trabalho de Guareschi et al. (2013a), sob Latossolo Vermelho no Cerrado. Esta relação está clara na fórmula CAM $=\mathrm{CT}-\mathrm{COP}$, conforme proposto por Conceição et al. (2014). Nos trabalhos de Figueiredo et al. (2010) e Guareschi et al. (2013a) é argumentado que o aumento dos teores de carbono associado aos minerais (CAM) é possível apenas pelo processo de decomposição (degradação) da fração COP, para que este, em processos posteriores possa ser agregado aos minerais e fazer parte do estoque de CAM. Em seu estudo Guareschi et al. (2013a), observaram também que em função do tempo de implantação do SPD houve uma gradual perda da fração COP e incremento da fração CAM, ocorrendo um aumento da fração estável conforme o tempo, tendendo a estabilização da MOS.

Os experimentos de Loss et al. (2014), em Latossolos Vermelhos de textura argilosa, em relevo ondulado, sob regime de lavoura convencional (20 anos), pastagem nativa e o sistema silvopastoril, em Santa Teresa-ES não encontraram diferenças nos teores das frações COP e CAM, quando comparados os distintos regimes de manejo.

O maior teor de COP é verificado na camada de 0-5 para todos os sistemas de manejo, sendo este mais proeminente na pastagem nativa, seguida do sistema silvopastoril e o menor teor de COP foi verificado na lavoura (Loss et al., 2014). Estes autores, afirmam que o menor estoque de COP observado na área da lavoura é consequência do revolvimento do solo que diretamente afeta a agregação e a proteção física da $\mathrm{MO}$, dentro dos agregados do solo, acelerando a mineralização da mesma.

\subsection{Frações da matéria da orgânica do solo obtidas pelo fracionamento físico-} granulométrico

Ao ser fracionada pelo método físico-granulométrico, a MOS é separada em duas frações básicas, obtendo-se carbono orgânico particulado (COP) e o carbono associado aos minerais (CAM) (Cambardela \& Elliot, 1992). 
O COP é o carbono presente na fração da MOS de tamanho semelhante à fração mineral areia $(>53 \mu \mathrm{m})$. O COP é geralmente composto por materiais que apresentam os tecidos intactos, podendo ser resíduos de plantas, hífas ou esporos de fungos (Koga \& Tsuji, 2009). Como o CAM está associado às frações argila e silte $(<53 \mu \mathrm{m})$, apresenta formas de proteção que propiciam um longo tempo de permanência (Koga \& Tsuji, 2009).

A fração CAM é caracterizada como aquela fração da MOS que apresenta maior resistência ao ataque microbiano, devido à proteção química proporcionada pela associação com as superfícies minerais, ou pela localização na parte interna dos agregados o que dificulta a ação dos microrganismos (Klug, 2014). A fração CAM representa dois terços do C do solo e possui um tempo de permanência superior no solo do que as frações de COP. O CAM apresenta uma maior resistência à variação, em um curto espaço de tempo (Bayer et al., 2004).

Em estudos conduzidos para verificar a variação da MOS após o plantio de florestas, percebeu-se que as mudanças no estoque de carbono ocorriam principalmente na fração lábil, enquanto o estoque da fração associada aos minerais permanecia relativamente constante (Eclesia et al., 2012).

O carbono orgânico particulado (COP) tem seu teor e comportamentos influenciados por propriedades como o clima, o acúmulo de resíduos sólidos, propriedades físicas e químicas do solo (Eclesia et al., 2012). Esta é uma das frações mais afetadas pelas mudanças no uso do solo, indicativo de alterações (Sturmer et al., 2011). Em seus estudos Loss et al. (2011) concluíram que o COP pode funcionar como um indicador eficiente frente a alterações decorrentes do manejo em um dado solo em curtos períodos de tempo, em períodos de cinco anos já podem ser observadas diferenças entre os tratamentos.

De acordo com Loss et al. (2014) o menor estoque de COP observado na área da lavoura é dado em virtude do revolvimento do solo, que diretamente afeta a agregação e a proteção física da MO dentro dos agregados do solo, acelerando a mineralização da mesma.

\subsection{Fracionamento químico baseado na solubilidade da matéria orgânica do solo em meio ácido e alcalino}

A separação das frações da MOS por meio de diferenças de solubilidade em solução ácida e alcalina é uma das formas clássicas de se conhecer as frações da matéria orgânica, 
obtendo-se três frações fundamentais: ácidos fúlvicos (AF), ácidos húmicos (AH) e huminas (HUM) (Carvalho, 2014).

As substâncias húmicas são constituídas de uma mistura homogênea de polieletrólitos advindos da decomposição de resíduos animais, vegetais e atividade dos microrganismos (Rosa et al., 2001). Os ácidos fúlvicos são solúveis em água, soluções ácidas e alcalinas de baixo peso molecular e tem alta capacidade de troca catiônica (Caron et al., 2015). As huminas por sua vez constituem um resíduo estável, materiais complexos, quimicamente heterogêneos e insolúveis, tanto em soluções ácidas como alcalinas (Caron et al., 2015).

O fracionamento químico da MOS nos sistemas estudados por Baldoto et al. (2015), revelou diferenças químico-estruturais em sua composição. O teor de ácidos fúlvicos livres (AFL) na camada de 0-20 cm foram superiores para os sistemas eucalipto e mata nativa, sendo acompanhados na sequência por pastagens, cutieira e área irrigada com pivô em regime de pastagem convencional. A amplitude dos teores variou na faixa de 1,23 a 2,47 $\mathrm{g} \mathrm{kg}^{-1}$. Os teores de AF tiveram uma variação menor na camada de 0-20 cm, a amplitude dos valores variou entre 1,52 a 2,13 $\mathrm{g} \mathrm{kg}^{-1}$, mantendo a ordem de pivô $<$ pastagem $=$ cutieira $<$ eucalipto $<$ mata. $\mathrm{O}$ valor da fração humina foi superior nos sistemas florestais, em comparação com as gramíneas (pivô e pasto), a amplitude registrada variou entre 3,60 a 7,53 $\mathrm{g} \mathrm{kg}^{-1}$ na camada de $0-20 \mathrm{~cm}$.

No trabalho de Loss et al., (2011) a fração humina prevaleceu em todos os sistemas estudados, os autores argumentam que este nível de humina foi observado devido a utilização dessas áreas como pasto contínuo, antes da mudança do manejo, por longos períodos, conforme também observado em (Camargo, 1999), e reforçado no trabalho de (Guareshi et al., 2013b). Esta redução na fração humina em áreas de longo uso como pastagem, cujos resíduos são pobres em lignina, precursora da humina, desta forma o pobre aporte vegetal refletiu nos teores de humina variando de 9,75 a $9,78 \mathrm{~g} \mathrm{~kg}^{-1}$. Os valores dos sistemas analisados por Guareshi et al. (2013b), sendo estes sistema de plantio direto com 15 anos (SPD15) e sistema de plantio direto com 20 anos (SPD20) foram muito próximos ao sistema de referência Cerrado Nativo, sendo estes $16,11 \mathrm{~g} \mathrm{~kg}^{-1} ; 16,28 \mathrm{~g} \mathrm{~kg}^{-1}$ e $17,10 \mathrm{~g} \mathrm{~kg}^{-1}$ respectivamente, para a profundidade de $0-5 \mathrm{~cm}$. Isso demonstra que os sistemas SPD com o decorrer do tempo aumentam o estoque do carbono da fração humina (C-HUM), promovendo por consequência uma expressão mais acentuada das propriedades coloidais da MOS, aumentando a capacidade de retenção de água, melhorando a 
agregação do solo, auxiliando na retenção de cátions devido ao incremento na CTC, todas características de grande importância no sistema de produção sustentável (Souza \& Melo, 2003).

Nos resultados apresentados por Guareshi et al. (2013b), os valores da relação AH/AF para todas as profundidades e sistemas de manejo foram superiores a 1, indicando que pelo teor alto de $\mathrm{AH}$ e a relação $\mathrm{AH} / \mathrm{AF}$ que estes solos são naturalmente férteis (Kononova, 1982), para os Latossolo do Cerrado a relação estimada de AH/AF para os solos de cerrado vária em média de 0,59 a 1,60 (Baldotto et al., 2015).

A relação $\mathrm{AH}+\mathrm{AF} / \mathrm{HUM}$ quando apresenta valores inferiores à $(<0,50)$ são indicativos da forte estabilidade da matéria orgânica, podendo ser analisado como indicador da estabilidade da matéria orgânica do solo. Valores altos desta relação $(>2,00)$ são indicativos de movimento das frações alcalino-solúveis, podendo ser usado como indicador da capacidade eluvial do solo (Ebeling et al., 2011).

Nos distintos sistemas de manejo estudados (pastagem, agricultura, cana e mata nativa) entre estas formas de manejo testadas, o sistema que apresentou o maior equilíbrio entre as formas de carbono foi o sistema florestal, com maior estabilidade da matéria orgânica do solo (Ribas et al., 2008). A mobilidade do carbono variou de acordo com a distribuição das frações da matéria orgânica do solo (Baldotto et al., 2015).

Nos trabalhos realizados por (Silva et al. 2011; Guareshi et al., 2013b; Baldotto et al., 2015) foram encontradas as mesmas relações entre as substâncias húmicas, com predomínio da fração humina para todas as profundidades, de tal forma que os sistemas integrados de lavourapecuária com 8 anos de implantação e o sistema de vegetação natural apresentaram os maiores estoques de carbono na fração humina quando comparados aos sistemas de plantio direto.

Observou-se de maneira geral a relação de C-HUM $>$ C-AH $>$ C-AF para os solos férteis (Guareshi et al., 2013b), enquanto que Silva et al. (2011) observaram uma relação C-HUM > C$\mathrm{AF}>\mathrm{C}-\mathrm{AH}$ para os solos pouco férteis, excluindo a área de referência de mata nativa.

\subsection{Carbono lábil (CL)}

Os sistemas conservacionistas que sofrem revolvimento somente nas linhas de plantio (SPD) têm um manejo adequado de rotação de culturas e fazem uso de técnicas de manutenção dos resíduos culturais na superfície, que tem como característica a lenta decomposição do material depositado, favorecem o acúmulo de carbono lábil (CL) e aumento do índice de manejo 
do carbono (IMC) (Guareshi et al., 2013b). O IMC leva em consideração a labilidade da MOS e busca unir características quantitativas e qualitativas da MOS, como forma de avaliar o desempenho de um determinado sistema de manejo (Rossi et al., 2011).

Em seu trabalho Loss et al. (2014) observaram diferença na comparação do COT entre uma área de manejo integrado com 8 anos de implantação e Cerrado Nativo, entretanto essa diferença foi muito menor do que a obtida na comparação do carbono lábil (CL), nestas duas áreas. Carbono lábil é definido como o constituinte do carbono mais facilmente mineralizável pelos micro-organismos do solo (Rangel et al., 2008).

Correlações positivas foram encontradas em Ghosha et al. (2016), entre CL e a produtividade dos sistemas, indicando uma relação entre teor de CL e incremento na produtividade das culturas, além de uma correlação inversa com o processo erosivo do solo. As mesmas correlações realizadas para o CL também foram válidas para o índice de manejo de carbono (IMC).

\subsection{Carbono da Biomassa Microbiana (CBM)}

A biomassa microbiana do solo (BMS) é definida como uma estimativa da massa microbiana viva do solo, considerando-se toda a massa microbiana como uma entidade apenas (De-Polly \& Guerra, 1999). O carbono da biomassa é primordialmente constituído por fungos, bactérias e arqueas (Kaschuk et al., 2010). A BMS é um importante componente na avaliação da qualidade do solo porque está diretamente ligado aos processos de decomposição natural, bem como a ciclagem de nutrientes e estabilização dos agregados (Mendes et al., 2003; Perez et al., 2004). A biomassa microbiana constitui uma fração pequena do COT, cerca de 2 a 5\% e de 1 a 5\% de N total do solo (Smith \& Paul, 1990; Ferreira, 2013). Os estudos de caráter qualitativo e quantitativo da fração CBM são fundamentais para o processo de formação de substâncias húmicas e de micro-agregados (Six et al., 2002).

A biomassa microbiana atua nos processos de decomposição natural, interagindo na dinâmica dos nutrientes, formação e estabilização de agregados. A biomassa do solo participa também dos processos de formação do solo (intemperização das rochas), biorremediação de poluentes e metais pesados, armazenamento da matéria orgânica, controle e supressão biológica de fitopatógenos. Esta é apontada como componente chave para manutenção da qualidade do solo e produtividade das plantas (Souza et al., 2015). 
Em seus estudos, Martins et al. (2011), realizaram comparações entre o teor de CBM em três sistemas: um de integração lavoura pecuária, uma mata nativa e uma área de milho sob regime de cultivo convencional, em um Latossolo Vermelho-Amarelo (LVa), no Estado do Mato Grosso (MT). Nesse experimento os valores de CBM dos sistemas integrados foram superiores à área do milho, e em alguns casos até maiores àqueles valores obtidos na área nativa. Estes resultados corroboram com observações prévias realizadas por Silva et al. (2010), que demonstram a rápida alteração e diminuição nos teores do CBM em áreas com implementação recente de sistemas conservacionistas. 


\section{REFERÊNCIAS BIBLIOGRÁFICAS}

ALVARENGA, R.C.; PORFÍRIO-DA-SILVA, V.; GONTIJO NETO, M.M.; VIANA, M.C. M.; VILELA, L. Sistema Integração Lavoura-Pecuária-Floresta: condicionamento do solo e intensificação da produção de lavouras. Informe Agropecuário, Belo Horizonte, v. 31, n. 253, p. $1-9,2010$.

ALVARENGA, R.C.; NOCE, M.A. Integração lavoura pecuária. Sete Lagoas: Embrapa Milho e Sorgo, p, 16. Embrapa Milho e Sorgo. Documentos, 47, 2005.

ALVIM, M.J.; BOTREL, M.A.; XAVIER, D.F. As principais espécies de Brachiaria utilizadas no país. Juiz de Fora: Embrapa Gado de Leite, p. 4, (Comunicado técnico, 22), 2002.

ANATER, M.J.N.; SANQUETTA, C.R.; SCHIAVO, B.N.D.; CORTE, A.P.D. Redução de gases de efeito estufa pelos projetos de crédito de carbono no setor energético brasileiro, Holos, v. 1, p. 310-323, 2016.

ARAÚJO, F.F.; PEDROSO, R.A.B. Interação de Bacillus sp. com a rizosfera de três espécies de plantas forrageiras. Bioscience journal, v. 29, n. 1, p. 152-158, 2013.

BAH, A.R.; RAHMAN, Z.A. Gliricidia (Gliricidia sepium): Green manures as a potencial source of $\mathrm{N}$ for maize production in the tropics. Optimizing Nitrogen Management in Food and Energy Production and Environmental Protection: Proceedings of the 2nd International Nitrogen Conference on Science and Policy. Scientific World Journal, v. 1, n. 2, p. 90-95, 2001.

BALBINO, L.C.; BARCELLOS, A.O.; STONE, L.F. Marco referencial: integração lavourapecuária-floresta. Brasília: Embrapa, p. 130, 2011.

BALBINO, L.C.; CORDEIRO, L.A.M.; OLIVEIRA, P.; KLUTHCOUSKI, J.; GALERANI, P.R.; VILELA, L. Agricultura sustentável por meio da integração lavoura pecuária floresta (ILPF). Informações Agronômicas, n. 138, p. 1-14, 2012.

BALDOTTO, M.A.; VIEIRA, E.M.; SOUZA, D.O.; BALDOTTO, L.E.B. Estoque e frações de carbono orgânico e fertilidade de solo sob floresta, agricultura e pecuária. Revista Ceres, v. 62, n. 3, p. 301-309, 2015.

BAYER, C.; MARTIN-NETO, L.; MIELNICZUK, J.; PAVINATO, A. \& DIEKOW, J. Carbon sequestration in two Brazilian Cerrado soils under no-till. Soil and Tillage Research, v. 86, p. 237-245, 2006.

BAYER, C.; MARTINS-NETO, L.; MIELNICZUK.; PAVINATO, A. Armazenamento de carbono em frações lábeis da matéria orgânica de um Latossolo Vermelho sob plantio direto. Pesquisa Agropecuária Brasileira, v. 39, n. 7, p. 677-683, 2004. 
BAYER, C.; MIELNICZUK, J. Dinâmica e função da matéria orgânica. In: SANTOS, G.A.; CAMARGO, F.A.O. eds. Fundamentos da matéria orgânica do solo. Ecossistemas tropicais e subtropicais. Gênesis, p. 9-26, 1999.

BERNOUX, M.; CERRI, C.C.; CERRI, C.E.P.; SIQUEIRA NETO, M.; METAY, A.; PERRIN, A.; SCOPEL, E.; BLAVET, D.; PICCOLO, M.C. Influence du semis directa veccou verture vegetal esurla séquestration du carbone et 1'érosionau Brésil. Bulletin Du Réseau Erosion, v. 23, p. 323-337, 2004.

BEUCHLE, R.; GRECCHI, R.C.; SHIMABUKURO, Y.E.; SELINGER, R.; EVA, H.D.; SANO, E.; ACHARD, F. Land cover changes in the Brazilian Cerrado and Caatinga biomes from 1990 to 2010 based on a systematic remote sensing sampling approach. Applied Geography, v. 58, p. 116-127, 2015.

BOWMAN, M. S.; ZILBERMAN, D. Economic factors affecting diversified farming systems. Ecology and Society, v. 18, p. 33, 2013.

BREEDY, T.L.; SNAPP, S.S.; AKINNIFESI, F.K.; SILESHI, G.W. Impact of Gliricidia sepium intercropping on soil organic matter fractions in a maize-based cropping system. Agriculture, Ecosystems and Environment, v. 138, n. 4, p. 139-146, 2010.

CAMBARDELLA, C.A.; ELLIOTT, E.T. Particulate soil organic-matter changes across a grassland cultivation sequence. Soil Science Society of America Journal, v. 56, p. 777-783, 1992.

CARMO, F.F.; FIGUEIREDO, C.C.; RAMOS, M.L.G.; VIVALDI, L.J.; ARAÚJO, L.G. Frações granulométricas da matéria orgânica em Latossolo sob plantio direto com gramíneas. Bioscience Journal, v.25, p. 420-431, 2012.

CARON, V.C.; GRAÇAS, J.P.; CASTRO, P.R.C. Condicionadores do solo: ácidos húmicos e fúlvicos. Série Produtor Rural - nº 58, 46 p. ESALQ - Divisão de Biblioteca, 2015.

CARVALHO, J.L.N.; CERRI, C.E.P.; FEIGL, B.J.; PICOLLO, M.C.; GODINHO, V.P.; CERRI, C.C. Carbon sequestration in agricultural soils in the Cerrado region of the Brazilian Amazon. Soil and Tillage Research, v. 103, p. 342-349, 2009.

CARVALHO, J.L.N.; RAUCCI, G.S.; FRAZÃO, L.A.; CERRI, C.E.; BERNOUX, M., CERRI, C.C. Crop-pasture rotation: A strategy to reduce soil greenhouse gas emissions in the Brazilian Cerrado. Agriculture, Ecosystems and Environment, v. 183, p. 167- 175, 2014.

CARVALHO, P.C. de F.; ANGHINONI, I.; MORAES, A. de; SOUZA, E.D. de; SULC, R.M.; LANG, C.R.; FLORES, J.P.; LOPES, M.L.T.; SILVA, J.L. da; CONTE, O.; WESP, C. de L.; LEVIEN, R.; FONTANELI, C.B. Managing grazing animals to achieve nutrient cycling and soil improvement in no till integrated systems. Nutrient Cycling in Agroecosystems, v. 88, p. 259273, 2010. 
CHADDAD, F. The Economic and Organization of Brazilian Agriculture. Agriculture in Southeastern Brazil: Vertically Integrated Agribusiness, $1^{\text {st }}$ ed., Academic Press, p. 178, 2015.

COMPANHIA NACIONAL DE ABASTECIMENTO. Acompanhamento da Safra Brasileira de Grãos, v.2 - Safra 2014/2015, n. 12 - Décimo segundo levantamento, p. 1- 134, 2015.

CONCEIÇÃO, P.C.; BAYER, C.; DIECKOV, J.; SANTOS, D. C. Fracionamento físico da matéria orgânica e índice de manejo do carbono de um Argissolo submetido a sistemas conservacionistas de manejo. Ciência Rural, v. 44, n. 5, p. 794-800, 2014.

COSTA, W.A.J.M.D.; SANGAKKARA, U.R. Agronomic regeneration of soil fertility in tropical Asian smallholder uplands for sustainable food production. Journal of Agricultural Science, v. 144, p. 111-133, 2006.

COSTA, R. N.; ADREOTTI, M.; LOPES, K.S.M.; YOKOBATAKE, L.; FERREIRA, J.P.; BONINI, C.S.; LONGHINI, V.Z. Atributos do solo e acúmulo de carbono na integração lavoura pecuária em sistema de plantio direto. Revista Brasileira de Ciência do Solo, v. 39, n. 3, p. 852$863,2015$.

CUBILlOS-HINOJOSA.; GUILLERMO， J.; MILIAN-MINDIOLA.; $\quad$ ERNESTO, P.; HERNANDEZ-MULFORD, J.L. Biological nitrogen fixation by Rhizobium sp. native gliricidia (Gliricidia sepium, Kunth ex Walp.) under greenhouse conditions. Agronomía Colombiana, Bogotá, v. 29, n. 3, p. 465-472, 2011.

CUERVO-JILMÉNES， A.; NARVÁEZ-SOLARTE， W.; VON-HESSBERG， C.H. Características forrageiras de la especie Gliricidia sepium (Jacq.) Stend, fabace. Boletín Científico. Centro de Museos. Museo de Historia Natural, v. 17, n. 1, p. 33-45, 2013.

DE-POLLI, H.; GUERRA, J.G.M. C, N e P na biomassa microbiana do solo. In: SANTOS, G.de A.; CAMARGO, F.A.de O. (Eds.) Fundamentos da matéria orgânica do solo: ecossistemas tropicais e subtropicais. Gênesis, p. 389-412, 1999.

DIAS-FILHO, M.B. Degradação de pastagens: processos, causas e estratégias de recuperação. 3. ed. Belém: Embrapa Amazônia Oriental, p. 190, 2007.

DIAS-FILHO, M.B. Degradação de pastagens: processos, causas e estratégias de recuperação. 4. ed. Revista, Atualizada e Ampliada, p. 216, 2011.

DIAS-FILHO, M.B. Recuperação de pastagens degradadas na Amazônia: desafios, oportunidades e perspectivas. In: SAMBUICHI, R. H. R. et al. (Org.). Políticas agroambientais e sustentabilidade: desafios, oportunidades e lições aprendidas p.149-169, 2014.

DIEL, D.; BEHLING, M.; NETO, A.L.F.; ISERNHAGER, E.C.C. Distribuição horizontal e vertical de fósforo em sistemas de cultivos exclusivos de soja e de integração lavoura pecuária floresta. Pesquisa Agropecuária Brasileira, v. 49, n. 8, p.639-647, 2014. 
DIOUF, A.; ABDOULAYE DIOP, T.; NDOYE, I.; GUEYE, M. Response of Gliricidia sepium tree to phosphorus application and inoculations with Glomus aggregatum and rhizobial strains in a sub-Saharian sandy soil. African Journal of Biotechnology, v. 7, n. 6, 766-771, 2008 .

DORNELES, E. P.; LISBOA, B.B.; ABICHEQUER, A.D.; BISSANI, C.A.; MEURER, E.J.; VARGAS, L.K.Tillage, fertilization systems and chemical attributes of a Paleudult. Scientia Agricola, v. 72, n. 2, p. 175-186, 2015.

EBELING, A.G.; ANJOS, L.H.C.; PEREIRA, M.G.; PINHEIRO, E.F.M.; VALLADARES, G. S. Substâncias húmicas e relação com atributos edáficos. Bragantia, v. 70, n. 1, p. 157$165,2011$.

ECLESIA, R. P.; JOBBAGY, E.G.; JACKSON, R.B.; BIGANZOLI, F.; PINHEIRO, G. Shifts in soil organic carbon for plantation and pasture establishment in native forests and grasslands of South America, Global Change Biology, v. 18, p. 3237-3251, 2012.

FERNANDES, M da S.; FINCO, N.V.A. Sistemas de integração lavoura-pecuária e políticas de mudanças climáticas. Pesquisa Agropecuária Tropical, v. 44, n. 2, p. 182-190, 2014.

FERREIRA, E.A.B. Dinâmica de longo prazo do carbono no solo em sistemas de manejo no Cerrado. Brasília: Programa de Pós-graduação em Ecologia, Universidade de Brasília, 235 páginas. Tese de doutorado, 2013.

FIGUEIREDO, C.C.; RESCK, D.V.S.; CARNEIRO M.A.C. Labile and stable fractions of soil organic matter under management systems and native Cerrado. Revista Brasileira de Ciência do Solo, v. 34, p. 907-916, 2010.

FRANCHINI, J.C.; DEBIASI, H.; WRUCK, F.J.; SKORUPA, L.A.; WINK, N.N.; GUISOLPHI, I.J.; CAUMO, A.L.; HATORI, T. Integração lavoura pecuária: alternativa para diversificação e redução do impacto ambiental do sistema produtivo no Vale do Rio Xingu, 2010, 20 p. (Embrapa Soja. Circular técnica, 77).

GAUDER, M.; BILLEN, R.; ZIKELI, S.; LAUB, M.; GRAEFF-HONNINGER.; CLAUPEIN, W. Soil carbon stocks in different bioenergy cropping systems including subsoil. Soil and Tillage Research, v. 155, p. 308-317, 2016.

GATTINGER, A.; MULLER, A.; HAENI, M.; SKINNER, C.; FLIEßRACH, A.; BUCHMANN, N.; MADER, P.; STOLZE, M.; SMITH, P.; SCIALABBA, N.H.; NIGGLI, U. Enhanced top soil carbon stocks under organic farming. Proceedings of the National Academy of Sciences of the United States of America, National Academy of Sciences , v. 109, p. 18226-18231, 2012.

GLENK, K.; SHRESTHA, S.; TOPP, C.F.E; SANCHEZ, B., IGLESIAS, A. DIBARI, C. MERANTE, P. A farm level approach to explore farm gross margin effects of soil organic carbon management. Agricultural Systems, v. 151, p. 33-46, 2017. 
GREEN, V.S.; STOTT, D.E.; CRUZ, J.C.; CURI, N. Tillage impacts on soil biological activity and aggregation in a Brazilian Cerrado Oxisol. Soil and Tillage Research, v. 92, p. 114-121, 2007.

GUARESCHI, R.F. Oxidizable carbon fractions in Red Latosol under different management systems. Revista Ciência Agronômica, v. 44, n. 2, p. 242-250, 2013 (a).

GUARESHI, R.F.; PEREIRA, M.G.; PERIN, A. Frações da matéria orgânica em áreas de Latossolo sob diferentes sistemas de manejo no Cerrado do estado de Goiás. Semina: Ciências Agrárias, Londrina, v. 34, n. 6, p. 2615-2628, 2013 (b).

GUO, L. B.; GIFFORD, R. M. Soil carbon stocks and land use change: a meta analysis. Global Change Biology, v. 8, p. 345-360, 2002.

HOBBS, R.J; HIGGS, E; HARRIS, J.A. Novel ecosystems: implications for conservation and restoration. Trends in Ecology and Evolution, v. 24, n. 11, p. 599-605, 2009.

HILLEL, D. O.; ROSENZWEIG, C. The role of soils in climate change. In Handbook of Climate Change and Agroecosystems: Impacts, Adaptation, and Mitigation. D. Hillel and C. Rosenzweig, Eds., ICP Series on Climate Change Impacts, Adaptation, and Mitigation. v. 1, Imperial College Press, p. 9-20, 2010.

JANK, L.; CALIXTO, S.; COSTA, J. C. G.; SAVIDAN, Y. H.; CURVO, J. B. E. Catálogo de caracterização e avaliação de germoplasma de Panicum maximum: descrição morfológica ecomportamento agronômico. Campo Grande: EMBRAPA-CNPGC, 1997. 53 p. (EMBRAPACNPGC. Documentos, 68).

HUNKE, P.; ZEILHOFER, R.; SCHORDER. P.; SHORDER. B.; MULLER, E.; NORA, E. Soil changes under different land-use in the Cerrado of Mato Grosso, Brazil. Geoderma, v. 4, p. 31 43, 2014.

KAHILUOTO, H.; SMITH, P.; MORAN, D.; OLESEN, J.E. Enabling food security by verifying agricultural carbon. Nature Climate Change, v. 4, 309-311, 2014.

KASCHUK, G.; ALBERTON, O.; HUNGRIA, M. Three decades of soil microbial biomass studies in Brazilian ecosystems: Lessons learned about soil quality and indications for improving sustainability. Soil Biology and Biochemistry, v. 42, p. 1-13, 2010.

KLUG, I. Estoque e frações granulométricas do carbono em solo de altitude do Rio Grande do Sul sob diferentes vegetações. 2014. 80 f. Dissertação (Mestrado em Ciência do Solo) Universidade do Estado de Santa Catarina. Programa de Pós-Graduação em Ciências Agrárias, Lages, SC, 2014.

KOGA, N.; TSUJI, H. Effects of reduced tillage, crop residue management and manure application practices on crop yields and soil carbon sequestration on an Andisol in Northern Japan. Soil Science and Plant Nutrition, v. 44, n. 4, p. 546-557, 2009. 
KONONOVA, M. M. Materia organica del suelo: su naturaleza, propiedades y métodos de investigación. Barcelona. Oikos-tau, 364 p, 1982.

LACERDA, S.G.; COUTO, H.T.Z.; HIROTA, M.M.; PASISHNYK, N.; POLIZEL, J.L. Estimativa da biomassa e carbono em áreas restauradas com plantio de essências nativas. Revista eletrônica do Centro de Métodos Quantitativos do Departamento de Ciências Florestais, ESALQ - USP. METRVM, n. 5, p. 21-22, 2009.

LAL R. Soil carbon sequestration impacts on global climate change and food security. Science, v. 304, p. 1623-1627, 2004.

LI, S.; LI, Y.; LI, X.; TIEN, X.; ZHAO, A.; WANG, S.; WANG, S.; SHI, J. Effect of straw maze management on carbon sequestration and grain production in a maize-wheat cropping system in Anthrosol of the Guanzhong Plain. Soil and Tillage Research, v. 157, p. 43-51, 2016.

LOSS, A.; PEREIRA, G.M.; SCHULTZ, N.; FERREIRA, E.P.; SILVA, E.M.R.; BEUTLER, S.J. Distribuição dos agregados e carbono orgânico influenciados por manejos agroecológicos. Acta Scientiarum Agronomy, v. 31, n. 3, p. 523-528, 2009.

LOSS, A.; PEREIRA, G.M.; GIÁCOMO, S.G.; PERIN, A.; ANJOS, L.H.C. dos. Agregação, carbono e nitrogênio em agregados do solo sob plantio direto com integração-lavoura-pecuária. Pesquisa Agropecuária Brasileira, v. 46, n. 10, p. 1269-1276, 2011.

LOSS, A.; RIBEIRO, E.C.; PEREIRA. M.G.; COSTA.E.M. Physical and chemical attributes in systems of the consortium and succession of crops, pasture and silvopastoril in Santa Teresa, Espírito Santo, Brazil. Bioscience Journal, v. 30, n.5, p. 1347-1357, 2014.

MACEDO, M. C. M. Integração lavoura e pecuária: o estado da arte e inovações tecnológicas. Revista Brasileira de Zootecnia, v. 38, p. 133- 146, 2009.

MARTINS, J.C.R.; FREITAS, A.D.S.; MENEZES, R.S.C.; SAMPAIO, E.V.S.B. Nitrogen symbiotically fixed by cowpea and gliricidia in traditional and agroforestry systems under semiarid conditions. Pesquisa Agropecuária Brasileira, Brasília, v. 50, n. 2, p. 178-184, 2015.

MARTINS, M. de E.; CAMPOS, D. T. da S.; WRUCK, F. de J. Caracterização microbiana em um Latossolo Vermelho-Amarelo Distroférico sob o sistema de integração lavoura pecuária. Global Science and Technology, v. 4, p. 38 - 46, 2011.

MENDES, I.C.; SOUZA, L.V.; RESCK, D.V.S.; GOMES, A.C. Biological properties of aggregates from a cerrado oxisol under conventional and no-till management systems. Revista Brasileira de Ciência do Solo, v. 27, p. 435-443, 2003.

MINISTÉRIO DO MEIA AMBIENTE. Recuperação de Áreas Degradadas, 2015. 
MOYSÉS, A.; RODRIGUES DA SILVA, E. Ocupação e urbanização do Cerrado: desafios para a sustentabilidade. Cadernos Metrópole 20, p. 197-220, 2008.

MUNIZ, L. C.; MADARI, B. E.; TROVO, J. B. de L.; CANTAHNÊDE, I. S. de L.; MACHADO, P. L. O. de A.; COBUCCI, T.; FRANÇA, A. F. de S. Soil biological attributes in pastures of different ages in a crop-livestock integrated system. Pesquisa Agropecuária Brasileira, Brasília, v. 46, n. 10, p. 1262-1268, 2011.

NOBREGA, R.L.B.; GUZHA, A.C.; TORRES, G. N.; KOVACS, K.; LAMPARTER, G.; AMORIM, R.S.S.; COUTO, E.; GEROLD, G. Identifying hydrological responses of microcatchments under contrasting land use in the Brazilian Cerrado. Hydrology and Earth System Science (HESS), v. 12, p. 9915-9975, 2015.

NODARI, R. O.; GUERRA, M. P. A agroecologia: estratégias de pesquisa e valores. Estudos Avançados, v. 29, n. 83, p. 183-207, 2015.

NUNES, R.S.; LOPES, A.A.C.; SOUZA, D.M.G.; MENDES, I.C. Sistemas de manejo e os estoques de carbono e nitrogênio em Latossolo do Cerrado com sucessão soja-milho. Revista Brasileira de Ciência do Solo, v. 35, n. 4, p. 1407-1419, 2011.

OLIVEIRA, P; FREITAS, R.J; KLUTHCOUSKI, J; RIBEIRO, A.A; CORDEIRO, L.A.M; TEIXEIRA, L.P; CASTRO E MELO, R.A; VILELA, L; BALBINO, L.C. Evolução dos sistemas de integração lavoura-pecuária-floresta (ILPF): estudo de caso Fazenda Santa Brígida, Ipameri, GO. Documentos/Embrapa Cerrados, p. 50, 2013.

OLIVEIRA, S.P.; CÂNDIDO, M.J.D.; WEBER, O.B.; XAVIER, F.A.; ESCOBAR, M.E.O.; TEÓGENES, S.O. Conversion of forest into irrigated pasture I. Changes in the chemical and biological properties of the soil. Catena, v. 137, p. 508-516, 2016.

PARK, C. W.; KO, S.; YOON, T.K.; HAN, S.; YI, K.; JO, W. Differences in soil aggregate, microbial biomass carbon concentration, and soil carbon between Pinus rigida and Larixkaempferi plantations in Yangpyeong, central Korea. Forest Science and Technology, v. 8, n. 3, 2012.

PAULA, D.P.; CAMPELO, E.F.C.; GUERRA, J.G.M.; SANTOS, G.A.; RESENDE, A.S. Decomposição das podas das leguminosas arbóreas Gliricidia sepium e Acacia angustissima em um sistema agrolforestal. Ciência Florestal, v. 25, n. 3, 2015.

PEREZ, K.S.S.; RAMOS, M.L.G.; MCMANUS, C. Carbono da biomassa microbiana em solo cultivado com soja sob diferentes sistemas de manejo nos Cerrados. Pesquisa Agropecuária Brasileira, Brasília, v. 40, n. 2, p. 567-573, 2004.

PERREIRA, M.G.; LOSS, A.; BEUTLER, S.J.; TORRES, J.L.R. Carbono, matéria orgânica leve e fósforo remanescente em diferentes sistemas de manejo do solo. Pesquisa Agropecuária Brasileira, v.45, n.5, p.508-514, 2010. 
PRASAD, J.V.N.S.; SRINIVASA RAO, C.H.; SRINIVAS, K.; NAGA JYOTHI, C.H.; VENKATESWARLU, B., RAMACHANDRAPPA, B.K.; DHANAPAL, G.N.; RAVICHANDRA, K.; MISHRA., P.K. Effect of ten years of reduced tillage and recycling of organic matter on crop yields, soil organic carbon and its fractions in Alfisols of semi arid tropics of southern India. Soil and Tillage Research, v. 156, p. 131-139, 2016.

QUEIROZ, L. R.; COELHO, F.C.; BARROSO, D.G.; QUEIROZ, V.A.V. Avaliação da produtividade de fitomassa e acúmulo de $\mathrm{N}, \mathrm{P}$ e $\mathrm{K}$ em leguminosas arbóreas no sistema de aléias, em Campos dos Goytacazes, RJ. Revista Árvore, v. 31, n. 3, p. 383-390, 2007.

RANGEL, O.J.P.; SILVA, C.A.; GUIMARÃES，P.T.C.; GUILHERME，L.R.G. Frações oxidáveis do carbono orgânico de Latossolo cultivado com cafeeiro em diferentes espaçamentos de plantio. Ciência e Agrotecnologia, v. 32, p. 429-437, 2008.

RECKLING, M.; BERGKVIST, G.; STODDARD, F.; WATSON, C.A.; PRISTERI,TONECEA, I.;WALKER, R.; ZANDER. P.; HECKER, J.M.; BACHINGER. J. Designing legumesupported cropping systems. E.S. Gritti, J. Wery (Eds.), Proceedings of the 5th International Symposium for Farming Systems Design, Montpellier, p. 181-182, 2015.

REGANOLD, J.P.; WATCHER, J.M. Organic agriculture in the twenty-first century. Nature Plants, v. 2, p. 8, 2016.

RESCK, D.V.S.; VASCONCELOS, C.A.; VILELA, L.; MACEDO, M.C.M. Impact of conversion of Brazilian cerrados to cropland and pasture land on soil carbon pool and dynamics. In: LAL, R.; KIMBLE, J.M.; STEWART, B.A. (Eds.) Global Climate Change and Tropical Ecosystems. Advances in Soil Science, Boca Raton: CRC Press, p. 169-196, 2000.

RIBAS. L.M; BALDOTTO. M.A; CANELLAS, L.P; REZENDE, C.E. Qualidade e mobilidade da matéria orgânica de sistemas adjacentes à Lagoa de Cima, Campos dos Goytacazes - RJ. Geochimica Brasiliensis, v. 22, p. 103-112, 2008.

ROBINSON, D.A.; HOCKLEY, N.; COOPER, D.M.; EMMETT, B.A.; KEITH, A.M.; LEBRON, I.; REYNOLDS, B.; TIPPING, E.; TUE, A.M.; WATTS, C.W.; WHALLEY, W.R.; BLACK, H.I.J.; WARREN, G.P.; ROBINSON, J.S. Natural capital and ecosystem services, developing an appropriate soils framework as a basis for valuation. Soil Biology Biochemistry, v. 57, p. 1023-1033, 2013.

ROSA, A.H.; ROCHA, J.C.; SARGENTINI JUNIOR, E. A flow procedure for extraction and fractionation of the humic substances from soils. In: SWIFT, R.S.; SPARK, K.M., (Ed.). Understanding and managing organic matter in soils, sediments and waters. New York. International Humic Substances Society, p. 41-46, 2001.

ROSCOE, R. O sequestro de carbono no sistema plantio direto: Possibilidades de contabilização. In: ROSCOE, R.; MERCANTE, F. M.; SALTON, J. C (Org.). Dinâmica da matéria orgânica do solo e sistemas conservacionistas: Modelagem matemática e métodos auxiliares. Dourados: Embrapa Agropecuária Oeste, p. 43-63, 2006. 
ROSSI, C.Q.; PEREIRA, M.G.; GIACOMO, S.G.; BETTA, M.; POLIDORO, J.C. Frações húmicas da matéria orgânica do solo cultivado com soja sobre palhada de braquiária e sorgo. Bragantia, v. 70, n. 3, p. 622-630, 2011.

SALTON, J.C.; MIELNICZUK, J.; BAYER, C.; FABRÍCIO, A.C.; MACEDO, M.C.M.; BROCH, D.L. Teor e dinâmica do carbono no solo em sistemas de integração lavoura-pecuária. Pesquisa Agropecuária Brasileira, v. 46, n. 10, p. 1349-1356, 2011.

SILVA, E.A.; GOMES, J.B.V.; FILHO, J.C.A.; SILVA, C.A.; CARVALHO, S.A.; CURI, N. Podzolização em solos de áreas de depressão de topo dos tabuleiros costeiros do Nordeste brasileiro. Revista Brasileira de Ciência do Solo, v. 37, n.1, p. 11-24, 2013.

SILVA, R. R. da.; SILVA, M. L. N.; CARDOSO, E. L.; MOREIRA, F. M. de S.; CURI, N.; ALOVISI, A. M. T. Biomassa e atividade microbiana em solo sob diferentes sistemas de manejo na região fisiográfica Campos das Vertentes - MG. Revista Brasileira de Ciência do Solo, v. 34, n. 5, p. 1585-1592, 2011.

SIQUEIRA NETO, M.; PICCOLO, M.C.; SCOPEL, E.; COSTA JUNIOR, C.; CERRI, C.C. \& BERNOUX, M. Carbono total e atributos químicos com diferentes usos do solo no Cerrado. Acta Scientiarum, Agronomy, 34:709-717, 2009.

SIX, J.; FELLER, C.; DENEF, K.; OGLE, S.M.; SA, J.C.D.; ALBRECHT, A. Soil organic matter, biota and aggregation in temperate and tropical soils-effect of no-tillage. Agronomie 22. EDP Sciences, p. 755-775, 2002.

SMITH, J.L.; PAUL, E.A. The significance of soil microbial biomass estimation. In: BOLLAG, J.; STOTZKY, D.G. Soil Biochemistry. New York, M. Dekker, v. 6, p. 357-396, 1990.

SOUZA NUNES, R; CASTRO LOPES, A.A; SOUZA, D.M.G; MENDES, I.C. Sistemas de manejo e estoques de carbono e nitrogênio em Latossolos do Cerrado com a sucessão soja-milho. Revista Brasileira de Ciência do Solo, v. 35, p. 1407-1419, 2011.

SOUZA, L.M.; SOUSA, D.M.G.; REÍS JÚNIOR F.B dos.; MENDES, I.C. Carbono da biomassa microbiana em Latossolos determinado por oxidação úmida e combustão a temperatura elevada. Pesquisa Agropecuária Brasileira, v. 50, n. 11, p. 1061-1070, 2015.

SOUZA, W.J.O.; MELO, W.J. Matéria orgânica de um Latossolo submetido a diferentes sistemas de produção de milho. Revista Brasileira de Ciência do Solo, v. 27, n. 6, p. 1113$1122,2003$.

STÜRMER, S. L. K.; ROSSATO, O.B.; COPETTI, A.C.C.; RHEINHEIMER, D.S.; BRUM, B. Variações nos teores de carbono orgânico em função do desmatamento e revegetação natural do solo. Ciência Florestal, v. 22, n. 2, p. 241-250, 2011. 
SULC, R.M; FRANZLUEBBERS, A.J. Exploring integrated crop-livestock systems in different ecoregions of United States. European Journal of Agronomy, v. 57, p. 21-30, 2014.

TOMITA, C.K. Manejo em sistemas orgânicos e convencionais: Epidemiologia e controle de doenças em culturas de goiaba, gispsofília e pupunha. Brasília: Instituto de Ciências Biológicas, Universidade de Brasília, 152 páginas, tese de doutorado, 2009.

TORRES, J.L.R.; PEREIRA, M.G.; FABIAN, A. J. Produção de fitomassa por plantas de cobertura e mineralização de seus resíduos em plantio direto. Pesquisa Agropecuária Brasileira, v. 23, p. 421-428, 2008.

TRISTRAM, O.; SIX, J. Considering the influence of sequestration duration and carbon saturation on estimates of soil carbon capacity. Climatic Change, v. 80, n. 1, p. 25-41, 2007.

VILELA, L.; MARTHA JÚNIOR, G. B.; MACEDO, M. C. M.; MARCHÃO, R.L.; GUIMARÃES JÚNIOR, R.; PULROLNIK, K.; MACLEL, G. A. Sistemas de integração lavoura-pecuária na região do cerrado. Pesquisa Agropecuária Brasileira, v. 46, n. 10, p. 1127 1138, 2011.

ZIMMER, A.H.; MACEDO, M.C.M.; KICHEL, A.N.; e ALMEIDA, R.G. de. Degradação, recuperação e renovação de pastagens. Embrapa Gado de Corte, p, 42, 2012. 


\section{HIPÓTESES E OBJETIVOS}

\subsection{Hipóteses}

A mudança de manejo da área passando de um regime de pasto degradado para o sistema de plantio direto com integração lavoura-pecuária-floresta, no espaço temporal de quatro anos de implementação, não apresenta incremento no carbono orgânico total do solo e nas frações estáveis da matéria orgânica do solo;

A adoção do sistema de integração lavoura pecuária floresta aumenta os teores de carbono nas frações lábeis da matéria orgânica do solo ao longo dos primeiros quatro anos de sua implementação;

Após quatro anos de implantação o sistema de integração lavoura pecuária apresentará melhorias na produtividade de grãos de milho.

\subsection{Objetivos}

\subsubsection{Objetivo geral}

Avaliar a dinâmica da matéria orgânica do solo e de suas frações ao longo da fase de implantação de um sistema ILPF em área anteriormente degradada.

\subsubsection{Objetivos específicos}

Determinar as variações dos teores de carbono orgânico total ao longo de um período de quatro anos ao longo da implementação de um sistema ILPF;

Avaliar as alterações ocorridas nas frações lábeis e estáveis da matéria orgânica do solo, durante o período de quatro anos ao longo da implementação de um sistema de ILPF;

Determinar a produtividade de grãos de milho ao longo da implementação de um sistema de ILPF. 


\section{MATERIAL E MÉTODOS}

\subsection{Descrição da área experimental}

O estudo foi realizado na área experimental do Centro de Manejo de Ovinos (CMO) localizado na Estação Experimental Fazenda Água Limpa da Universidade de Brasília, conforme Figura 1. A área experimental encontra-se em um Latossolo Vermelho de textura argilosa. As coordenadas geográficas da área experimental são $15^{\circ} 56^{\prime} 00^{\prime \prime} \mathrm{S}$ (latitude) e $47^{\circ} 56^{\prime} 00^{\prime \prime} \mathrm{W}$ (longitude); e $1.090 \mathrm{~m}$ (altitude).

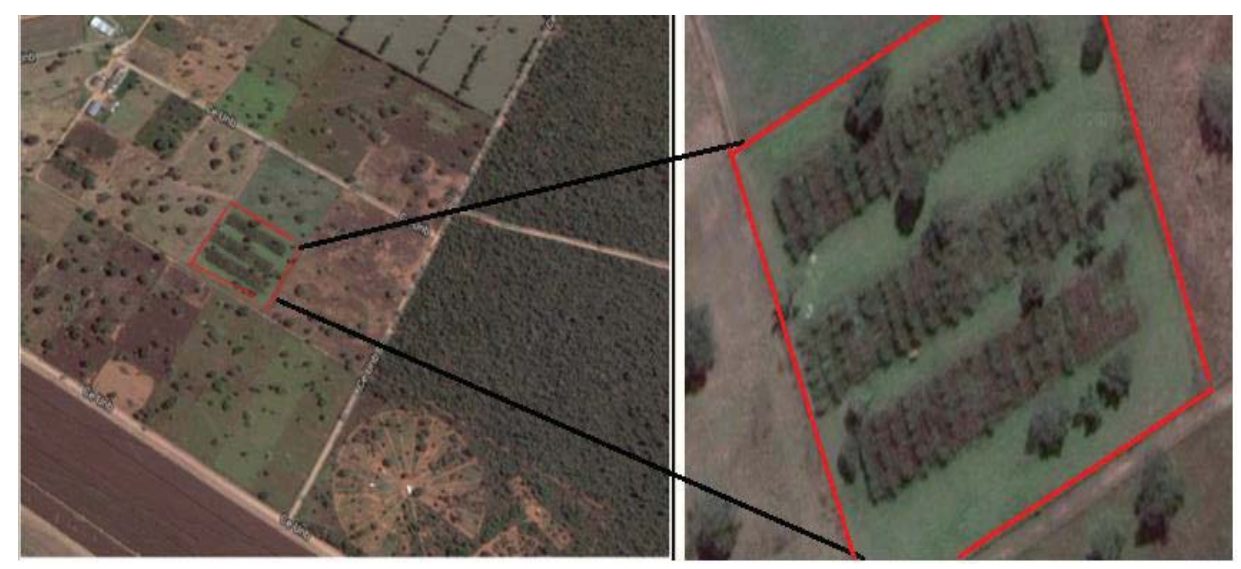

Figura 1. Mapa da localidade do experimento, Fazenda Água Limpa, Universidade de Brasília, Distrito Federal, Brasil, localidade exata representada pelo quadrado vermelho.

O clima da região é classificado como Tropical Chuvoso - Cwa, segundo a classificação de Koppen (Alvares et al., 2013), com temperatura média $28,5^{\circ} \mathrm{C}$ e mínima de $12{ }^{\circ} \mathrm{C}$. A umidade relativa entre os meses de maio a setembro fica abaixo de $70 \%$ e a umidade mínima ocorre em agosto, com uma média de $47 \%$ podendo cair a $15 \%$ nos períodos mais secos. A precipitação acumulada anual é de $1428 \mathrm{~mm}$, sendo concentrada nos meses de outubro a março e as médias mensais variam de $17,5^{\circ} \mathrm{C}$ a $21,8^{\circ} \mathrm{C}$ (Tabela 1 ).

$\mathrm{O}$ período seco se concentra entre os meses de maio a setembro em que as precipitações variam entre $2 \mathrm{~mm}$ a $75,4 \mathrm{~mm}$ (Tabela 1 ). 
Tabela 1. Variação da precipitação e temperatura registradas no local com base em dados dos anos de 2001 a 2016.

\begin{tabular}{|c|c|c|c|c|c|c|c|c|c|c|c|c|c|}
\hline \multicolumn{14}{|c|}{ Precipitação (mm) } \\
\hline Ano & Jan & Fev & Mar & Abr & Mai & Jun & Jul & Ago & Set & Out & Nov & Dez & Anual \\
\hline 2001 & 146,7 & 168,9 & 266,6 & 110,4 & 27,8 & 0 & 0 & 30,5 & 47,8 & 220,5 & 167,7 & 175,8 & 1361,7 \\
\hline 2002 & 187,1 & 214,4 & 245,6 & 65,5 & 3,8 & 0 & 6,3 & 2,3 & 127 & 136,5 & 207,3 & 230,4 & 1426,2 \\
\hline 2003 & 180,9 & 116,6 & 183,1 & 70,1 & 50,5 & 5,3 & 0 & 44,2 & 23,9 & 53,3 & 212,6 & 192,3 & 1132,8 \\
\hline 2004 & 296,9 & 373,4 & 328,4 & 130,3 & 10,4 & 3,8 & 1 & 0,3 & 22,3 & 113,8 & 82,3 & 172,5 & 1535,4 \\
\hline 2005 & 242,8 & 371,1 & 380,2 & 74,7 & 17,3 & 4,1 & 2 & 10,3 & 32,8 & 146,8 & 218 & 228,1 & 1728,2 \\
\hline 2006 & 89,6 & 142,8 & 257,2 & 102,1 & 79,3 & 13,2 & 15,2 & 10,7 & 67,8 & 240,8 & 295,9 & 228,1 & 1542,7 \\
\hline 2007 & 251,7 & 237 & 19,3 & 88,1 & 1,3 & 0 & 0 & 0 & 0,5 & 74,9 & 142 & 228,3 & 1043,1 \\
\hline 2008 & 297,4 & 282,7 & 257,6 & 191,8 & 0 & 0 & 0 & 2,3 & 36,3 & 26,7 & 152,7 & 246,4 & 1493,9 \\
\hline 2009 & 219,4 & 122,9 & 217,4 & 156 & 99,1 & 14,7 & 0 & 53,2 & 35,8 & 197,6 & 129 & 269 & 1514,1 \\
\hline 2010 & 213,9 & 80,3 & 254,7 & 112,8 & 5,1 & 4,3 & 0 & 0 & 0,5 & 200,1 & 233,7 & 245,9 & 1351,3 \\
\hline 2011 & 122,8 & 166,4 & 129,6 & 110,4 & 30,5 & 5 & 2 & 0 & 7,2 & 421,6 & 269,6 & 433,8 & 1698,9 \\
\hline 2012 & 243,4 & 196,4 & 131,8 & 76,4 & 59,4 & 16,2 & 1 & 0 & 26,4 & 74,4 & 374,4 & 136 & 1335,8 \\
\hline 2013 & 368,8 & 128,2 & 196,2 & 132,8 & 36,2 & 3,2 & 0 & 0 & 27,2 & 160,8 & 207,2 & 297,4 & 1558,0 \\
\hline 2014 & 101,6 & 131,4 & 407,4 & 206,4 & 12,6 & 4,6 & 1,4 & 0 & 11,6 & 69,4 & 437,8 & 189,6 & 1573,8 \\
\hline 2015 & 112,2 & 174,6 & 300,2 & 129,2 & 23,8 & 0 & 1 & 0 & 24,5 & 64,5 & 140,1 & 148,5 & 1118,6 \\
\hline 2016 & 263.9 & 144.2 & 231.6 & 9.4 & 30.2 & 0 & 0 & 38.6 & 23.8 & 84.4 & ND & ND & ND \\
\hline Média & 263,9 & 190,6 & 231,6 & 82,7 & 15,1 & 5,0 & 2,0 & 10,8 & 75.4 & 84.4 & 218,0 & 228,1 & 1427,6 \\
\hline \multicolumn{14}{|c|}{ Temperatura média do ar $\left({ }^{\circ} \mathrm{C}\right)$} \\
\hline Ano & Jan & Fev & Mar & Abr & Mai & Jun & Jul & Ago & Set & Out & Nov & Dez & Anual \\
\hline 2001 & 21,4 & 21,5 & 20,7 & 20,6 & 19,5 & 17,9 & 17,9 & 18,5 & 21,0 & 20,6 & 21,0 & 21,2 & 20,2 \\
\hline 2002 & 21,6 & 20,8 & 21,3 & 20,9 & 19,3 & 17,6 & 18,6 & 19,7 & 20,7 & 22,7 & 21,6 & 21,8 & 20,6 \\
\hline 2003 & 21,9 & 21,6 & 20,8 & 21,0 & 18,4 & 17,5 & 17,0 & 19,2 & 21,1 & 21,4 & 21,3 & 22,2 & 20,3 \\
\hline 2004 & 21,2 & 20,7 & 20,7 & 20,2 & 19,4 & 16,8 & 16,7 & 18,9 & 21,2 & 22,3 & 21,6 & 21,1 & 20,1 \\
\hline 2005 & 21,7 & 21,9 & 21,2 & 21,1 & 18,7 & 17,4 & 17,5 & 19,0 & 21,3 & 21,8 & 21,4 & 21,3 & 20,4 \\
\hline 2006 & 21,2 & 21,5 & 20,9 & 20,3 & 18,5 & 16,5 & 17,0 & 19,8 & 20,8 & 20,8 & 20,8 & ND & 19,8 \\
\hline 2007 & 21,3 & 20,8 & 21,1 & 20,5 & 18,9 & 17,6 & 18,0 & 18,5 & 21,3 & 22,3 & 21,7 & 21,1 & 20,3 \\
\hline 2008 & 20,7 & 20,6 & 20,2 & 20,4 & 18,3 & 17,3 & 16,4 & 18,9 & 21,3 & 22,8 & 21,4 & 20,8 & 19,9 \\
\hline 2009 & 21,4 & 21,2 & 21,5 & 20,1 & 18,7 & 17,3 & 18,0 & 18,7 & 21,5 & 21,3 & 21,8 & 20,7 & 20,2 \\
\hline 2010 & 21,3 & 21,9 & 21,7 & 20,1 & 19,6 & 17,3 & 17,6 & 18,2 & 21,0 & 22,2 & 20,7 & 21,4 & 20,3 \\
\hline 2011 & 21,3 & 21,1 & 21,3 & 20,8 & 18,9 & 17,5 & 17,5 & 19,7 & 21,0 & 20,4 & 20,4 & 20,8 & 20,1 \\
\hline 2012 & 20,3 & 20,8 & 21,1 & 21,2 & 18,4 & 18,7 & 17,6 & 18,6 & 21,5 & 22,2 & 21,4 & 21,7 & 20,3 \\
\hline 2013 & 21,1 & 21,8 & 21,7 & 20,0 & 18,9 & 18,6 & 18,0 & 19,0 & 21,3 & 21,1 & 21,2 & 21,3 & 20,3 \\
\hline 2014 & 21,1 & 21,0 & 20,7 & 20,8 & 18,8 & 17,6 & 17,1 & 18,9 & 22,0 & 22,0 & 21,4 & 20,9 & 20,2 \\
\hline 2015 & 22,0 & 21,2 & 20,4 & 21,2 & 18,8 & 17,5 & 18,0 & 19,1 & 22,2 & 23,6 & 22,9 & 22,5 & 20,8 \\
\hline 2016 & 21.6 & 22.2 & 28.9 & 21.2 & 19.8 & 18.2 & 18.4 & 19.6 & 22.1 & 22.3 & ND & $\mathrm{ND}$ & ND \\
\hline Média & 21,3 & 21,2 & 21,0 & 20,6 & 18,9 & 17,5 & 17,5 & 19,0 & 21,3 & 21,8 & 21,4 & 21,3 & 20,3 \\
\hline
\end{tabular}

(*) Fonte: Estação Climatológica Fazenda Água Limpa, Universidade de Brasília, Distrito Federal. Temperatura medida em graus Celsius e precipitação mensurada em milímetros de chuva ou litros por $\mathrm{m}^{2}$. 
Na Tabela 2 são apresentados os resultados da análise química do solo antes da instalação do experimento.

Tabela 2. Resultados da análise química do solo da área antes da instalação do experimento.

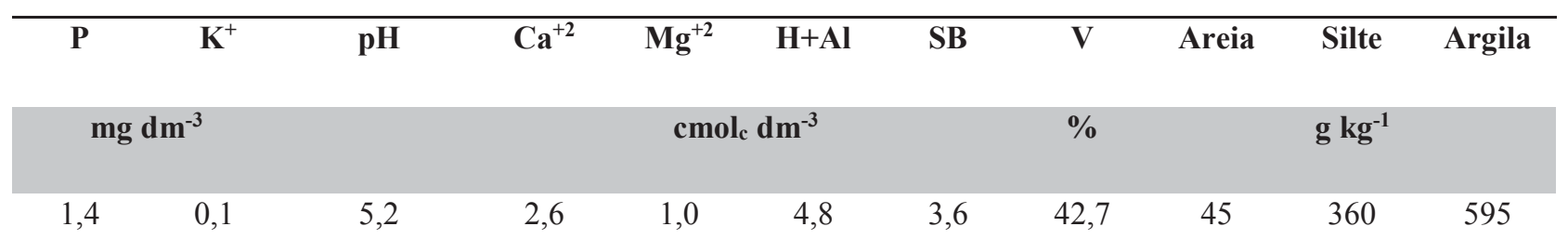

P e K: extraídos por Mehlich ${ }^{-1}\left(\mathrm{HCl}\right.$ 0,05 mol L-1 $+\mathrm{H}_{2} \mathrm{SO}_{4}$ 0,0125 mol L-1); Ca e Mg: extraídos com 1 mol L-1 KCl; H + Al:

Extração com solução tampão de acetato de cálcio a pH 7,0; $\mathrm{SB}$ = soma de bases; V: saturação por bases.

Os valores encontrados para o Cálcio e Magnésio são descritos como adequados segundo a tabela de fertilidade dos solos do Cerrado (Souza \& Lobato, 2004).

Conforme apresentado na Figura 2, os meses com a maior média nos níveis de precipitação foram os meses de Novembro, Janeiro e Março.

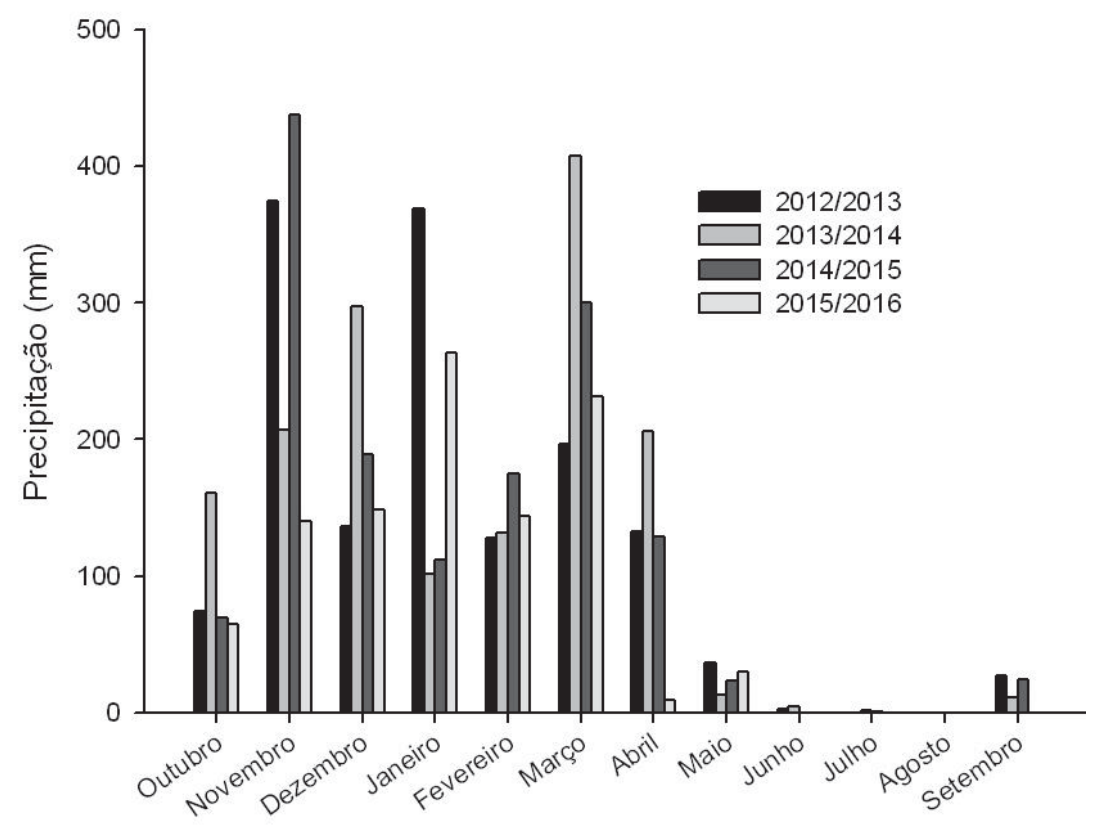

Figura 2. Precipitação pluviométrica mensal, Estação Climatológica da Fazenda Água Limpa, Universidade de Brasília, Distrito Federal. 


\subsection{Delineamento e condução do experimento}

O experimento foi estabelecido em uma área de aproximadamente um hectare, que se encontrava em processo de degradação, sendo o solo caracterizado por ausência de cobertura vegetal e perda da capacidade natural de regeneração vegetal. Após o preparo do solo foram plantadas as culturas do milho e gramíneas forrageiras a lanço Panicum máximum cv. Massai no experimento, sendo que esta gramínea foi plantada de forma consorciada com o milho, conforme esquema apresentado na Tabela 3.

Para avaliar as alterações promovidas nos anos iniciais da adoção do sistema ILPF, foram avaliadas as épocas T0, T1, T2 e T3 que correspondem aos seguintes momentos: quando a área se encontrava com pasto degradado, condição que permaneceu entre os anos de 2006 a 2012 (T0); transição de pasto degradado para sistema integrado de produção com consórcio de milho (Zea mays) e capim (Panicum maximum cv. Massai) (T1 e T2); época sobre o efeito do componente arbóreo, gliricídia (Gliricidia sepium) (T3), onde se estabeleceu um sistema de integração lavoura pecuária floresta, com espaçamento entre linhas de $5 \mathrm{~m}$ e espaçamento entre árvores variando de 1,5 m a 3,0 m (1333 plantas ha ${ }^{-1}$ a 667 plantas ha $^{-1}$, respectivamente) (Figura 3).

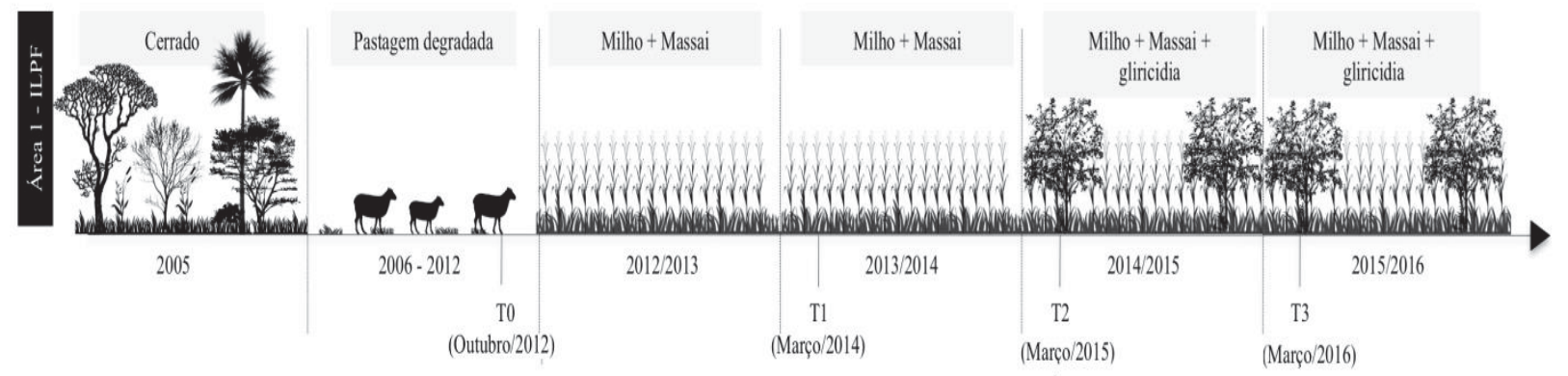

Figura 3. Ilustração do histórico de uso da área experimental e os períodos de coleta de solo (T0, T1, T2, T3), Fazenda Água Limpa, Universidade de Brasília, Distrito Federal, Brasil.

Em dezembro de 2012 foram aplicados 1,5 t ha-1 de calcário dolomítico (PRNT a 100\%) no experimento para que se elevasse a saturação por bases a $50 \%$. Ainda em dezembro do mesmo ano foram aplicados $200 \mathrm{~kg} \mathrm{ha}^{-1} \mathrm{de}^{\mathrm{P}_{2} \mathrm{O}_{5}}$ (que corresponde a 87,33 $\mathrm{kg} \mathrm{ha}^{-1} \mathrm{de} \mathrm{P}$ ) na forma de fosfato super-simples (SS), como adubação corretiva, sendo realizada a incorporação por meio de uma grade niveladora, assim como apresentado na Tabela 3. 
O plantio das gramíneas foi realizado em janeiro de 2013 em seus respectivos piquetes com taxa de semeadura de $10 \mathrm{~kg} \mathrm{ha}^{-1}$. Ainda em janeiro de 2013, foi plantado no piquete o milho híbrido AG 1051 cuja adubação foi realizada com base na análise de solo (Tabela 2). Um resumo das operações realizadas no experimento é apresentado na Tabela 3. Uma sequência das operações realizadas ao longo dos anos é apresentada na Figura 4.

Tabela 3. Histórico de manejo da área experimental por safra agrícola.

\section{Safra 2012/2013/T0}

- Preparo do solo e calagem: aração seguida de grade niveladora e aplicação de $1,5 \mathrm{t} \mathrm{ha}^{-1}$ de calcário dolomítico (PRNT $100 \%$ )

- $\quad$ Adubação corretiva: $87 \mathrm{~kg} \mathrm{ha}^{-1} \mathrm{P}_{2} \mathrm{O}_{5}$ na forma de superfosfato simples

- Semeadura do milho: janeiro/2013 com o milho híbrido AG1051

- Semeadura das forrageiras: Panicum maximum cv. Massai numa densidade de $10 \mathrm{~kg} \mathrm{ha}^{-1}$ de sementes viáveis

- $\quad$ Adubação de plantio: $20 \mathrm{~kg} \mathrm{~N} \mathrm{ha}^{-1}+100 \mathrm{~kg} \mathrm{P}_{2} \mathrm{O}_{5} \mathrm{ha}^{-1}+84 \mathrm{~kg} \mathrm{~K}_{2} \mathrm{O} \mathrm{ha}^{-1}$

- Adubação de cobertura: $50 \mathrm{~kg} \mathrm{~N} \mathrm{ha}^{-1}+40 \mathrm{~kg} \mathrm{~K}_{2} \mathrm{O} \mathrm{ha}^{-1}$ (fevereiro, 2013)

- Colheita do milho: julho, 2013

- Entrada dos animais bovinos e ovinos após a colheita do milho para consumir a forragem.

\section{Safra 2013/2014/T1}

- Aplicação de $1,5 \mathrm{t} \mathrm{ha}^{-1}$ de calcário dolomítico (PRNT 100\%)

- Semeadura do milho: dezembro/2013 com o milho híbrido LG 6030

- Adubação de plantio: $30 \mathrm{~kg} \mathrm{~N} \mathrm{ha}^{-1}+120 \mathrm{~kg} \mathrm{ha}^{-1} \mathrm{P}_{2} \mathrm{O}_{5}+64 \mathrm{~kg} \mathrm{ha}^{-1} \mathrm{~K}_{2} \mathrm{O}$

- Adubação de cobertura: $65 \mathrm{~kg} \mathrm{~N} \mathrm{ha}^{-1}$ (janeiro, 2014) e $65 \mathrm{~kg} \mathrm{~N} \mathrm{ha}^{-1}+65 \mathrm{~kg} \mathrm{~K}_{2} \mathrm{O}$ ha ${ }^{-1}$ (fevereiro, 2014)

- Aplicação de inseticida Match $\left(2 \mathrm{~L} \mathrm{ha}^{-1}\right)$ e Stron $\left(1 \mathrm{~L} \mathrm{ha}^{-1}\right)$ (janeiro, 2014) para a lagarta do cartucho

- Aplicação de inseticida Match $\left(1 \mathrm{~L} \mathrm{ha}^{-1}\right)$ e Kaplon $\left(2 \mathrm{~L} \mathrm{ha}^{-1}\right)$ (fevereiro, 2014) para a lagarta do cartucho

- Colheita do milho: julho, 2014

Safra 2014/2015/T2

- Aplicação de 0,6 $\mathrm{t} \mathrm{ha}^{-1}$ de calcário dolomítico (PRNT 100\%).

- Semeadura do milho: dezembro/2014 com o milho híbrido LG 6030

- Adubação de plantio: $20 \mathrm{~kg} \mathrm{~N} \mathrm{ha}^{-1}+150 \mathrm{~kg} \mathrm{P}_{2} \mathrm{O}_{5} \mathrm{ha}^{-1}+80 \mathrm{~kg} \mathrm{~K}_{2} \mathrm{O} \mathrm{ha}^{-1}$

- Adubação de cobertura: $80 \mathrm{~kg} \mathrm{~N} \mathrm{ha}^{-1}$ (janeiro, 2015) e $60 \mathrm{~kg} \mathrm{~N} \mathrm{ha}^{-1}+60 \mathrm{~kg} \mathrm{~K}_{2} \mathrm{O}_{\text {ha }}^{-1}$ (fevereiro, 2015)

- Plantio da Gliricidia sepium: fevereiro/2015 com espaçamento entre linhas de $5 \mathrm{~m}$ e espaçamento entre árvores de $1,5 \mathrm{~m}$. A adubação da cova constou de $50 \mathrm{~g}$ de superfosfato simples, $25 \mathrm{~g}$ de $\mathrm{KCl}$ e $10 \mathrm{~g}$ de FTE BR12, densidade de 1333 planta/ha-1

- Colheita do milho: junho, 2015

Safra 2015/2016/T3

- Adubação da Gliricidia sepium: 50 g de superfosfato simples, 25 g de KCl e 10 g de FTE BR12 na projeção da copa

- $\quad$ Aplicação de herbicida Gramoxone 200 (1,5 L hä $\left.\mathrm{L}^{-1}\right)$, em dezembro, 2015

- Semeadura do milho: dezembro/2015 com o milho híbrido LG 6030

- $\quad$ Adubação de plantio: $30 \mathrm{~kg} \mathrm{~N} \mathrm{ha}^{-1}+150 \mathrm{~kg} \mathrm{ha}^{-1} \mathrm{P}_{2} \mathrm{O}_{5}+50 \mathrm{~kg} \mathrm{ha}^{-1} \mathrm{~K}_{2} \mathrm{O}+66 \mathrm{~kg} \mathrm{ha}^{-1}$ FTE BR12

- Adubação de cobertura: $90 \mathrm{~kg} \mathrm{~N} \mathrm{ha}^{-1}+30 \mathrm{~K}_{2} \mathrm{O} \mathrm{ha}^{-1}$ (janeiro, 2016) e $60 \mathrm{~kg} \mathrm{~N} \mathrm{ha}^{-1}+60 \mathrm{~kg} \mathrm{~K}_{2} \mathrm{O}$ ha-1 (fevereiro, 2014)

- Colheita do milho: maio, 2016 

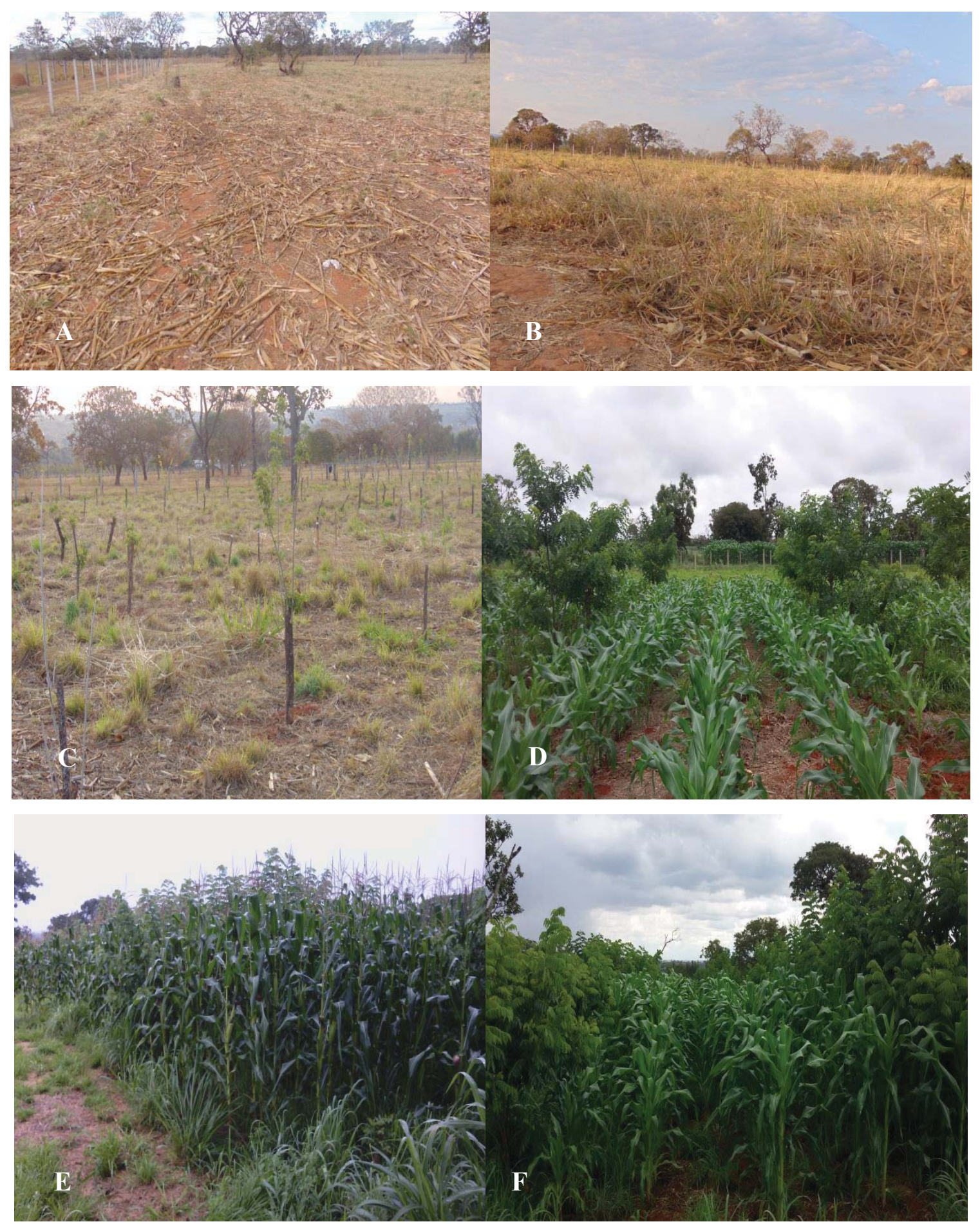

Figura 4. Ilustração da mudança no uso do solo, A e B área no tempo T2, sem o componente arbóreo, C e D mostram o período de plantio e desenvolvimento das mudas de Gliricídia, E e F mostram o ILPF no tempo T3 com a presença do componente arbóreo estabelecido. 


\subsection{Amostragem do solo}

Amostras de solo deformadas foram coletadas na área experimental em cinco épocas: outubro de 2012 quando a área estava sobre pastagem degradada (T0); março de 2014 no segundo ano de implantação dos sistemas ILP, com coleta de solo realizada na floração do milho (T1); março de 2015 (T2); março de 2016 (T3), ambas no período de floração do milho. Na coleta de 2016, a área já se encontrava sobre a influência do componente arbóreo (gliricídia). O solo foi coletado nas profundidades de 0-10, 10-20 e 20-40 cm. Na área experimental, foram coletadas cinco amostras compostas, cada uma contendo a mistura de seis sub-amostras simples. As amostras simples referentes a outubro de 2012 (T0) foram coletadas de forma aleatória na área experimental, enquanto que as amostras compostas das épocas T1, T2, T3 foram coletadas na entrelinha (4 sub-amostras simples) e linha de plantio ( 2 sub-amostras simples) do milho.

As amostras de solo foram acondicionadas em caixas térmicas com gelo e levadas para laboratório, onde foram armazenadas em câmara fria com temperatura de $8^{\circ} \mathrm{C}$ até o momento de realização da análise de biomassa microbiana do solo. Uma alíquota de cada amostra composta foi retirada para as análises químicas e de fracionamento da matéria orgânica do solo. Após serem destorroadas e homogeneizadas, as amostras foram secas ao ar e peneiradas em malha de 2,0 mm (TFSA).

Amostras indeformadas para determinação da densidade e umidade do solo também foram coletadas com o uso de anéis volumétricos $\left(100 \mathrm{~cm}^{3}\right)$ e nas profundidades de 0-10, 10-20 e 20-40 cm, em cinco locais de amostragem.

\subsection{Procedimentos analíticos}

A determinação do teor de COT e das frações da MOS foram realizados no Laboratório de Estudos da Matéria Orgânica do Solo, Faculdade de Agronomia e Medicina Veterinária $\mathrm{FAV} / \mathrm{UnB}$.

\subsubsection{Determinação do carbono orgânico total}

Para a determinação do teor de carbono orgânico total, foram retiradas, das amostras de terra fina seca ao ar (TFSA), alíquotas de $10 \mathrm{~g}$ de solo, que uma vez maceradas foram passadas

em peneira de 0,149 mm. A partir da alíquota foram pesadas aproximadamente $70 \mathrm{mg}$ de solo e colocadas em cápsulas de estanho. Os teores de carbono total foram determinados por combustão 
seca em analisador elementar (CNHS). O método da medição é por meio de oxidação catalítica realizada em temperaturas de $1200^{\circ} \mathrm{C}$, realizando-se a medição de $\mathrm{CO}_{2}$ por meio de espectrometria infravermelha, utilizou-se um analisador de C orgânico total (TOC cube, Elementar Analysen systeme GmbH, Hanau, Alemanha). A injeção das amostras foi automática com uso de um carrossel com capacidade para 100 cápsulas.

\subsubsection{Fracionamento físico-granulométrico da matéria orgânica do solo}

O fracionamento físico granulométrico da matéria orgânica foi realizado conforme Cambardella \& Elliott, (1992), com adaptações no peso da amostra utilizada, segundo Bayer et al. (2004) e Bongiovanni \& Lobartini, (2006). Por este fracionamento foram obtidas a fração particulada $(>53 \mu \mathrm{m})$ e a associada aos minerais $(<53 \mu \mathrm{m})$. Aproximadamente $20 \mathrm{~g}$ de solo foram colocados em frascos de vidro com $70 \mathrm{~mL}$ de hexametafosfato de sódio na concentração de $5 \mathrm{~g} \mathrm{~L}^{-1} \mathrm{e}$ agitadas por 15 horas em agitador horizontal a $150 \mathrm{rpm}$. A seguir, a suspensão foi passada em peneira com malha de $53 \mu \mathrm{m}$ com auxílio de jato de água. O material retido na peneira, que consiste da matéria orgânica particulada, foi seco em estufa a $60^{\circ} \mathrm{C}$, pesado, moído em gral de porcelana e analisado em relação ao teor de C na fração particulada da MOS (COP). Uma alíquota da amostra de solo passada em peneira de $2 \mathrm{~mm}$ foi moída em gral de porcelana e posteriormente utilizada para a análise do carbono orgânico total (COT). O carbono orgânico associado aos minerais (CAM) foi calculado pela diferença entre o COT e COP. As análises de C da matéria orgânica total e particulada foram realizadas por combustão via seca, em analisador elementar de CHN (modelo PE 2400, Série II CHNS/O, Perkin Elmer, Norwalk, USA).

\subsubsection{Carbono da biomassa microbiana}

O carbono da biomassa microbiana (CBM) foi determinado pelo método fumigaçãoirradiação, conforme Islam \& Weils, (1998). As amostras de solo da câmara fria foram tamisadas em peneira de $2 \mathrm{~mm}$, e depois de excluídos os restos de raízes, as amostras foram deixadas em temperatura ambiente por 24 horas. Para cada amostra composta foram utilizadas seis repetições analíticas, sendo três irradiadas e três não irradiadas, cada uma contendo $20 \mathrm{~g}$ de solo. As amostras de solo foram irradiadas em forno de micro-ondas por um período de 137 segundos. $\mathrm{O}$ tempo de irradiação foi calculado em função da potência real do forno micro-ondas. O CBM foi extraído colocando-se $80 \mathrm{~mL}$ de uma solução de sulfato de potássio $\left(\mathrm{K}_{2} \mathrm{SO}_{4}\right)$ a $0,5 \mathrm{~mol} \mathrm{~L}^{-1}$ nas 
amostras de solo e agitando-as em agitador horizontal por 30 minutos a $150 \mathrm{rpm}$. Depois disso as amostras foram filtradas em papel filtro de passagem lenta $(8 \mu \mathrm{m})$. Foi utilizada uma alíquota de $8 \mathrm{~mL}$ do extrato filtrado para a determinação do CBM. Adicionaram-se $2 \mathrm{~mL}$ de dicromato de potássio $\left(\mathrm{K}_{2} \mathrm{Cr}_{2} \mathrm{O}_{7}\right)$ a $0,066 \mathrm{~mol} \mathrm{~L}^{-1}$ e $10 \mathrm{~mL}$ de ácido sulfúrico concentrado $\left(\mathrm{H}_{2} \mathrm{SO}_{4}, 98 \%\right)$. As amostras foram então deixadas em repouso por 30 minutos para oxidação do $\mathrm{C}$ presente nas amostras de solo. Após resfriamento e oxidação, o $\mathrm{K}_{2} \mathrm{Cr}_{2} \mathrm{O}_{7}$ residual foi quantificado através da titulação com sulfato ferroso amoniacal $0,033 \mathrm{~mol} \mathrm{~L}^{-1}$, na presença do indicador Ferroin $(1,485 \mathrm{~g}$ de Orto-Fenantrolina + 0,695 g de Sulfato Ferroso em $100 \mathrm{~mL}$ de água destilada). O CBM foi calculado pela fórmula: $\mathrm{CBM}=(\mathrm{CI}-\mathrm{CNI}) / \mathrm{Kec}$, onde, $\mathrm{CI}$ e $\mathrm{CNI}$ : representam o $\mathrm{C}$ extraído das amostras irradiadas e não irradiadas, respectivamente; Kec: representa fator de correção de 0,33 (Mendonça \& Matos, 2005).

\subsubsection{Carbono Inerte}

O carbono inerte $(\mathrm{CI})$ foi determinado conforme procedimento descrito por Jackson (1958). Realizou-se a pesagem de 1,0 g de solo e colocado em um Becker de $100 \mathrm{~mL}$, contendo $10 \mathrm{~mL}$ de peróxido de hidrogênio a $30 \%(\mathrm{p} / \mathrm{v})$. O becker foi então colocado numa placa aquecedora a $100{ }^{\circ} \mathrm{C}$ para que o peróxido de hidrogênio fervesse e secasse. Após secar, foi adicionado $5 \mathrm{~mL}$ de solução de peróxido de hidrogênio e deixado novamente a $100{ }^{\circ} \mathrm{C}$ até não possuir mais efervescência. Em seguida os beckeres foram secados numa estufa a $100{ }^{\circ} \mathrm{C}$ por 12 $\mathrm{h}$, deixados esfriar e pesados. Estas amostras de solo foram maceradas e analisadas quanto à concentração total de C usando o analisador elementar (modelo PE 2400, Série II CHNS/O, Perkin Elmer, Norwalk, USA). A concentração total do C não oxidável (inerte) do solo após a oxidação com $\mathrm{H}_{2} \mathrm{O}_{2}$ foi calculada a partir dos resultados da concentração de $\mathrm{C}$ e o peso do solo nos beckeres após oxidação.

\subsubsection{Carbono Lábil}

O C orgânico lábil (CL) foi determinado por oxidação com permanganato de potássio (Shang \& Tiessen, 1997). O solo foi passado em peneira com malha de $0,5 \mathrm{~mm}$ e $1 \mathrm{~g}$ do mesmo foi colocado em tubos de centrífuga de $50 \mathrm{~mL}$ e enrolados com papel alumínio para evitar a fotoxidação do permanganato. Foram adicionados $25 \mathrm{~mL}$ da solução de permanganato de

potássio $\left(\mathrm{KMnO}_{4}\right)$ a $0,033 \mathrm{~mol} \mathrm{~L}-1$, agitados por 1 hora a $60 \mathrm{rpm}$, e em seguida centrifugados 
por 5 minutos a $7000 \mathrm{rpm}$. Após centrifugação, $1 \mathrm{~mL}$ do sobrenadante foi pipetado em balões volumétricos de $250 \mathrm{~mL}$, completando seu volume com água destilada. A leitura foi realizada em espectrofotômetro em comprimento de onda de $565 \mathrm{~nm}$. Para determinação do CL, foi feita uma

curva padrão a partir de uma solução contendo $0,00060 \mathrm{~mol} \mathrm{~L}^{-1}$ de $\mathrm{KMnO}_{4}$. Para cada ponto da curva foram pipetadas em balões de 100 mL quantidades correspondentes a: 13,3; 16,67; 18,67; 20,0; e 22,0 mL, completando o volume com água destilada. A mudança na concentração de $\mathrm{KMnO}_{4}$ foi usada para estimar a quantidade de $\mathrm{C}$ oxidado, assumindo que $1 \mathrm{~mm} \mathrm{MnO}_{4}$ é consumido (MnVII + MnII) na oxidação de $0,75 \mathrm{mmol}$ ou $9 \mathrm{mg}$ de C.

\subsection{6 Índice de manejo do carbono}

$\mathrm{O}$ índice de manejo de carbono $(\mathrm{IMC})$ foi determinado pelo cálculo $\mathrm{IMC}=$ índice de compartimento de carbono (ICC) x índice de labilidade (IL) x 100 (Blair et al., 1995).

Os cálculos para a estimativa do Índice de Manejo de Carbono foram realizados considerando a época T0 como referência em relação aos outros tempos (T1, T2, T3) de uso da terra (IMC $=100)$. Para estimar o IMC foi necessário obter o índice de compartimento do carbono (ICC), labilidade (L) e índice de labilidade (IL) Estes foram obtidos através das seguintes fórmulas:

$$
\begin{gathered}
\mathrm{CNL}=\mathrm{COT}-\mathrm{CL} \\
\mathrm{ICC}=\mathrm{COT} \text { do tratamento } / \text { COT ref. } \\
\mathrm{L}=\mathrm{CL} / \mathrm{CNL} \\
\mathrm{IL}=\mathrm{L} \text { do tratamento } / \mathrm{L} \text { ref. }
\end{gathered}
$$

Em que:

$\mathrm{CNL}=$ teor de carbono não lábil $\left(\mathrm{g} \mathrm{kg}^{-1}\right) ; \mathrm{COT}=$ teor de carbono orgânico total $\left(\mathrm{g} \mathrm{kg}^{-1}\right)$; $\mathrm{CL}=$ teor de carbono lábil $\left(\mathrm{g} \mathrm{kg}^{-1}\right)$; ICC = índice de compartimento do carbono; COT do tratamento $=$ teor de carbono no solo do tratamento $\left(\mathrm{g} \mathrm{kg}^{-1}\right)$; COT ref. $=$ teor de carbono no solo do sistema referência $\left(\mathrm{g} \mathrm{kg}^{-1}\right) ; \mathrm{L}=$ labilidade do carbono; $\mathrm{IL}$ = índice de labilidade do carbono no solo; Ltra = labilidade do carbono no solo no tratamento e Lref = labilidade do carbono no solo no sistema referência. A partir do ICC e IL, foi calculado o IMC. 


\subsubsection{Determinação da produtividade do milho (Zea mays)}

A produção de grãos foi determinada por meio de secagem dos grãos colhidos, pesados e

transformados em $\mathrm{kg} \mathrm{ha}^{-1}$ (13\% da base úmida). Para determinação de produtividade colheram-se 3 linhas de 2 metros em 5 repetições.

\subsubsection{Análise Estatística}

Os dados foram submetidos à análise estatística descritiva, por meio de box plot. As análises foram realizadas por meio do software XLSTAT 2013 (ADDINSOFT, 2013). 


\section{RESULTADOS E DISCUSSÃO}

Na Figura 5 (A, B, e C) são apresentados os teores de carbono orgânico total (COT) nas profundidades 0-10, 10-20 e 20-40 cm, respectivamente, nas diferentes épocas de amostragem. De maneira geral, em todas as profundidades, houve um destacado incremento de COT no solo após a recuperação da pastagem e a implantação do sistema de ILPF. Percebeu-se que o incremento de COT na camada superficial foi verificado logo após o primeiro ano de implantação do sistema. Na camada de 10-20 cm esse acúmulo de COT é mais gradual com o tempo e fortemente influenciado pela presença da espécie arbórea (Loss et al., 2011). Esses resultados reforçam o potencial do sistema ILPF de promover uma melhoria das propriedades biológicas do solo, se refletindo em maior capacidade de acumular carbono, superior a encontrada em pastagem degradada (Muniz et al., 2011). Esse incremento no acúmulo de COT em relativo pouco tempo de adoção do sistema reforça a função de sistemas integrados de produção como uma alternativa para a viabilização de uma agricultura de baixa emissão de carbono.

Os teores de COT variaram de $14,9 \mathrm{~g} \mathrm{~kg}^{-1}$ a $25,5 \mathrm{~g} \mathrm{~kg}^{-1}$, considerando todas as profundidades, sendo que os maiores teores foram observados na camada de 0-10 $\mathrm{cm}$. Os teores médios foram de $24 \mathrm{~g} \mathrm{~kg}^{-1}$; 21,96 $\mathrm{g} \mathrm{kg}^{-1}$ e 18,30 $\mathrm{g} \mathrm{kg}^{-1}$ nas camadas de 0-10, 10-20 e 20-40 cm, respectivamente. Os valores encontrados para o COT foram semelhantes aos obtidos por outros autores em solos do Cerrado (Figueiredo et al., 2010; Viana et al., 2011; Souza et al., 2015), porém foram menores que os resultados encontrados nos trabalhos de Santana et al. (2011) e Beutler et al. (2016), fato devido ao período de implementação mais longos do sistema integrado.

O impacto inicial da mudança de uso do solo teve uma resposta rápida no acúmulo de COT no solo. Contrariando a hipótese do presente estudo, a mudança de pastagem degradada para um sistema ILPF, num curto período, entre os anos de 2013 e 2014, elevou os teores de COT em todas as profundidades estudadas (Figura 5).

Deve-se destacar que a recuperação da pastagem degradada foi realizada com o fornecimento de adubo mineral para o milho, o que deve ter proporcionado o estágio inicial de acúmulo de MOS, mediante uma maior produção de biomassa das culturas. O trabalho realizado por Zhang et al. (2015), aponta que o fornecimento de adubo mineral a solos em sistemas 
integrados incrementa os teores de COT nos anos iniciais, ao passo que os fertilizantes orgânicos se tornam mais importantes à medida que o sistema se estabiliza, ao longo do tempo.

Após o segundo ano de recuperação houve pouco acúmulo de COT, não apresentando diferenças entre as épocas de coleta T1, T2 e T3. Esses resultados indicam a necessidade de acompanhamento do acúmulo de COT por um período de tempo maior para constatar se houve ou não estabilização do acúmulo de COT no solo.

No presente estudo, tendo em vista que o sistema ILPF apresenta apenas quatro anos de condução, é razoável esperar que não tenha sido atingido o potencial pleno de acúmulo de COT desse sistema, uma vez que apenas na época T3 o componente arbóreo começa a contribuir com incremento de COT, tanto pelo aporte de biomassa de serapilheira como em profundidade pelo sistema radicular da leguminosa arbórea.

Desta forma o presente estudo corrobora as conclusões encontradas no trabalho de Oliveira et al. (2016) que destaca o COT como indicador eficiente para avaliar o processo de mudança do solo. 

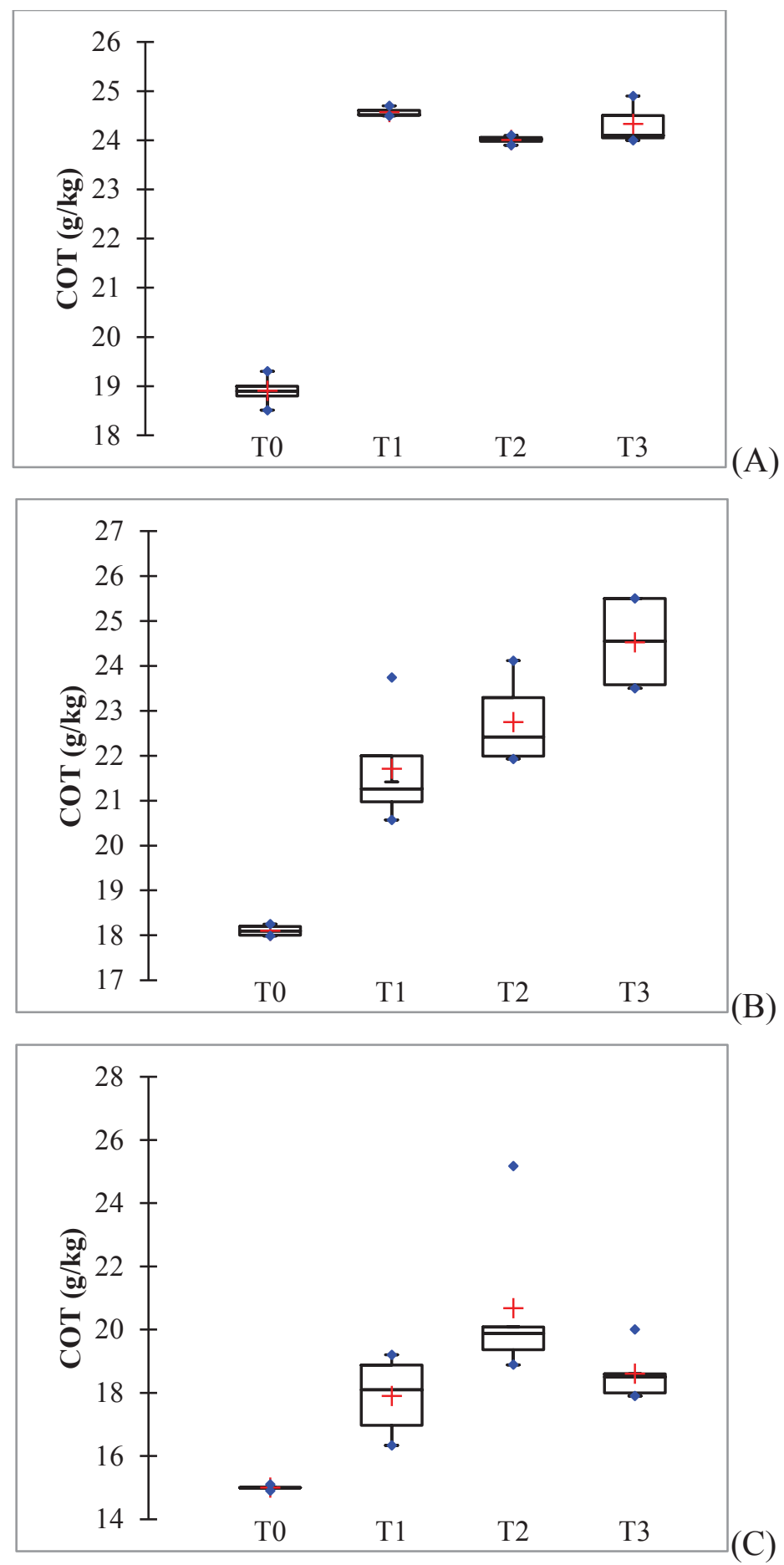

Figura 5. Carbono orgânico total (COT) nas profundidades 0-10 cm (A); 10-20 cm (B); e 20-40 cm (C), em área sob integração lavoura-pecuária-floresta. Coletas realizadas em 2012 com a área ainda degradada (T0); na safra 2013/2014 (T1); na safra 2014/2015 (T2) e na safra 2015/2016 (T3). 


\subsection{Frações lábeis da matéria orgânica do solo}

$\mathrm{Na}$ figura 6 (A, B, e C) são apresentados os teores de carbono nas frações lábeis da matéria orgânica do solo na profundidade de 0-10 cm, nas diferentes épocas de amostragem. Verifica-se um incremento do carbono da biomassa microbiana (CBM) ao longo do tempo, porém, a variabilidade dos dados é elevada na camada superficial do solo (Figura 6A).

Os valores de CBM variaram de $93 \mathrm{mg} \mathrm{kg}^{-1}$ até um valor máximo de 331,20 mg kg-1, sendo que para a camada de 0-10 cm foi obtido um teor médio de 247,2 $\mathrm{mg} \mathrm{kg}^{-1}$, o que Lopes et al. (2013) descrevem como um teor moderado de CBM em áreas de produção agrícola no Cerrado. Estes valores de CBM foram muito semelhantes aos obtidos em Oliveira et al. (2016), para sistemas integrados de pastagem, cana-de-açúcar e Cerrado nativo, observando-se dados desses autores que um incremento na complexidade dos sistemas elevou os teores de CBM em um prazo de 4 anos.

Os dados apontam que o CBM tem sido influenciado pela época de amostragem na camada de 10-20 cm. Esta é uma influência indireta originada pelo incremento de COT na mesma camada, uma vez que o incremento de COT influencia diretamente no valor do CBM. Esta relação pode estar associada à formação de agregados que oferecem proteção ao CBM como observado em outros trabalhos (Dick \& Burns, 2011; Lopes et al., 2013). O fornecimento de adubação nitrogenada na recuperação da pastagem é uma prática importante, sobretudo nos estágios iniciais de implantação dos sistemas, pois incrementa o aporte de biomassa, que nos estágios posteriores, por meio do aumento da MOS, aumenta a participação das frações do carbono orgânico na sustentabilidade dos sistemas (Luo et al., 2015).

Já no primeiro ano após as operações adotadas para a recuperação da pastagem, o carbono lábil (CL) foi incrementado com teores duas vezes superiores ao solo degradado. Esses resultados demostram a sensibilidade dessa fração em expressar em curto período as mudanças que ocorrem com a adoção de um sistema conservacionista.

A fração CL apresentou teor mínimo de $1,01 \mathrm{~g} \mathrm{~kg}^{-1}$ e teor máximo de 2,64 $\mathrm{g} \mathrm{kg}^{-1}$. Os teores médios das épocas de coleta foram de $0,94 \mathrm{~g} \mathrm{~kg}^{-1}, 1,99 \mathrm{~g} \mathrm{~kg}^{-1}$ e $1,81 \mathrm{~g} \mathrm{~kg}^{-1}$ para os tempos T0, T1 e T3, respectivamente, observando-se uma tendência de decréscimo em função da

profundidade. Os teores obtidos no presente estudo foram semelhantes aos encontrados por Souza et al. (2016) para Latossolos. 
O incremento dos teores de CL em função da mudança do uso do solo é importante, uma vez que esta fração do $\mathrm{C}$ é mais sensível às mudanças de uso de solo (Culman, 2012). O CL representou uma proporção de 33,27\% do COP, este resultado é inferior ao observado por Skjemstad et al. (2006), porém deve ser levado em consideração que este autor avaliou a média de múltiplos solos e áreas florestais, de forma que a maior concentração de CL é esperada.

No trabalho de Aguilar et al. (2015), é apresentada a dependência dos teores de CL em função da intensidade da exploração do solo, bem como, as medidas implementadas para o seu manejo e manutenção. Como o CL foi relacionado com os conteúdos de MOS depositados na superfície, o incremento de seus teores está relacionado com áreas de cultivo diversificado, assim como observado por outros autores (Dou et al., 2008; Urquiza Rodrigues et al., 2011).

Autores como Blair et al. (1995), têm sugerido que a fração de CL é constituída de matéria húmica lábil e polissacarídeos. A rápida resposta desta fração do $\mathrm{C}$ em função da mudança no uso do solo também foi observada em outros trabalhos (Haynes, 2005; Yang et al., 2012).

Apesar de sua importância, o CL tem sido menos estudado do que as frações biológicas como o CBM, portanto seus mecanismos de funcionamento ainda não são bem claros, assim como a sua função na nutrição vegetal (Haynes, 2005). Entretanto diversos trabalhos têm demonstrado que o CL é indicador confiável de manejo, uso e práticas de adubação do solo (Haynes, 2005; Yang et al., 2012; Souza et al., 2016).

Da mesma forma, os teores de carbono orgânico particulado (COP) foram incrementados no solo já no primeiro ano após a recuperação da pastagem. Entretanto deve-se destacar que na última coleta (T3), já influenciada pela gliricídia, os teores de COP continuaram com forte acúmulo no solo, demostrando que o efeito da implantação do componente arbóreo tem destacada influência nessa fração da matéria orgânica do solo.

Os teores COP variaram de 1,66 $\mathrm{g} \mathrm{kg}^{-1}$ a $11,56 \mathrm{~g} \mathrm{~kg}^{-1}$ para a profundiade de 0-40 $\mathrm{cm}$. Os valores se mostraram consistentes com os encontrados por outros autores (Loss et al., 2014; Ferreira et al., 2016), em Latossolos Vermelhos. É importante notar que em termos percentuais o COP foi o componente do $\mathrm{C}$ que teve a maior variação percentual em função da época de amostragem. Verificou-se, na época T3 (ILPF), um incremento de 370\% em relação ao estágio T0 (pasto degradado), esta variação foi superior a apresentada pela fração CL o que leva a 
conclusão que assim como destacado por Durival et al. (2016), o COP é a fração orgânica mais sensível a mudanças de prática agrícola.

Os teores obtidos foram superiores em T3 aos encontrados por Souza (2015), para plantio direto em Latossolos Vermelhos, o que pode ser explicado em virtude do aporte de biomassa fornecido pelo componente arbóreo, assim como pela presença da forrageira (Panicum maximim $C V$. Massai). Entretanto, os valores do presente trabalho foram inferiores aos observados por Gazolla et al. (2015), em Latossolos do Cerrado do estado do Goías, com sistemas conservacionistas de manejo (ILP e SPD), com longos períodos de implementação, 17 anos de sistema ILP, que apresentou resultados de COP, duas vezes superiores ao observado no presente trabalho, o que pode indicar que o potencial acúmulo de COP varia em função do aporte de MOS e do tempo de implantação do sistema.

Em estudos mais antigos como os de Bolinder et al. (1999), bem como em estudos mais recentes como o de Coser et al. (2007), tem sido destacado a contribuição das raízes de milho no acúmulo de matéria orgânica solo, o que pode acarretar incremento das frações lábeis de C nas camadas subsuperficais, uma vez que os compostos orgânicos advindos destas raízes permanecem na mesma profundidade após a colheita. Nesse sentido, o trabalho de Carmo et al. (2012), encontrou que o milho consorciado com Panicum maximum cv. Aruana ou Brachiaria apresentou maiores teores de COP do que o milho solteiro.

Trabalhos como o de Cates et al. (2016), afirmam que o COP, assim como o COT e o N total, provenientes dos agregados ilustram que a quantidade e qualidade de $\mathrm{C}$ na biomassa, o manejo do solo e a decomposição de resíduos, interagem de maneira complexa durante décadas para manter a conteúdo da MOS. 
Camada $0-10 \mathrm{~cm}$
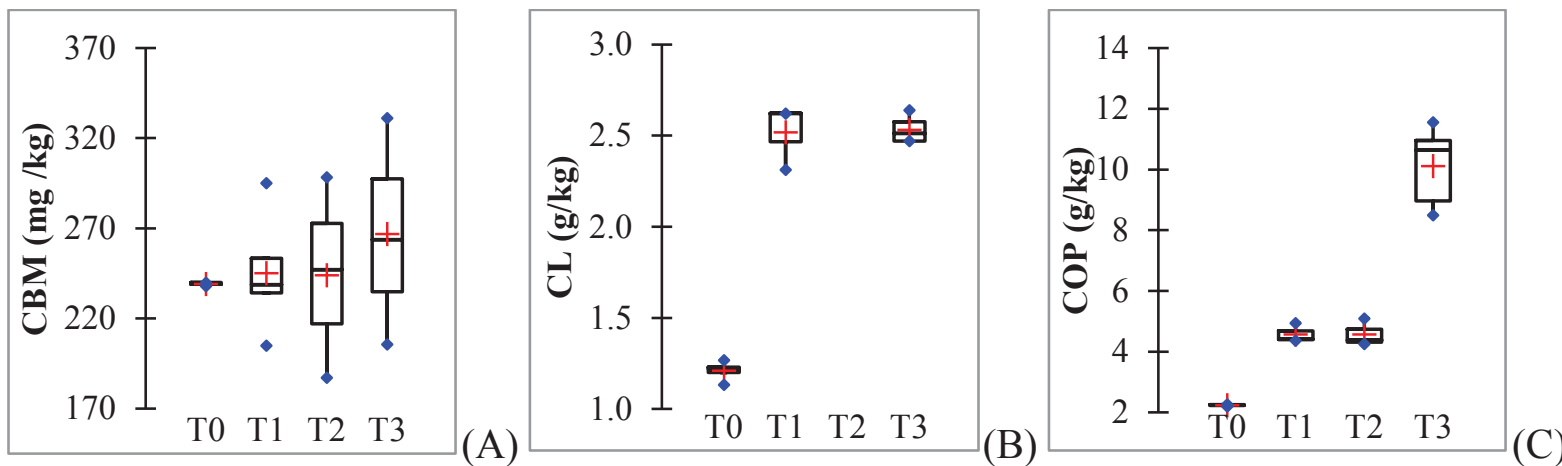

Camada $10-20 \mathrm{~cm}$
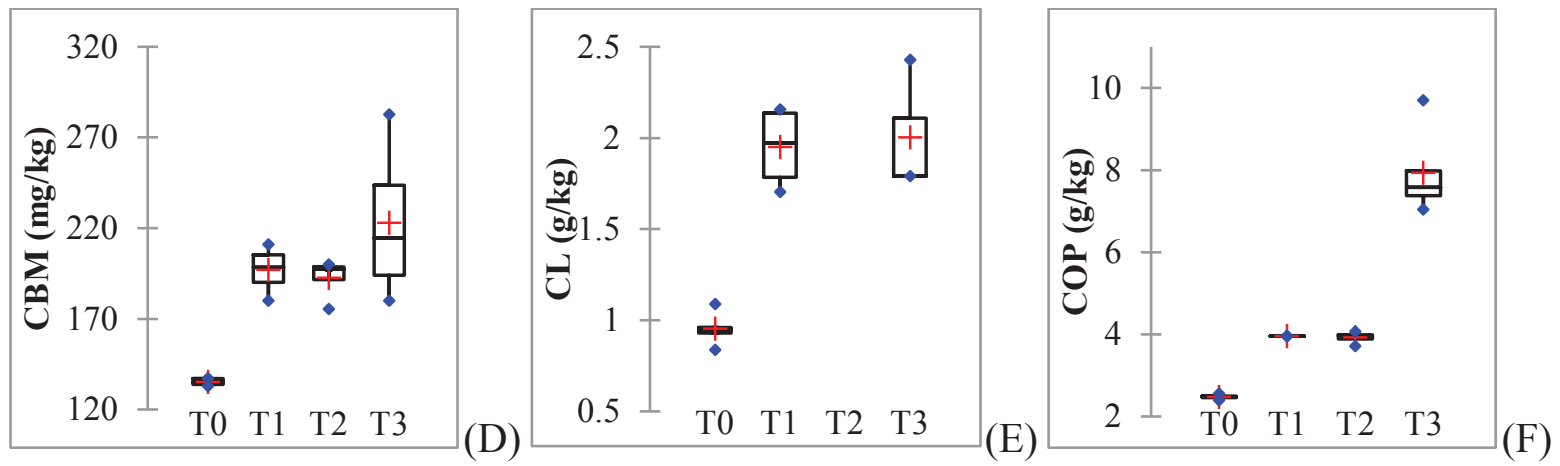

Camada $20-40 \mathrm{~cm}$
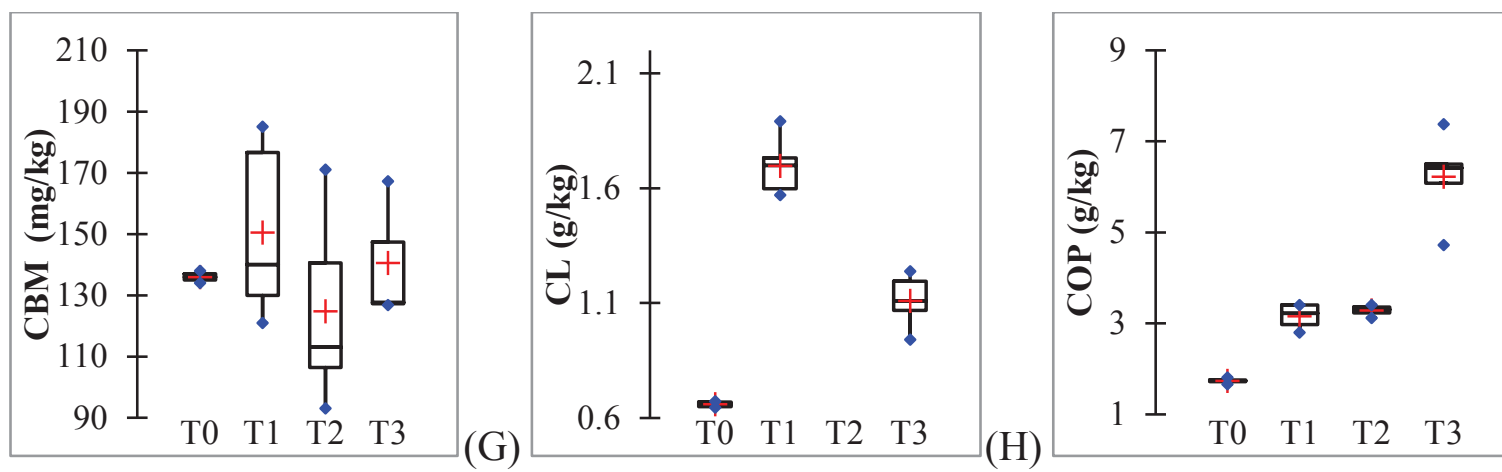

Figura 6. Teores de carbono das frações lábeis da matéria orgânica do solo na profundidade de 0-10 cm, 10-20 cm e 20-40 cm, em área sob integração lavoura-pecuária-floresta, ao longo de 4 anos de implementação do sistema. CBM - carbono da biomassa microbiana (A); CL - carbono lábil (B) e COP - carbono orgânico particulado (C). Coletas realizadas em 2012 com a área ainda degradada (T0); na safra 2013/2014 (T1); na safra 2014/2015 (T2) e na safra 2015/2016 (T3). 
Nas profundidades de 10-20 e 20-40 cm (Figura 6 D, E, F, G, H, I) as frações lábeis apresentaram incrementos ao longo dos anos, da mesma forma que a camada superficial do solo 0-10 cm. Isso indica que a recuperação de pastagems degradadas com o uso de sistemas integrados de produção, diferentemente dos diversos sistemas apenas com produção de grãos, incrementam a matéria orgânica em profundidade, como no presente estudo até $40 \mathrm{~cm}$.

Os resultados apontam uma redução no teor de COP de 36\% da camada de 0-10 cm para a camada de 10-20 cm, este resultado foi consistentes com os valores encontrados em Ferreira et al. (2016), para Latossolo Vermelho Distrófico (LVd) em sistemas de manejo integrado com 30 anos de implementação, que encontram no seu trabalho uma redução de $40 \%$ na transição da camada de 0-10 para a de 10-20 cm. Resultados semelhantes também foram encontrados por Souza et al. (2016), que encontraram uma redução de $42 \%$ quando comparadas as mesmas camadas. O CL teve variações de $20 \%$ a $25 \%$ entre as duas profundidades, apresentando assim menor sensibilidade à variação da profundidade do solo. 


\subsection{Frações estáveis da matéria orgânica do solo}

Algumas frações mais estáveis da matéria orgânica também foram incrementadas no solo ao longo do tempo de adoção do ILPF, nas diferentes profundidades avaliadas (Figura 7, A, B, C, D, E e F). Na camada superficial 0-10 cm, todas as frações sofreram aumentos consideráveis após as operações realizadas para a recuperação da pastagem (Figura 7), com maiores teores observados no T3, sobre o efeito da espécie arbórea gliricídia.

Os teores de carbono inerte (CI) variaram de $3,7 \mathrm{~g} \mathrm{~kg}^{-1}$ a $13,7 \mathrm{~g} \mathrm{~kg}^{-1}$ ao longo dos anos na profundidade de $0-10 \mathrm{~cm}$. Foram verificados incrementos superiores a $100 \%$ no T3 comparado ao T0, para todas as profundidades. O CI apresentou incrementos conforme o aumento da complexidade do sistema. Esses resultados demonstram que a fração CI, normalmente relacionada com a presença de C na forma de carvão (Jantalia et al., 2007), com elevada estabilidade pode conter outros compostos que são alterados em curto período de manejo do solo.

Nesse sentido, Marschner et al. (2008) sugerem uma mudança na definição de CI para uma fração isolada da fração biológica, por meio de barreiras físicas, químicas ou biológicas. O trabalho de Sanderman et al. (2016), ao analisar conteúdos de CI em diversos sistemas a longo prazo, concluiram que as frações de CI são sim protegidas por estas barreiras conforme foram definidas por Marschner et al. (2008). No entanto, essas barreiras podem ser superadas pelos microrganismos do solo a partir do momento que se observar incrementos significantes de COT no sistema, e consequente aumento da atividade microbiana (Sanderman et al., 2016).

Em condições desfavoráveis, como no caso da pastagem degradada (T0), a fração CI se mantêm inerte, mas uma vez que occorre incremento $C$ essa fração pode sofrer alterações rápidas, como no caso da mudança de uso do solo na época T3 (Sanderman et al., 2016). Estas observações são pertinentes com os resultados obtidos no presente trabalho.

As condições de queimada natural que se verificam nos cerrados brasileiros favorecem ao acúmulo desta fração mais estável, que até recentemente se pensava como muito difícil de aproveitamento nas atividades agrícolas, entretanto experimentos de longa duração demonstraram que esta fração apresenta características auxiliares ao processo de retenção de água no solo, bem como de nutrientes (Oliveira et al., 2016). Esta observação é explicada em virtude da estrutura das cadeias aromáticas encontradas nas suas moléculas, assim como a sua atuação como fonte para compostos orgânicos solúveis (Novotny, 2009). 
Até mesmo as frações húmicas, que normalmente sofrem poucas alterações em curto prazo, foram incrementadas ao longo do tempo de implantação do ILPF. Estes resultados demonstram que a recuperação de pastagens degradadas com adoção de ILPF promove acúmulo de carbono nas frações lábeis e estáveis, com reflexos tanto na nutrição das plantas quanto no sequestro de carbono no solo.

Houve aumento da fração ácido fúlvico (AF) após as operações iniciais para a recuperação da pastagem degradada. A partir do T1 não houve mais incremento nos teores dessa fração.

Os teores de AF variaram de 3,85 $\mathrm{g} \mathrm{kg}^{-1}$ a $6,21 \mathrm{~g} \mathrm{~kg}^{-1}$ estes resultados são consistentes com aqueles obtidos por Sousa et al. (2015). Os teores médios de AF também foram similares aos obtidos por Kotzé et al. (2016), para solos transformados de degradados para sistemas integrados de produção na África do Sul. Os teores de AF do presente trabalho foram mais que o dobro dos valores encontrados por Loss et al. (2014), para sistemas conservacionistas em Latossolos Vermelhos do Cerrado.

Os teores de ácidos húmicos (AH) variaram de $0,74 \mathrm{~g} \mathrm{~kg}^{-1}$ a $3,93 \mathrm{~g} \mathrm{~kg}^{-1}$. Estes valores foram inferiores aos observados por Sousa et al. (2015) e Kotzé et al. (2016) assim como ligeiramente superiores aos encontrados por Loss et al. (2014), e similares aos obtidos por Rossi et al. (2016), para Latossolos Vermelhos sob distintos manejos, de tal forma verificando que o tempo de implementação do sistema de manejo influência esta fração das substâncias humicas.

$\mathrm{O}$ AH foi a menor fração entre as substâncias húmicas. Essa fração é um componente estável da matéria orgânica do solo, como consequência do seu acúmulo, incrementa o desempenho das culturas pelos mecanismos quelação, que aumenta a disponibilidade de nutrientes para as culturas (Tahir et al., 2011).

Em seus estudos Kotzé et al. (2016), concluíram que mesmo se conhecendo que as substâncias húmicas possuem natureza recalcitrante, práticas de manejo que reduzem o revolvimento do solo são necessárias para impedir a oxidação destas frações pelos microrganismos do solo, desta forma reduzindo as perdas de $\mathrm{C}$ e $\mathrm{N}$ para a atmosfera.

Os teores de $\mathrm{C}$ na fração humina variaram de $6,32 \mathrm{~g} \mathrm{~kg}^{-1}$ a $12,66 \mathrm{~g} \mathrm{~kg}^{-1}$, sendo que os maiores teores foram encontrados na profundidade $0-10 \mathrm{~cm}$. 
A época de amostragem influenciou os teores de humina. Na profundidade de $0-10 \mathrm{~cm}$, houve aumento do teor de humina já a partir do T1, portanto, no segundo ano após as operações de recuperação da pastagem, seguindo o mesmo comportamento do COT.

A humina foi a fração húmica mais abundante no solo, em todas as profundidades observadas. Esta predominância da humina em relação às outras frações das substâncias húmicas é bem conhecida na literatura e se justifica pela sua forte interação com a fração mineral do solo, por meio dos complexos argilo-húmicos estáveis, resistentes à decomposição microbiana (Fontana et al., 2011).

Os teores de carbono orgânico associado aos minerais (CAM) variaram de $11,12 \mathrm{~g} \mathrm{~kg}^{-1} \mathrm{a}$ 22,60 $\mathrm{g} \mathrm{kg}^{-1}$. As frações de CAM são comumente consideradas como estáveis (Smit et al., 2006). Entretanto estudos recentes propuseram que todo o conteúdo dos compostos orgânicos pode ser decomposto no solo, independentemente da recalcitrância molecular (Lehmann \& Kleber, 2015; Oliveira et al., 2016). O que pode justificar o decréscimo da fração CAM ao longo dos anos observada no presente trabalho.

Os resultados apresentados demonstram a necessidade de analisar escalas temporais superiores para análise mais precisas da dinâmica de C (Marland, 2011). 
Camada 0-10 cm
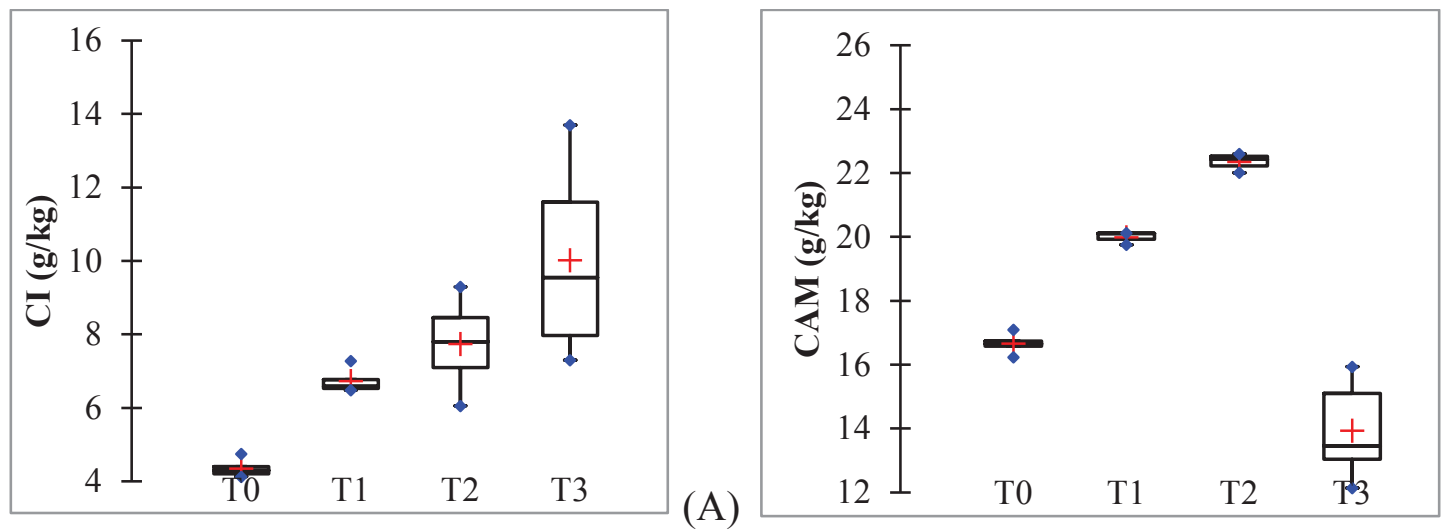

Camada $10-20 \mathrm{~cm}$

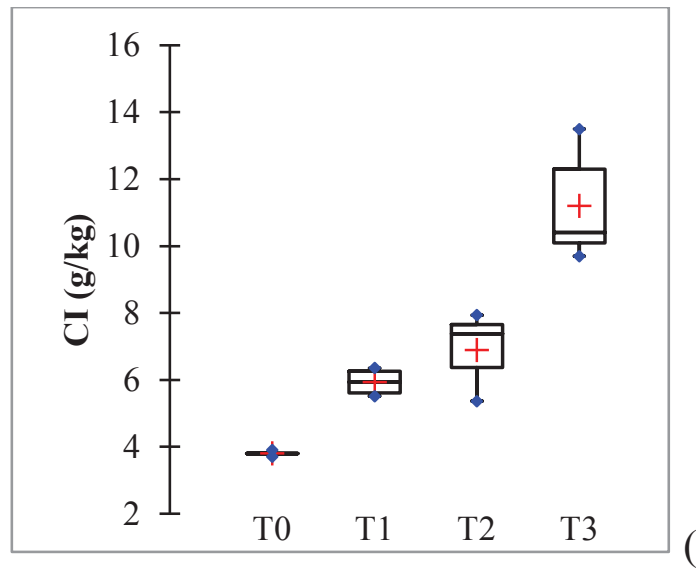

(C)

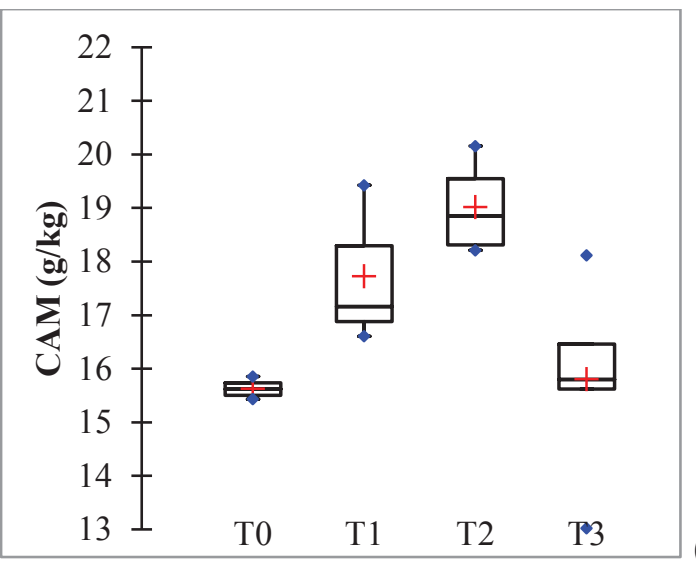

Camada $20-40 \mathrm{~cm}$

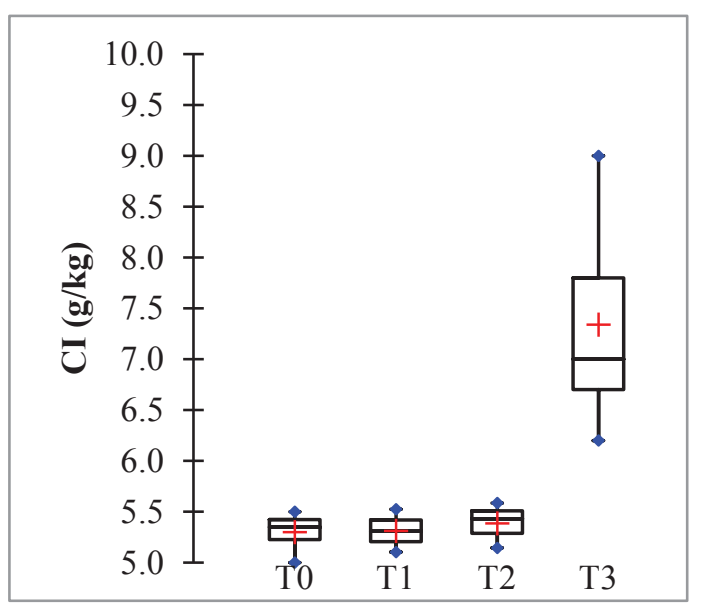

(E)

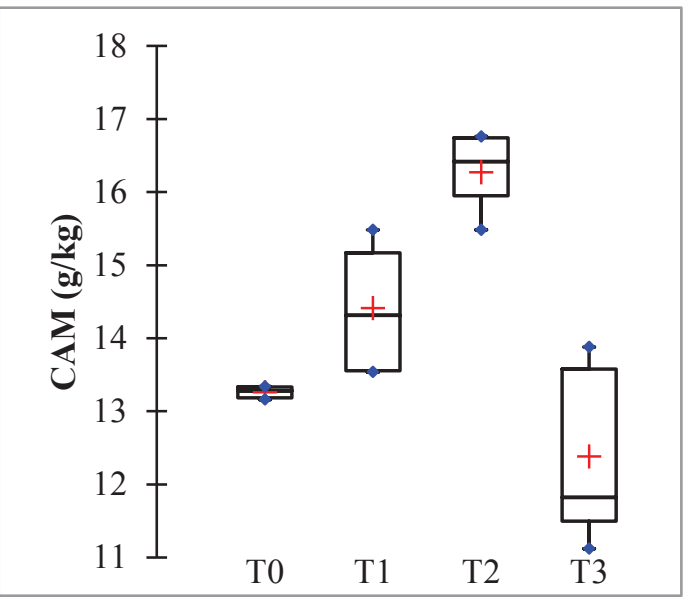

(F)

Figura 7. Teores de carbono inerte e carbono associado aos minerais da matéria orgânica do solo na profundidade de $0-10 \mathrm{~cm}, 10-20 \mathrm{~cm}$ e $20-40 \mathrm{~cm}$, em área sob integração lavoura-pecuáriafloresta, ao longo de 4 anos de implementação do sistema. CI - carbono inerte (A, C, E); CAM - 
carbono associado aos minerais (B, D, F). Coletas realizadas em 2012 com a área ainda degradada (T0); na safra 2013/2014 (T1); na safra 2014/2015 (T2) e na safra 2015/2016 (T3).

Camada $0-10 \mathrm{~cm}$

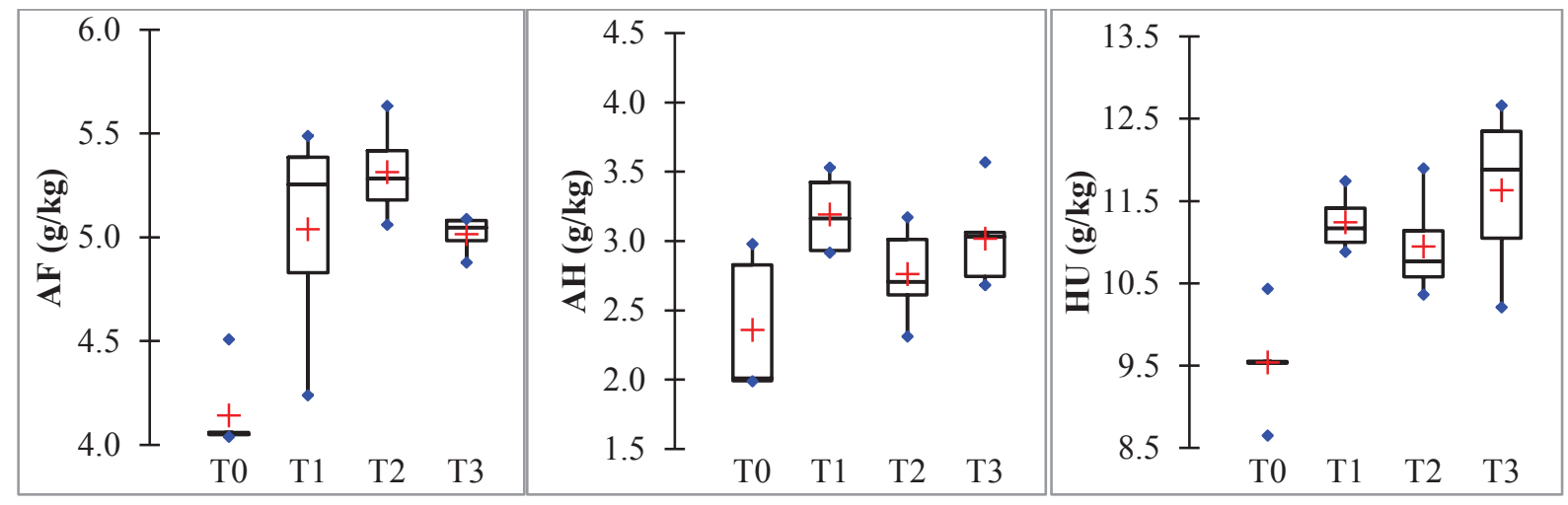

Camada $10-20 \mathrm{~cm}$

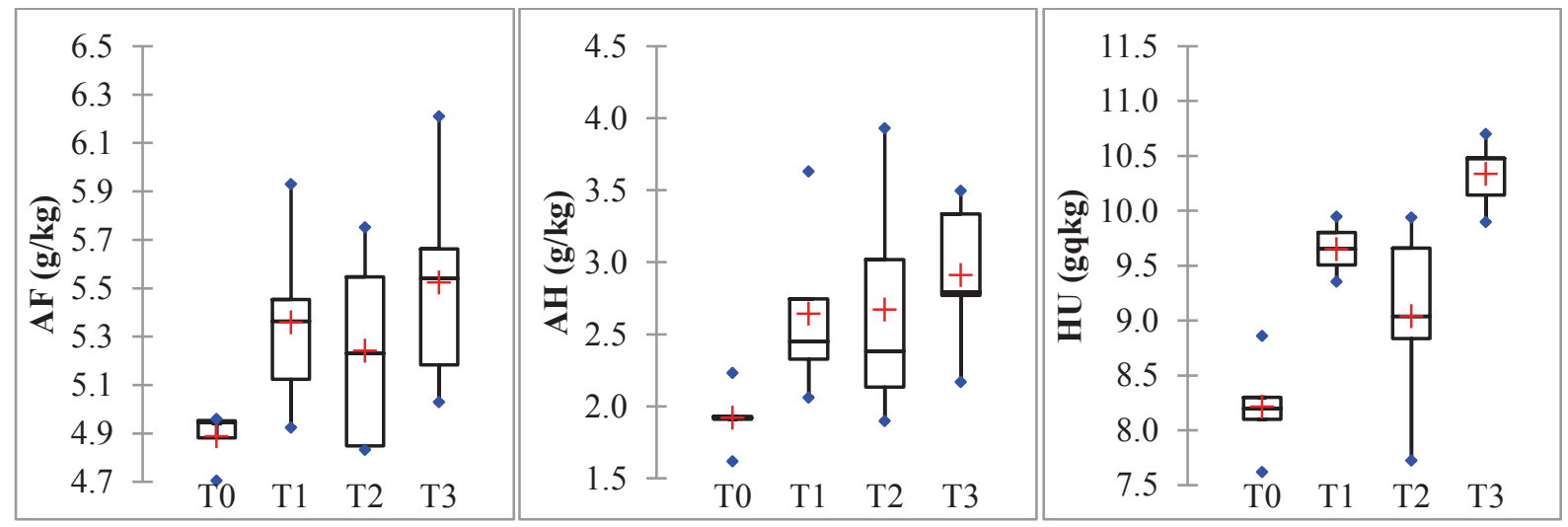

Camada $20-40 \mathrm{~cm}$

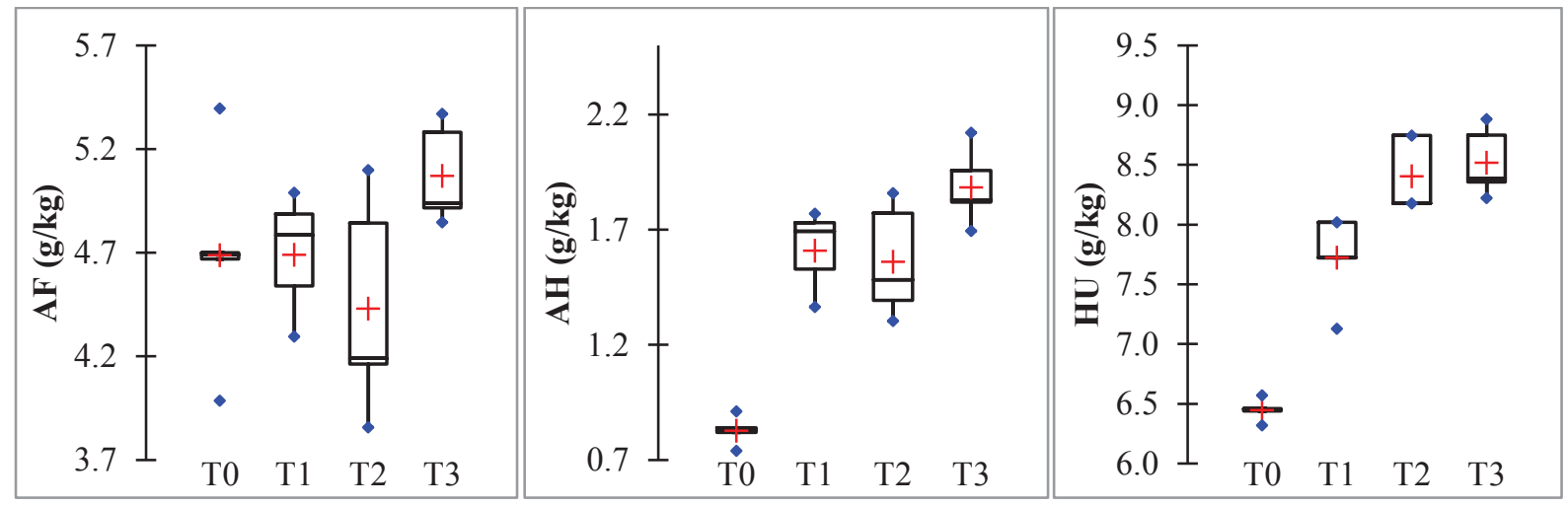

Figura 8. Teores das substâncias húmicas na profundidade de $0-10 \mathrm{~cm}, 10-20 \mathrm{~cm}$ e $20-40 \mathrm{~cm}$, em área sob integração lavoura-pecuária-floresta, ao longo de 4 anos de implementação do sistema. AF - ácido fúlvico; AH - ácido húmico; HU- humina. Coletas realizadas em 2012 com 
a área ainda degradada (T0); na safra 2013/2014 (T1); na safra 2014/2015 (T2) e na safra 2015/2016 (T3).

Estes resultados obtidos negam a hipótese proposta no trabalho, que em quatro anos da implantação de um sistema ILPF em área previamente ocupada por pasto degradado, não haverá um incremento do carbono em frações estáveis.

Apesar de menos acentuados, incrementos nas frações estáveis da matéria orgânica também foram verificados nas profundidades de 10-20 cm e 20-40 cm (Figura 8).

Os dados apontam que houve redução nos teores de CI entre as camadas de 0-10 cm e a 10-20 cm (Figura 8), enquanto que os teores de CAM tiveram um incremento, passando de 13 $\mathrm{g} / \mathrm{kg}$ para $16 \mathrm{~g} / \mathrm{kg}$ na época T3. O mesmo comportamento foi observado nas demais épocas avaliadas. Resultados semelhantes foram obtidos por Loss et al. (2014).

$\mathrm{Na}$ profundidade de $20-40 \mathrm{~cm}$ foi encontrado um incremento nos teores de todas as frações estáveis do C, em função do incremento da complexidade do sistema e aporte da MO, com excessão do CAM, devido a sua relação inversa com a fração COP, isto é devido ao fato de ser necessária uma redução dos teores de COP para que ocorra a decomposição desta fração, pelos microorganismos, para posterior associação com os minerais do solo (silte e argila), conforme notado em Guareshi et al. (2013). Além disso, observa-se uma estabilização na fração HU, que resultou em uma redução da participação dessa fração, incrementando o índice de labilidade do sistema. 


\subsection{Relações entre as Substâncias Húmicas}

Os dados apontam que a fração AF é superior à fração $\mathrm{AH}$, para todos os tratamentos, assim como para todas as profundidades, os resultados do indicador AH/AF variaram entre 0,177 a 0,645 , sendo que a variação entre as camadas de $0-10 \mathrm{~cm}$ foi entre 0,494 a 0,645 , para $10-20$ cm entre 0,388 a 0,535, e de 0,177 a 0,370 para camada de $20-40 \mathrm{~cm}$, observamos reduções para a relação AF/AF em função da profundidade analisada, conforme apresentado na Tabela 4.

Pode se observar que os maiores valores relação AH/AF foram encontrados para a época o T1 na camada de 0-10 cm, este indicador inferior a 1 , ou seja $\mathrm{AH} / \mathrm{AF}<1$, indica que a proporção de ácidos fúlvicos superam os ácidos húmicos, os valores desta relação influenciam na mobilidade do carbono orgânico do solo, os valores mais próximos de 1 são associados boa qualidade da matéria orgânica e a qualidade física dos solos (Guimarães et al., 2013).

Os dados da relação (AH+AF)/HU variaram entre 0,027 a 0,058 esta relação de é importante pois indica a perda da matéria orgânica do solo ao longo dos perfis analisados, demonstrando à predominância da fração da substâncias húmicas HU, estes resultado podem também ser explicados devido a forte interação entre as frações carbono orgânico total e as frações recalcitrantes, resultando em maior estabilidade da MOS dentro destas frações (Canella et al., 2008, Guimarães et al., 2013).

Apesar de algum indício de incremento na fração ácido húmico, os dados não apresentarem diferenças significativas para um valor $\mathrm{p}>0,05$ nas médias dos indicadores da relação $\mathrm{AH} / \mathrm{AF}$ ou $(\mathrm{AH}+\mathrm{AF}) / \mathrm{HU}$, em função do estágio de integração do sistema de produção

(Tabela 5). De forma que pode se concluir que em um sistema integrado de produção com quatro anos de implementação os indicadores (AH/AF) assim como a relação $(\mathrm{AH}+\mathrm{AF}) / \mathrm{HU}$ não permitem observar distinções entre as épocas.

Estudos com períodos de duração mais longos podem ser necessários para apurar devidamente a existência de influência dos sistemas integrados, em longo prazo, sobre a perda da fração lábil das substâncias húmicas, uma vez que o período de quatro anos não permite observar alterações estatisticamente significativas, conforme observado na Tabela 5. 


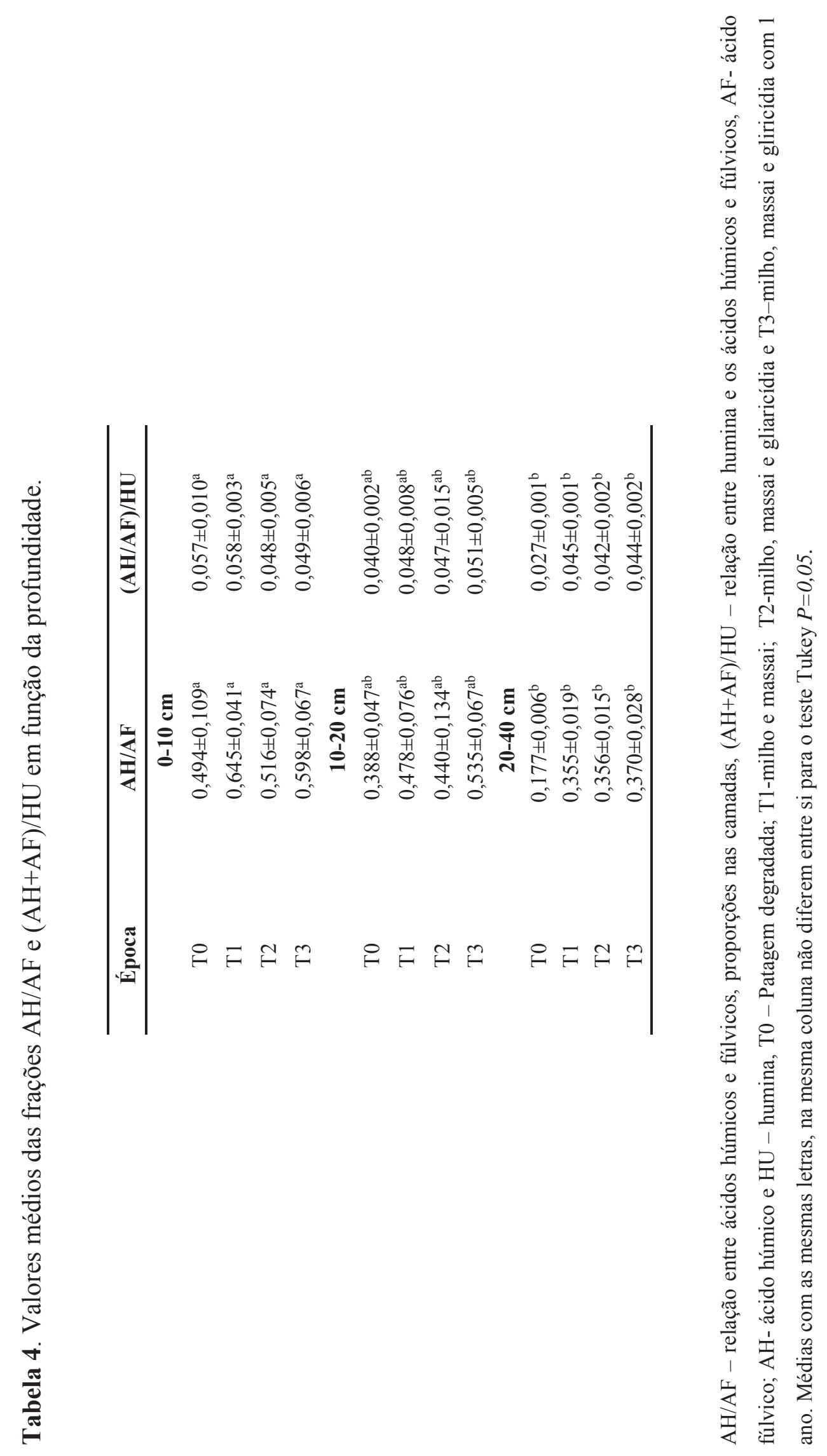




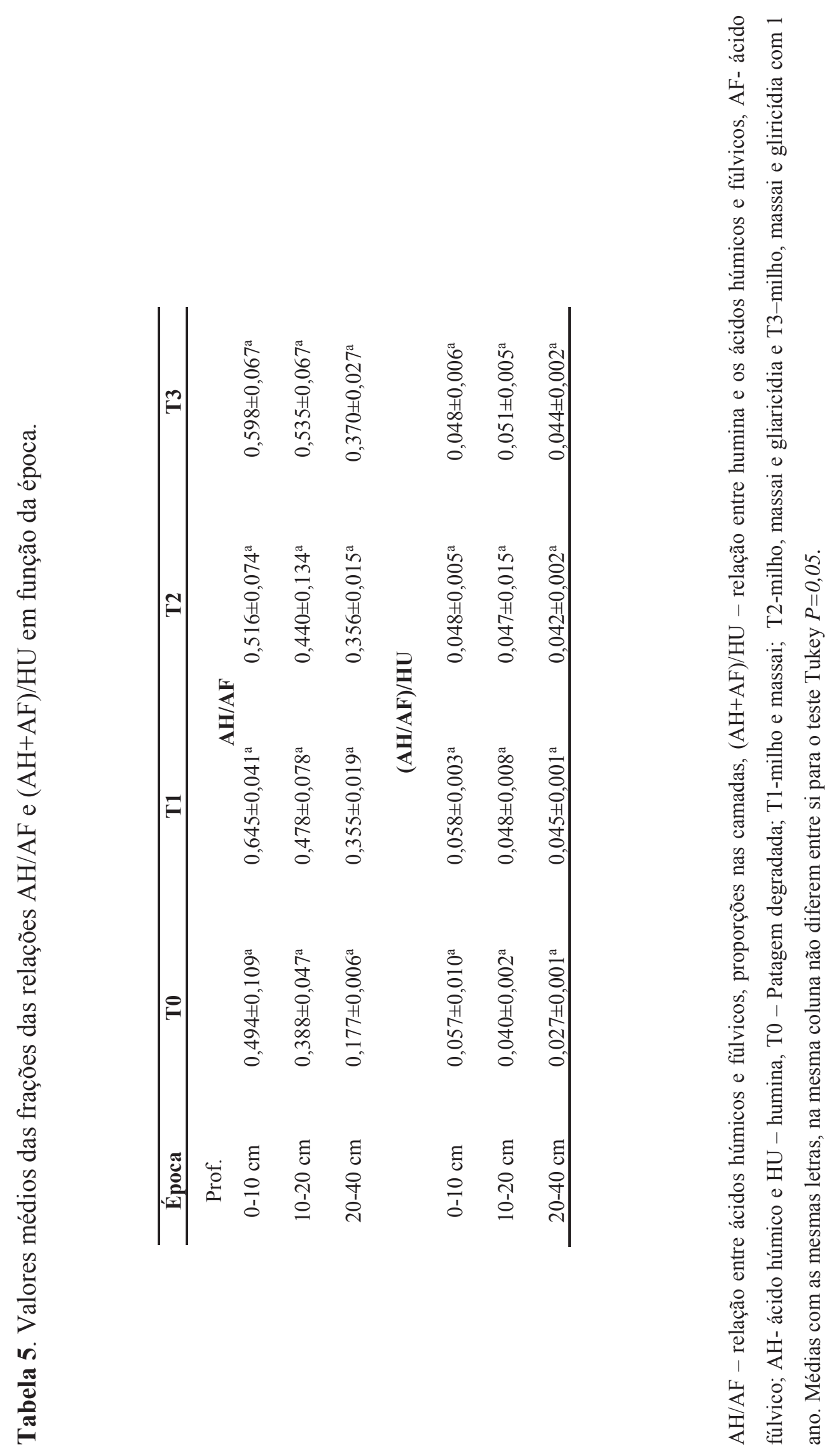




\section{4 Índice de manejo de carbono e produtividade do componente milho (Zea mays)}

$\mathrm{O}$ índice de manejo de carbono apresentou um incremento em todas as profundidades, conforme apresentado na tabela 6, quando comparados às épocas T0 (área referência, sob cobertura de pasto degradado) e T3 (área amostral, representando o sistema de produção integrado ILPF), os valores variaram de um IMC de 100,00 até 376,9 indicando que houve alterações no estoque de C orgânico, levando-se em consideração os aspetos de labilidade do C orgânico deste referido solo, como indicado nos trabalhos de (Nicoloso, 2005; Rossi et al., 2012).

$\mathrm{O}$ índice de manejo de carbono (IMC) foi distinto entre as épocas T0 e as demais, as épocas T1 e T2 não apresentaram diferenças entre si, sendo distintas das outras, a época T3 é distinta das demais (Tabela 6). Os resultados apontam que os sistemas de produção integrada como ILPF promovem o maior incremento no IMC e na labilidade do $\mathrm{C}$ orgânico na profundidade de 20-40 cm em relação à profundidade de 10-20 cm, esses dados são confirmados no trabalho de Rossi et al. (2012), onde os autores também encontraram as maiores alterações do IMC analisando distintos sistemas de manejo nas camadas mais profundas.

Tabela 6. Índices labilidade e manejo da área, em função da época e da profundidade.

\begin{tabular}{ccc}
\hline Época & IL & IMC \\
\hline & $\mathbf{0 - 1 0} \mathbf{~ c m}$ & \\
T0 & $1,000^{\mathrm{a}}$ & $100,000^{\mathrm{a}}$ \\
T1 & $1,568^{\mathrm{b}}$ & $203,851^{\mathrm{b}}$ \\
T2 & $1,565^{\mathrm{b}}$ & $198,787^{\mathrm{b}}$ \\
T3 & $2,928^{\mathrm{c}}$ & $376,983^{\mathrm{c}}$ \\
& $\mathbf{1 0 - 2 0} \mathbf{~ c m}$ & \\
T0 & $1,000^{\mathrm{a}}$ & $100,000^{\mathrm{a}}$ \\
T1 & $1,429^{\mathrm{b}}$ & $171,334^{\mathrm{b}}$ \\
T2 & $1,374^{\mathrm{b}}$ & $172,592^{\mathrm{b}}$ \\
T3 & $2,113^{\mathrm{c}}$ & $286,249^{\mathrm{c}}$ \\
& $\mathbf{2 0 - 4 0} \mathbf{c m}$ & \\
T0 & $1,000^{\mathrm{a}}$ & $100,000^{\mathrm{a}}$ \\
T1 & $1,790^{\mathrm{b}}$ & $213,639^{\mathrm{b}}$ \\
T2 & $1,624^{\mathrm{b}}$ & $223,796^{\mathrm{b}}$ \\
T3 & $2,561^{\mathrm{c}}$ & $317,538^{\mathrm{c}}$ \\
\hline C.V & $36.73 \%$ & $42.68 \%$ \\
\hline
\end{tabular}

IL- Índice de labilidade; IMC - Índice de manejo do carbono, C.V - Coeficiente de variação; T0 - Patagem degradada; T1-milho e massai; T2-milho, massai e gliaricídia e T3-milho, massai e gliricídia com 1 ano. Médias com as mesmas letras, na mesma coluna não diferem entre si para o teste Tukey $P=0,05$. 
Os valores de IMC superiores nas três profundidades da época T3 em relação a T0, pode indicar que o sistema de produção integrado ILPF por meio de seu superior aporte de resíduos vegetais assim como maior proteção da MOS, devido a agregados (Vieira et al., 2007), pode ser uma forma de manejo adequada para recalcitrar nutrientes e matéria orgânica, além de incrementar o enraizamento das culturas em profundidade (Rossi et al., 2012).

Como foi tomada por referência a área T0 que se encontrava sobre o regime de pasto degradado, o índice de IMC superior a 100 indica prática benéficas para a manutenção da MOS e qualidade do solo (Rossi et al., 2012). Resultando em incremento no estoque e labilidade do solo comparando as épocas $\mathrm{T} 0$ com as demais.

As épocas $\mathrm{T} 1$ e $\mathrm{T} 2$ apresentaram valores de $\mathrm{IMC}$ superiores à época $\mathrm{T} 0$ e inferiores a época T3, cumprindo o papel intermediário dentro da complexidade do sistema. Levando em consideração o incremento da MOS, as épocas T1 e T2 receberam adubação mineral, incrementado o seu $\mathrm{C}$ em relação ao T0, entretanto não receberam o aporte de resíduos vegetais em volume semelhante a época T3 com o desenvolvimento do componente arbóreo.

A época T3 apresentou um ICC alto indicando um aporte superior de $\mathrm{C}$ orgânico em comparação com as épocas T0, T1 e T2 a sua labilidade também foi superior à encontrada nestas épocas.

Os resultados da produtividade do componente Milho (Zea mays) demonstraram aumento, conforme o incremento da complexidade do sistema, passando pelas épocas pasto degradado, ILP e ILPF, seguindo a tendência do crescimento da complexidade do sistema e o aporte de MOS (Figura 9).

Este incremento na produtividade da cultura em sistemas integrados de produção como ILPF foi observado também no trabalho de (Vilela e Marta Júnior, 2010; Balbino et al., 2011a), que tinham como referências sistemas ILP e ILPF respectivamente. No presente trabalho, em relação ao pasto degradado obteve um incremento da produtividade com a adoção do ILP de $400 \%$ comparando a época T0 com a T3.

A produtividade de grãos de milho foi aumentando ao longo dos anos de implementação do sistema ILPF, passando de $2.300 \mathrm{~kg} \mathrm{ha}^{-1}$ na primeira safra para $8.000 \mathrm{~kg} \mathrm{ha}^{-1}$ na safra 2015/2016 (Figura 9). 


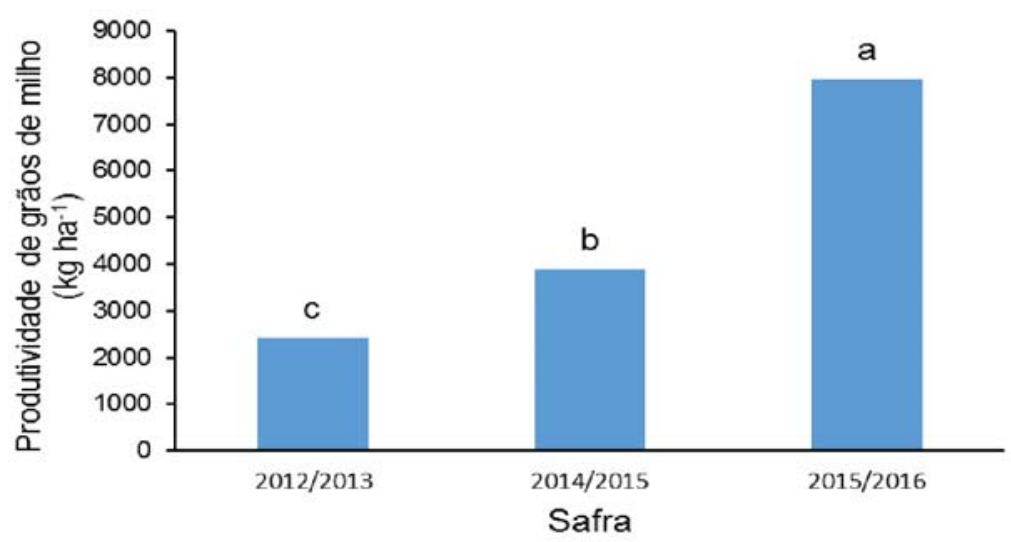

Figura 9. Produtividade de grãos de milho em área sob integração lavoura-pecuária-floresta.

A produtividade de milho alcançada com a implantação do ILPF está dentro do valor médio observado de produtividade para o Distrito Federal, na safra de 2016, segundo IBGE (2016) que foi de $8,098 \mathrm{~kg} \mathrm{ha}^{-1}$. Esses resultados apontam o potencial dos sistemas integrados como alternativa, em curto prazo, para tornar áreas de pastagens degradadas em áreas agrícolas que aliam altas produtividades com acúmulo de MOS.

Os resultados de produtividade do milho obtidos no presente trabalho, confirmam a hipótese estabelecida de que a produtividade do milho é incrementada com o aumento da complexidade do sistemas de produção ao longo da implantação de um sistema ILPF.

Os dados da produtividade da Safra 2013/2014 foram perdidos de forma que não foram contabilizados no resultado final da análise nos quatro anos. 


\section{CONCLUSÕES}

Os resultados demonstraram que houve incremento do teor de COT, em quatro anos de implementação nas três profundidades de 0-10, 10-20 e 20-40 cm, ao longo da implantação do sistema ILPF também houve acúmulo de carbono nas frações lábeis e estáveis da matéria orgânica do solo, com exceção da fração CAM.

A fração das substâncias húmicas com maior participação em todas as épocas avaliadas foi a humina, seguida pelo ácido fúlvico e com menor participação da fração ácido húmico.

A fração COP foi a que sofreu maior incremento relativo ao longo do tempo de implementação do sistema ILPF e funcionou como um sensível indicador das mudanças que ocorreram no solo.

Os resultados demonstram que a fração ácido húmico (AH) é mais participativa nas camadas superiores, em específico na camada de 0-10 cm, apresentando uma redução de valores médios na camada de $20-40 \mathrm{~cm}$. Os estágios de implementação do ILPF não apresentaram diferenças entre épocas $\mathrm{T} 0$ a $\mathrm{T} 3$ para a relação $\mathrm{AH} / \mathrm{AF}$ ou a (AH/AF)/HU.

Os resultados do IMC demonstram que houve incremento nos estoques $\mathrm{C}$ e na labilidade das frações, melhorando a qualidade do solo, quando observadas às épocas T0 e T3, demonstrando que os sistemas integrados têm capacidade de prover um aporte superior de MOS e nutrientes, o que se refletiu na produtividade do componente milho que teve resultados quatro vezes superiores no sistema de ILPF, aos obtidos no início das operações de recuperação da pastagem.

O presente trabalho aponta que a complexidade dos sistemas influência a produtividade e a capacidade de captação de $\mathrm{C}$ pelo solo, tanto das frações lábeis quanto as estáveis do $\mathrm{C}$, o trabalho indica também que em regiões tropicais, com amplo aporte de matéria orgânica a fração COT é um indicador eficiente para determinação de mudança de uso do solo, em curto período de tempo partindo-se de uma pastagem degradada.

Os teores do CI apresentaram incrementos em função do tempo em todas as profundidades, sendo que na profundidade $20-40 \mathrm{~cm}$ os teores de CI se mantiveram semelhantes nos tempos (T0, T1 e T2) enquanto que, no tempo T3 já sob sistema ILPF o CI apresentou teores médios superiores aos outros tempos observados indicando a eficiência de captação desta fração 
estável do C no sistema integrado, provavelmente influenciando este reservatório de $\mathrm{C}$ do solo em virtude do aporte de matéria orgânica ao solo.

O uso de espécies leguminosas como a Gliricidia Sepium que tem boa adaptabilidade para as condições climatológicas do Cerrado se apresenta como uma boa alternativa ao produtor, uma vez que se trata de uma espécie que tem boa produtividade de folhas com alto valor nutritivo para os animais, assim como seu resíduo é eficiente para promover o acúmulo de C no solo, está espécie tem crescimento rápido e tem características muito atrativas para sua implantação em sistemas integrados de produção.

A espécie forrageira Panicum maximum cv. Massai em consórcio com o Zea mays e a espécie arbórea Gliricidia Sepium apresentam bons resultados na capacidade de incrementar tanto as frações lábeis quanto as estáveis de carbono, promovendo a sustentabilidade do sistema a longo prazo, assim como possibilitando o aumento da rentabilidade por área para o produtor. 


\section{REFERÊNCIAS BIBLIOGRÁFICAS}

ADDINSOFT INC. XLSTAT: Statistical and data analysis software. Online at: http//www.addinsoft.com, 2013.

AGUILAR, G.M.; ALFARO, R.; CALERO MARTIN, M.; PONCE de LEÓN, B.D; FONT VILA. Carbono lábil como un indicador de cambios en dos suelos bajo diferentes usos. Cultivos Tropicales, v. 36, p. 64-70, 2015.

ALVARES, C.A.; STAPE, J.L.; SENTELHAS, P.C.; GONÇALVES, J.L.M.; SPAROVEK, G. Koppen's climate classification map for Brazil. Meteorologische Zeitschrift, v.22, p.711-728, 2013.

BAYER, C.; MARTINS-NETO, L.; MIELNICZUK.; PAVINATO, A. Armazenamento de carbono em frações lábeis da matéria orgânica de um Latossolo Vermelho sob plantio direto. Pesquisa Agropecuária Brasileira, v. 39, n. 7, p. 677-683, 2004.

BEUTLER, S.J, PERREIRA, M.G, LOSS, A., PERIN, A., SILVA, C.F. Edaphic attributes of a crop-livestock integration system in the Cerrado biome. Revista Caatinga, v. 29, n. 4, p. 892 900, 2016.

BLAIR, G.J.; LEFROY, D.B.; LISLE, L. Soil carbon fractions based on their degree of oxidation, and the development of a carbon management index for agricultural systems. Australian Journal of Agricultural Research, v. 46, p. 1459-1466, 1995.

BOLINDER, M.A.; ANGERS, D.A.; GIROUX, M.; LAVERDIERE, M.R. Estimating C inputs retained as soil organic matter from corn (Zea mays L.). Plant Soil, v. 215, p. 85-91, 1999.

BONGIOVANNI, M.D.; LOBARTINI, J.C. Particulate organic matter, carbohydrate, humic acid contents in soil macro- and microaggregates as affected by cultivation. Geoderma, v. 136, p. 660-665, 2006.

CAMBARDELLA, C.A.; ELLIOTT, E.T. Particulate soil organic-matter changes across a grassland cultivation sequence. Soil Science Society of America Journal, v. 56, p. 777-783, 1992.

CANELLA, L.P.; TEIXEIRA L.R.L.; DOBBSS, L.B.; SILVA, C.A.; MEDICI, L.O.; ZANDONADI, D.B.; FAÇANHA, A.R. Humic acids cross interactions with root and organic acids. Annals of Applied Biology, v. 153, p. 157-166, 2008.

CARMO, F.F.; FIGUEIREDO, C.C.; RAMOS, M. L. G.; VIVALDI, L.J.; ARAÚJO, L.G. Frações granulométricas da matéria orgânica em Latossolo sob plantio direto com gramíneas. Bioscience Journal, v. 28, p. 420-431, 2012. 
CATES, M.A.; RUARK, M.D.; HEDTCKE, J.L.; POSNER, J.L. Long-term tillage, rotation and perennialization effects on particulate and aggregate soil organic matter. Soil and Tillage Research, v. 155, p. 371-380, 2016.

CORBEELS, M.; MARCHÃO, R.L.; NETO, M.S.; FERREIRA, E.G.; MADARI, B.E.; SCOPEL, E.; BRITO, O.R. Evidence of limited carbon sequestration in soils under no-tillage systems in the Cerrado of Brazil. Scientific Reports, v. 6, p.24-49, 2016.

COSER, T.R.; RAMOS, M.L.G.; AMABILE, R.F.; RIBEIRO JÚNIOR, W.Q. Nitrogênio da biomassa microbiana em solo de Cerrado com aplicação de fertilizante nitrogenado. Pesquisa Agropecuária Brasileira, v. 42, p. 399-406, 2007.

CULMAN, S.W.; SNAP, S.S.; SCHIPANSKI, M.E.; FREEMAN, M.A.; BENISTON, J.; DRINKWATER, L.E. Permanganate oxidizable carbon reflects a processed soil fraction that is sensitive to management. Soil Science Society of America journal, v. 76, p. 494-504, 2012.

DICK, R.P.; BURNS, R.G. A brief history of soil enzymology research. In: R. P. Dick, editor, Methods of soil enzymology. SSSA Book Series 9. SSSA, p. 1-19, 2011.

DOU, F.; WRIGHT, A.L.; HONS; F.M. Sensitivy of labile soil organic carbon to tillage in wheat-based cropping systems. Soil Science Society of America Journal, v. 72, p. 1445-1453, 2008.

DURIVAL, E.M.; GALANTINI, J.E.; MARTÍNEZ, J.M.; LÓPEZ, F.M.; WALL, L.G. Sensitivity of different soil quality indicators to assess sustainable land management: Influence of site features and seasonality. Soil and Tillage Research, v. 159, p. 9-22, 2016.

EMPRESA BRASILEIRA DE PESQUISA AGROPECUÁRIA (EMBRAPA). Manual de métodos de análise de solo: EMBRAPA-CNPS, p. 212, 1997.

FERREIRA, E.A.B.; BUSTAMANTE, M.M.C.; RESCK, D.V.S.; FIGUEIREDO, C.C.; PINTO, A.S.; MALAQUIAS, J.V. Carbon Stocks in Compartments of Soil Organic Matter 31 Years after Substitution of Native Cerrado Vegetation by Agroecosystems. Revista Brasileira de Ciência do Solo, v. 40, p.15, 2016.

FIGUEIREDO, C.C.; RESCK, D.V.S.; CARNEIRO M.A.C. Labile and stable fractions of soil organic matter under management systems and native Cerrado. Revista Brasileira de Ciência do Solo, v. 34, p. 907-916, 2010.

FONTANA, A.; SILVA, C.F.S.; PEREIRA, M.G.; LOSS, A.; BRITO, J.R.; BENITES, V.M. Avaliação dos compartimentos da matéria orgânica em área da mata atlântica. Acta Scintiarum. Agronomy, v. 33, p. 545-550, 2011.

GAZZOLA, P.R.; GUARESHI, R.F.; PERIN, A.; PERREIRA, M.G.; ROSSI, C.Q. Fractions of soil organic matter under pasture, tillage system and crop-livestock integration Semina: Ciências Agrárias, v. 36, n. 2, p. 693-704, 2015. 
GUARESHI, R.F.; PEREIRA, M.G.; PERIN, A. Frações da matéria orgânica em áreas de Latossolo sob diferentes sistemas de manejo no Cerrado do estado de Goiás. Semina: Ciências Agrárias, Londrina, v. 34, n. 6, p. 2615-2628, 2013.

GUIMARÃES, D.V.; GONZAGA, T.O; Da SILVA, T.L.; Da SILVA-DIAS, N.; MATIAS, M.I.S. Soil organic matter pools and carbon fractions in soil under different land uses. Soil and Tillage Research, v. 126, p. 177-182, 2013.

HAYNES, R. J. Labile organic matter fractions as central components of the quality of agricultural soils: An overview. Advances in Agronomy, v. 85, p. 221-268, 2005.

INSTITUTO BRASILEIRO DE GEOGRÁFIA E ESTATÍSTICA, Indicadores. Estatística da Produção Agrícola, p. 77, 2016.

ISLAM, K.R.; WELL, R.R. Microwave irradiation of soil for routine measurement of microbial biomass carbon. Biology and Fertility of Soils, v. 27, p. 408-416, 1998.

JACKSON, M.L. Soil Chemical Analysis. Prentice-Hall. Englewood Cliffs, p. 498, 1958.

JANTALIA, C.P.; RESCK, D.V.S.; ALVES, B.R.J.; ZOTARELLI, L.; URQUIAGA, S.; BODDEY, R.M. Tillage effect on $\mathrm{C}$ stocks of a clayey Oxisol under a soybean-based crop rotation in the Brazilian Cerrado region. Soil and Tillage Research, v. 95, p. 97-109, 2007.

KOTZÉ, E.; LOKE, P.F.; AKHOSI-SETAKA, M.C.; DU PREEZ, C.C. Land use change affecting soil humic substances in three semi-arid agro-ecosystems in South Africa. Agriculture, Ecosystems and Environment, v. 216, p. 194-202, 2016.

LEHMANN, J.; KLEBER, M. The contentious nature of soil organic matter. Nature, v. 528, p. 60-68, 2015.

LIMA, C.E.P.; FONTENELLE, M.R.; MADEIRA, N.R.; SILVA, J.; GUEDES, I.M.R.; SILVA, L.B.S.; SOARES, D.C. Compartimentos de carbono orgânico em Latossolo cultivado com hortaliças sob diferentes manejos. Pesquisa Agropecuária Brasileira, v. 51, n.4, p.378-387, 2016.

LOPES, A.A. de C.; SOUSA, D.M.G. de; CHAER, G.M.; REIS JÚNIOR, F.B. dos; GOEDERT, W.J.; MENDES, I. de C. Interpretation of microbial soil indicators as a function of crop yield and organic carbon. Soil Science Society of America Journal, v. 77, p. 461-472, 2013.

LOSS, A.; RIBEIRO, E.C.; PEREIRA, M.G.; COSTA, E.M. Atributos químicos e físicos dos solos em sistema de consórcio e sucessão de lavoura, pastagem e silvopastoril em Santa Teresa ES. Bioscience Journal, v. 30, n. 5, p. 1347-1357, 2014.

LUO, P.; HAN, X.; WANG, Y.; HAN, M.; SHI, H.; LIU, N.; BAI, H. Influence of long-term fertilization on soil microbial biomass, dehydrogenase activity, and bacterial and fungal community. Annals of Microbiology, v. 65, p. 533-542, 2015. 
MARLAND, G. Accounting for carbon dioxide emissions from bioenergy systems. Journal of Industrial Ecology, v. 14, p. 866-869, 2011.

MARQUES, J.D.O.; LUIZÃO, F.J.; TEXEIRA, W.G.; SARRAZIN, M.; FERREIRA, F.J.S.; BELDINI, T.P.; MARQUES, E.M.A. DISTRIBUTION OF ORGANIC CARBON IN DIFFERENT SOIL FRACTIONS IN ECOSYSTEMS OF CENTRAL AMAZONIA. Revista Brasileira da Ciência do Solo, v. 39, n. 1, p. 232-242, 2015.

MARSCHNER, B.; BRODOWSKI, S.; DREVES, A.; GLEIXNER, G.; GUDE, A.; GROOTES, P. M.; HAMER, U.; HEIM, A.; JANDL, G.; JI, R.; KAISER, K.; KALBITZ, K.; KRAMER, C.; LEINWEBWER, P.; RETHEMEYER, J.; SCHAEFFER, A.; SCHMIDT, M.W.I.; SCHWARK, L.; WIESENBERG, G.L.B. How relevant is recalcitrance for the stabilization of organic matter in soils? Journal of Plant Nutrition and Soil Science-Zeitschrift Fur Pflanzenernahrung Und Bodenkunde, v. 171, p. 91-110, 2008.

MENDONÇA, E.S.; MATOS, E.S. Matéria orgânica do solo: métodos de análises. Viçosa: UFV, p. 107, 2005.

MUNIZ, L. C.; MADARI, B. E.; TROVO, J. B. de L.; CANTAHNÊDE, I. S. de L.; MACHADO, P. L. O. de A.; COBUCCI, T.; FRANÇA, A. F. de S. Soil biological attributes in pastures of different ages in a crop-livestock integrated system. Pesquisa Agropecuária Brasileira, v. 46, n. 10, p. 1262-1268, 2011.

NICOLOSO, R.S. Dinâmica da matéria orgânica do solo em áreas de integração lavourapecuária sob sistema plantio direto. 149 p. 2005. Tese (Mestrado) - Universidade Federal de Santa Maria, Santa Maria.

NOVOTNY, E. H.; HAYES, M. H. B.; MADARI, B.E.; BANAGAMBA, T.J.; AZEVEDO, E.R.; SOUZA, A. A.; SONG, G.; NOGUEIRA, C. M.; MANGRICH, A.S., Lessons from the Terra Preta de Índios of the Amazon Region for the utilization of Charcoal for Soil Amendment. Journal of the Brazilian Chemical Society, v. 20, n. 6, p. 1- 8, 2009.

OLIVEIRA D. M. S.; PAUSTIAN, K.; COTRUFO, M.F.; FIALlOS, A. R.; CERQUEIRA, A.G.; CERRI, C.E.P. Assessing labile organic carbon in soils undergoing land use change in Brazil: A comparison of approaches. Ecological Indicators, v. 72, p. 411-419, 2016.

ROSSI, C.Q.; PERREIRA, M.G.; GIÁCOMO, S.G.; BETTA, M.; POLIDORO, J.C. Frações orgânicas e índice de manejo de carbono do solo em Latossolo Vermelho sob plantio de soja no cerrado goiano. Revista Brasileira de Ciências Agrárias, v. 7, n.2, p.233-241, 2012.

ROSSI, C.Q.; PEREIRA, M.G.; MOURA, O.V.T.; ALMEIDA, A.P.C.A. Vias de formação, estabilidade e características químicas de agregados em solos sob sistemas de manejo agroecológico. Pesquisa Agropecuária Brasileira, v.51, n.9, p.1677-1685, 2016.

SANDERMAN, J.; TROY BAISDEN, W.; FALLON, S. Redefining the inert organic carbon pool. Soil Biology and Biochemistry, v. 92, p. 149-152, 2016. 
SANTANA, G.S.; DOCK, D.P.; JACQUES, A.V.A.; CHITARRA, G.S. Substâncias húmicas e suas interações com $\mathrm{Fe}$ e Al em Latossolo subtropical sob diferentes sistemas de manejo de pastagem. Revista Brasileira de Ciência do Solo, v. 35, n. 2, p. 461-472, 2011.

SHANG, C.; TIESSEN, H. Organic matter lability in a tropical oxisol: evidence from shifting cultivation, chemical oxidation, particle size, density, and magnetic fractionations. Soil Science, Baltimore, v. 162, p. 795-807, 1997.

SILVA, J. R.; SILVA, D. J.; GAVA, C. A. T.; OLIVEIRA, T. C. T. de.; FREITAS, M. do S. C. de. Carbon in humic fractions of organic matter in soil treated with organic composts under mango cultivation. Revista Brasileira de Ciência do Solo, v. 40, p. 11, 2016.

SKJEMSTAD, J. O.; SWIFT, R. S.; McGOWAN, J. A. Comparison of the particulate organic carbon and permanganate oxidation methods for estimating labile soil organic carbon. Australian Journal of Soil Research, v. 44, n. 3, p. 255-263, 2006.

SMITH, J.E.; HEATH, L.S; SKOG, K.E. Methods for Calculating Forest Ecosystem and Harvested Carbon with Standard Estimates for Forest Types of the United States.Gen. Tech. Rep. U.S. Department of Agriculture, Forest Service, Northeastern Research Station, p. 216, 2006.

SOUSA, R. F.; BRASIL, E.P.F.; FIGUIREDO, C.C.; LEANDRO, W.M. Soil organica matter fractions in preserved and disturbed wetlands of Cerrado biome. Revista Brasileira de Ciência do Solo, v. 39, n. 1, p. 222-231, 2015.

SOUZA, D.M.G.; LOBATO, E. Cerrado: correção do solo e adubação. 2 ed. Brasília: Embrapa Cerrados, p. 416, 2004.

SOUZA, G. P.; FIGUEIREDO, C. C. de.; SOUSA, D. M. G. de. Relationships between labile soil organic carbon fractions under different soil management systems. Scientia Agricola. v. 73, n. 6 , p. 535-542, 2016.

SOUZA, L.M.; SOUSA, D.M.G.; REÍS JÚNIOR F.B dos.; MENDES, I.C. Carbono da biomassa microbiana em Latossolos determinado por oxidação úmida e combustão a temperatura elevada. Pesquisa Agropecuária Brasileira, v. 50, n. 11, p. 1061-1070, 2015.

TAHIR, M. M.; KHURSHID, M.; KHAN, M. Z.; ABBASI, M. K.; KAZMI, M. H. Lignitederived humic acid effect on growth of wheat plants in different soils. Pedosphere. v. 21, n.1, p. 124-131, 2011.

URQUIZA RODRÍGUES, M.N.; ALEMÁN GARCÍA, C.; FLORES VALDÉS, L.; PAULA RICARDO, M.; AGUILAR PANTOJA, Y. Manual de procedimientos para manejo sostenible de tierras, editora CIGEA, La Habana, Cuba, p. 67, 2011. 
VIANA, E.T.; BATISTA, M.A.; TORMENA, C.A.; COSTA, A.C.S.; INOUE, T.T. Atributos físicos e carbono orgânico em Latossolo Vermelho sob diferentes sistemas de uso e manejo. Revista Brasileira de Ciência do Solo, v. 35, p. 2105-2114, 2011.

VIEIRA, F. C. B.; BAYER, C.; ZANATTA, J. A.; DIECKOW, J.; MIELNICZUK, J.; HE, Z. L. Carbon management index based on physical fractionation of soil organic matter in an Acrisol under long-term no-till cropping systems. Soil and Tillage Research, v. 96, p. 195204, 2007.

VILELA, L.; MARTHA JÚNIOR, G. B. Integração lavoura-pecuária no Cerrado. Planaltina: Embrapa Cerrados, 3 p, 2010.

YANG, X.; REM, W.; SUM, B.; ZHANG, S. Effects of contrasting soil management regimes on total and labile soil organic carbon fractions in a loess soil in China. Geoderma, v. 177-178, p. 49-56, 2012.

YANG, X.Y.; REN, W.D.; SUN, B.H.; ZHANG, S.L. Effects of contrasting soil management regimes on total and labile soil organic carbon fractions in a loess soil in China. Geoderma, v. 177-178, p. 49-56, 2012.

ZHANG, F.; ZHANG, W.; LI, M.; ZHANG, Y.; LI, F.; LI, C. Is crop biomass and soil carbon storage sustainable with long-term application of full plastic film mulching under future climate change?

Agricultural

Systems,

v. 150 ,

p.

67-77, 2016. 